\title{
The effects of asynchronous computer voice conferencing on learners' anxiety when speaking a foreign language
}

\author{
Maria Isabel Charle Poza \\ West Virginia University
}

Follow this and additional works at: https://researchrepository.wvu.edu/etd

\section{Recommended Citation}

Charle Poza, Maria Isabel, "The effects of asynchronous computer voice conferencing on learners' anxiety when speaking a foreign language" (2005). Graduate Theses, Dissertations, and Problem Reports. 3415. https://researchrepository.wvu.edu/etd/3415

This Dissertation is protected by copyright and/or related rights. It has been brought to you by the The Research Repository @ WVU with permission from the rights-holder(s). You are free to use this Dissertation in any way that is permitted by the copyright and related rights legislation that applies to your use. For other uses you must obtain permission from the rights-holder(s) directly, unless additional rights are indicated by a Creative Commons license in the record and/ or on the work itself. This Dissertation has been accepted for inclusion in WVU Graduate Theses, Dissertations, and Problem Reports collection by an authorized administrator of The Research Repository @ WVU. For more information, please contact researchrepository@mail.wvu.edu. 
The Effects of Asynchronous Computer Voice Conferencing on Learners' Anxiety When Speaking a Foreign Language.

\author{
María Isabel Charle Poza
}

\author{
Dissertation submitted to the \\ College of Human Resources and Education \\ at West Virginia University \\ in partial fulfillment of the requirements \\ for the degree of
}

\author{
Doctor of Education \\ in \\ Technology Education
}

John Wells, Ph.D., Chair

María Amores, Ph.D.

Tracy Dingess, M.A.

D. J. Hendricks, Ed.D.

David McCrory, Ph.D.

Department of Advanced Educational Studies

\author{
Morgantown, West Virginia
}

2005

Keywords: foreign language anxiety, asynchronous computer voice conferencing

Copyright 2005 María Isabel Charle Poza 


\title{
ABSTRACT \\ The Effects of Asynchronous Computer Voice Conferencing on Learners' Anxiety When Speaking a Foreign Language.
}

\author{
María Isabel Charle Poza
}

This study investigated the influence of asynchronous computer voice conferencing on learners' anxiety when speaking in a foreign language. The technology chosen was the voice board powered by Wimba. Three research questions guided this study: Research Question 1: What is the learners' perception of their language anxiety when speaking in the asynchronous computer voice conferencing environment?, Research Questions 2: How empowered do the learners feel to take risks in the asynchronous computer voice conferencing environment?, and Research Question 3: How concerned are the learners about being evaluated by others when making oral mistakes in the foreign language in the asynchronous computer voice conferencing environment?

The study involved both quantitative and qualitative research methods. The population for the quantitative component of this study consisted of 35 students enrolled in two sections of college-level Intermediate Spanish 2 (Spanish 204). Four questionnaires were used to gather the quantitative data of this study: A demographic survey, the Computer Anxiety Index (CAIN), the Foreign Language Classroom Anxiety Scale (FLCAS), and the Wimba Anxiety Scale. Using purposeful sampling methods, four participants were interviewed for the qualitative component of this investigation. In addition, a rubric was designed and used for the evaluation of risk-taking in student contributions to the Wimba and classroom discussions.

Results indicate that there was a strong potential for the reduction of anxiety associated with the voice board. A number of students experienced a reduction of their level of anxiety due to the elimination of the time pressure of the classroom and opportunity to edit their contributions. The conditions of the point of access to the technology were found to have a negative effect on student anxiety on the voice board. A negative attitude towards going to the language laboratory, technical difficulties during the Wimba activities, and instructional time had a negative effect on the level of anxiety. Increased risk-taking in oral contributions and reduced fear of negative evaluation were also found in the Wimba environment. 


\section{DEDICATION}

I wish to dedicate this dissertation to my parents, Carlos and Sari, who from a very early age instilled in me the importance of family, education, and hard work. I know that having a daughter so far away from home has not been easy for you, so I thank you for giving me your unconditional love and support in spite of the distance. To my sister, Cristina, who always believed in me and encouraged me throughout this journey. You have always been a true friend to me and words cannot express my love and appreciation for you. To my boyfriend, Greg, for his endless patience and help in this dissertation. I thank you for always offering me a shoulder to rest my head upon when it was hard to see the light at the end of the tunnel.

I love you all very much.

Deseo dedicar esta tesis doctoral a mis padres, Carlos y Sari, quienes desde pequeña me inculcaron la importancia de la familia, la educación, y el trabajo duro. Sé que no ha sido fácil para vosotros que vuestra hija esté tan lejos de casa. Por eso quiero daros las gracias por vuestro amor incondicional y por vuestro apoyo a pesar de la distancia. A mi hermana, Cristina, que siempre ha creído en mí y me ha dado ánimos durante este trayecto. Siempre has sido una amiga de verdad y mi amor por tí no puede expresarse con palabras. A mi novio, Greg, por su eterna paciencia y ayuda en esta tesis. Te doy las gracias por ofrecerme siempre un hombro en el que apoyarme cuando resultaba difícil ver la luz al final del túnel.

Os quiero mucho a todos. 


\section{ACKNOWLEDGEMENTS}

I would like to acknowledge the efforts of the many people without whose help, this dissertation would not have been possible. In particular, I wish to express my gratitude to Dr. John G. Wells, my advisor, for his guidance during the process of my doctoral studies, this dissertation, and the onset of my professional career. I would not have been successful as a doctoral student without his inestimable knowledge, experience, and professionalism. Dr. Wells,

I thank you for dedicating so much of your time to me, for believing in me, and for giving me valuable feedback and advice that always brought out the best in me as a student and a researcher.

I also want to express my deepest gratitude to my committee. Special thanks to Dr. María Amores, who gave me the opportunity to come to West Virginia University and who has always believed in my work as a student and a professional. María, thank you for your trust, for the many opportunities to grow, and for your help in this dissertation. Thank you also for teaching me everything that I know about foreign language teaching and academic life in the United States. I am also deeply grateful to Mr. Tracy Dingess, for helping me to bring together the areas of Second Language Acquisition and Instructional Technology, Dr. D. J. Hendricks, for her inestimable help in the quantitative analysis of my data, and to Dr. David McCrory, for the valuable knowledge that I acquired in his classes and for always challenging me to do better in my dissertation.

Many thanks to the people that collaborated with me in the process of validating the instruments of this dissertation and complying with IRB regulations: My boyfriend Gregory Mundy, and my friends and coworkers Aurora Castillo, Alex Castañeda, and Tina Cowger. 
Many thanks also to the participants of this study, my students, especially those who so kindly agreed to be interviewed.

Finally, I am grateful to the many friends that have supported me in the process of my studies in the United States. To those in Spain for keeping in touch over the years and across the distance, it is always a blessing to see all of you every time I go back home. To those in the United States, thanks for being my home away from home and for making every day better and more enjoyable. Special thanks to my friend Merche, for always being there for me during all these years. 


\section{TABLE OF CONTENTS}

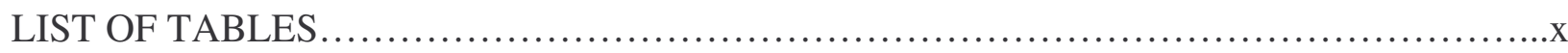

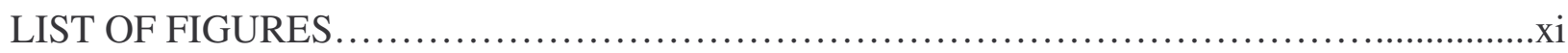

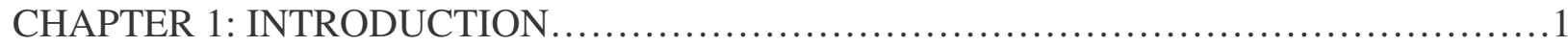

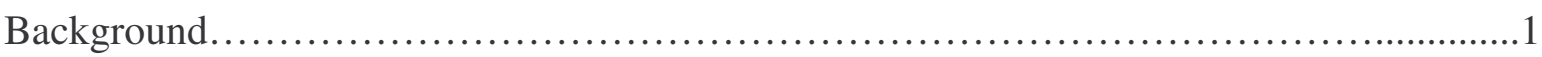

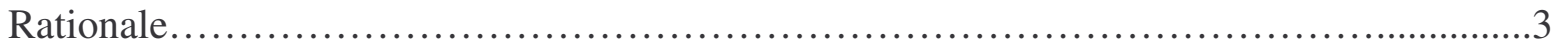

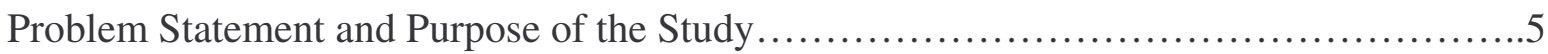

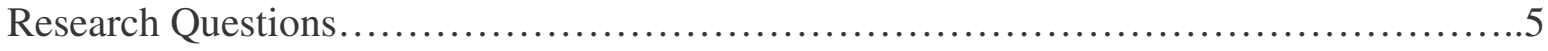

Definition of Terms................................................................

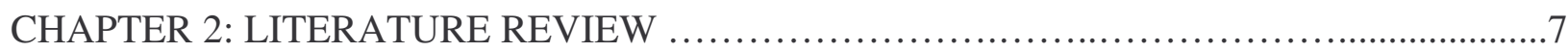

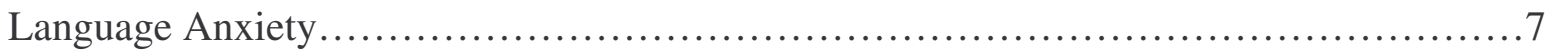

Text-Based Computer Conferencing Technologies and Learning.......................13

Text-Based Computer Conferencing Technologies and Second Language

Acquisition...................................................................

Learner's Perception of Their Language Anxiety in Computer Conferencing

Environments.............................................................

Risk-Taking in Computer Conferencing Environments.........................................17

Concern about Negative Evaluation in Computer Conferencing Environments.........24

Computer Voice Conferencing Technologies and Second Language Acquisition.............25

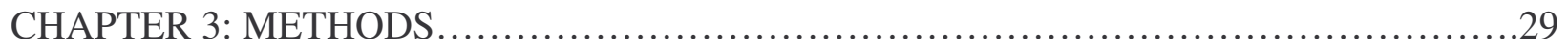

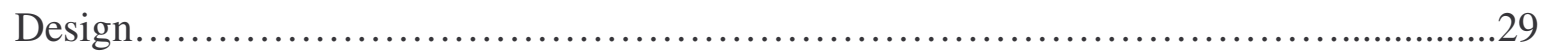

Asynchronous Computer Voice Conferencing Activities.......................... 30

Integration of the Activities in the Spanish 204 Syllabus............................32 


\section{TABLE OF CONTENTS (CONTINUED)}

Data Collection Methodology..................................................... 33

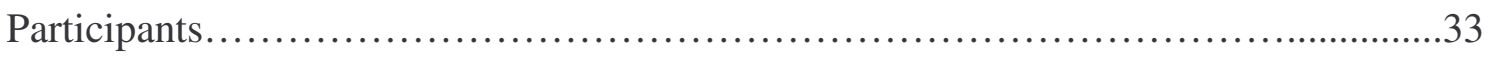

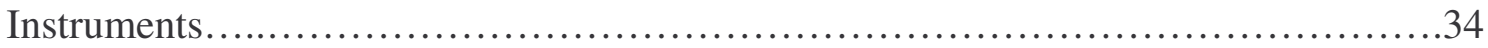

Procedures...............................................................44

Methods of Data Analysis...................................................... 46

Limitations of the Study .....................................................

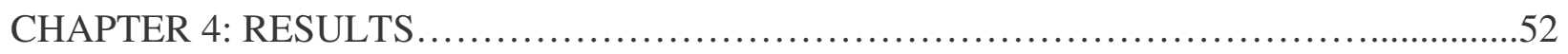

Results by Data Collection Points ..........................................52

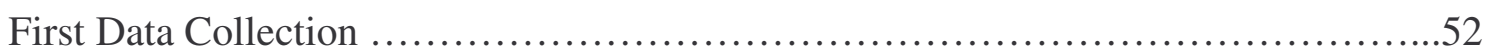

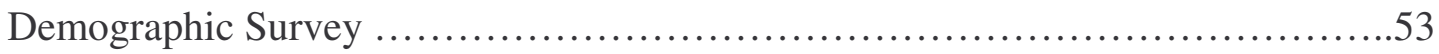

Computer Anxiety: CAIN .................................................54

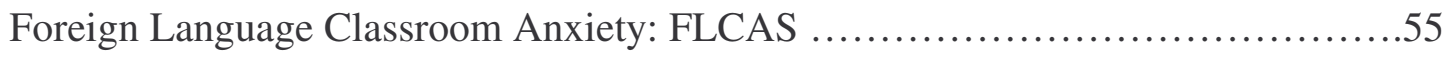

Second Data Collection: Evaluation Rubric .....................................58

Third Data Collection: The Wimba Anxiety Scale ...............................62

Language Anxiety in the Asynchronous Computer Voice Conferencing Environment:

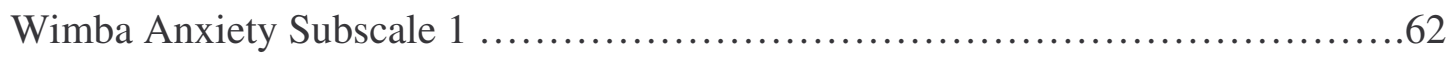

Anxiety about Negative Evaluation in the Asynchronous Computer Voice

Conferencing Environment: Wimba Anxiety subscale 2 .......................65

Correlational Analyses ................................................67

Summary of Quantitative Findings ........................................68

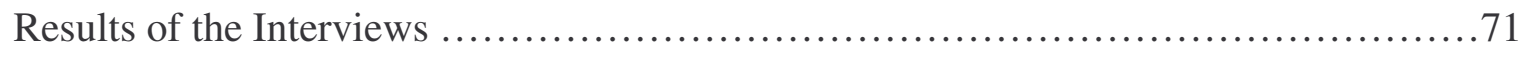

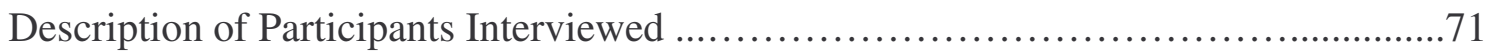




\section{TABLE OF CONTENTS (CONTINUED)}

Computer Anxiety and Classroom Language Anxiety ..................................73

Anxiety in the Asynchronous Computer Voice Conferencing Environment .............76

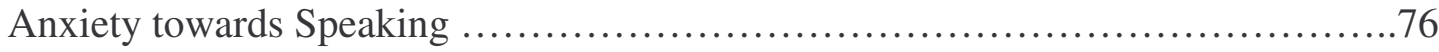

Risk-Taking ......................................................... 78

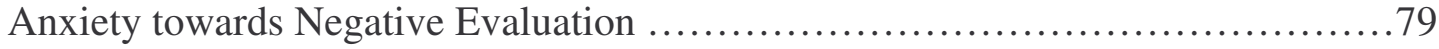

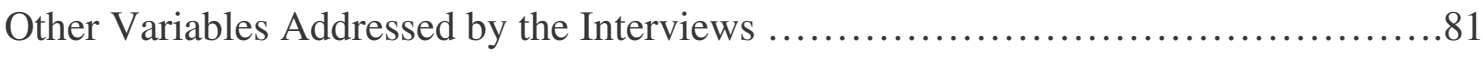

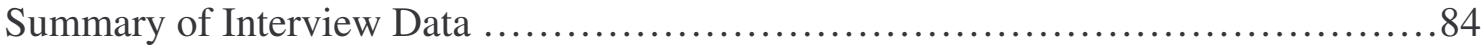

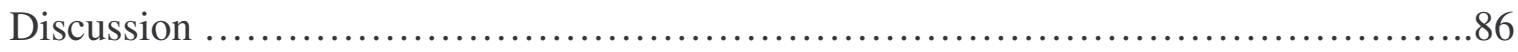

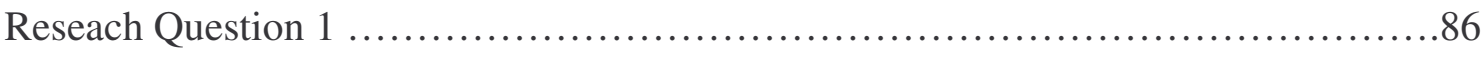

Research Question 2 ..................................................... 87

Research Question 3 .................................................... 87

\section{CHAPTER 5: CONCLUSIONS, IMPLICATIONS, AND RECOMMENDATIONS FOR}

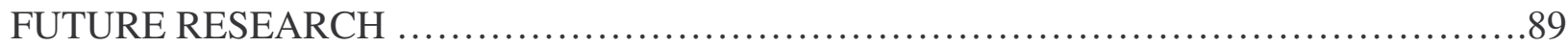

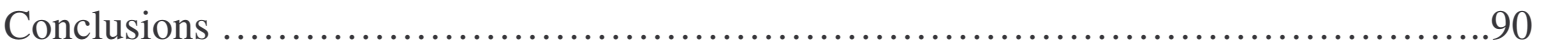

Participants' Perceptions of their Anxiety.................................... 91

Conditions of the Place of Access Where Wimba Is Used ........................92

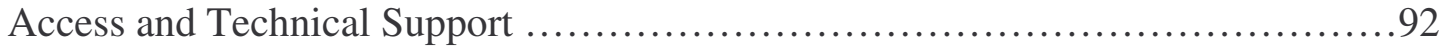

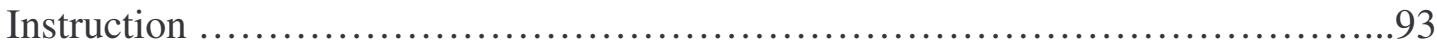

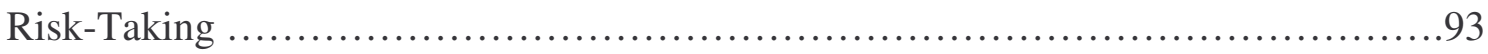

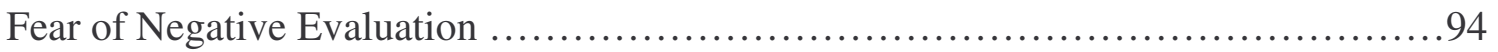

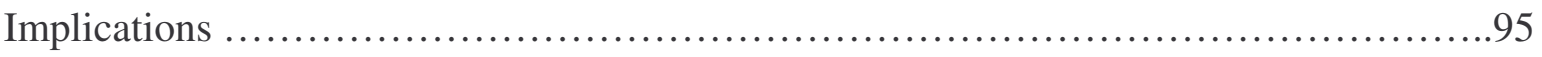

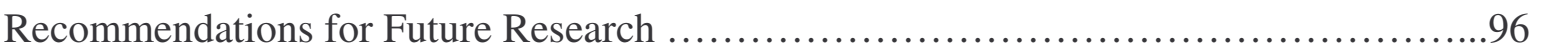


TABLE OF CONTENTS (CONTINUED)

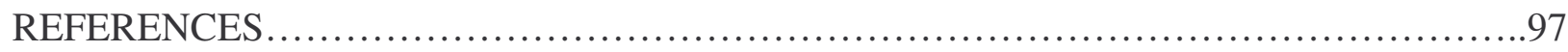

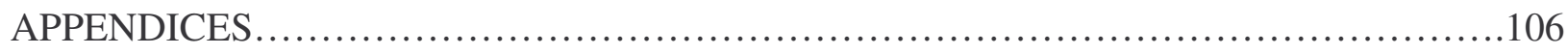

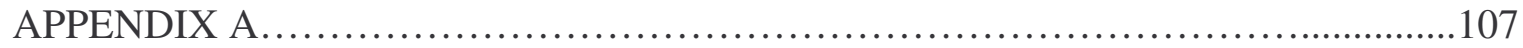

APPENDIX B ............................................................ 110

APPENDIX C................................................................

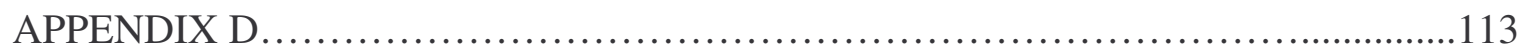

APPENDIX E........................................................... 115

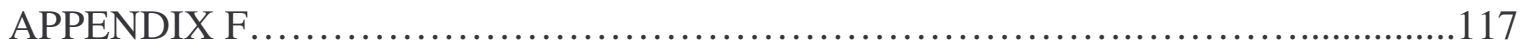

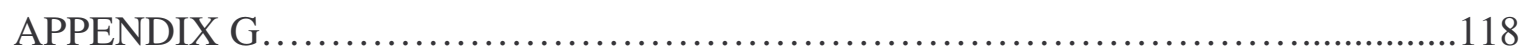

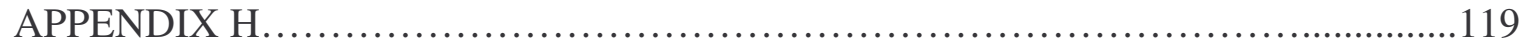

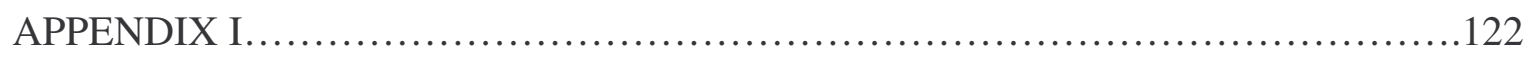

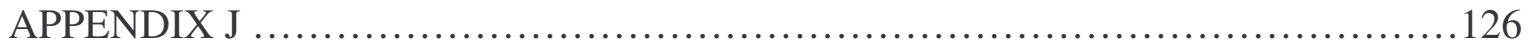

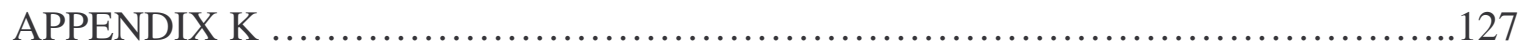

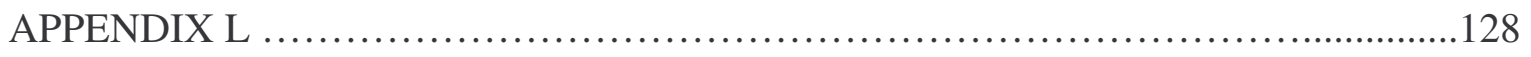

APPENDIX M 


\section{LIST OF TABLES}

Table 1: Relationship between Instruments and their Purpose in this Study

Table 2: Overview of Quantitative Data Analysis Methods for the Description of the

Participants and Research Questions

Table 3: Descriptive Statistics of the CAIN for the Two Studies .54

Table 4: FLCAS Items with Percentages of Selections for Each Alternative, and Means

of Scores

Table 5: Evaluation of Classroom and Wimba Discussions .50

Table 6: Evaluation of Student Contributions

Table 7: Subscale 1 Items with Percentages of Students Selections for Each

Alternative, and Means of Scores .64

Table 8: Subscale 2 Items with Percentages of Students Selections for Each

Alternative, and Means of Scores .66

Table 9: Correlations of the CAIN and FLCAS with the Wimba Anxiety Subscales .68

Table 10: Summary of Interview Data about Computer Anxiety and Classroom Language Anxiety .74

Table 11: Summary of Interview Data about Other Variables that May Influence the Results .82 


\section{LIST OF FIGURES}

Figure 1: Concurrent Triangulation Strategy ..........................................29

Figure 2: Data Collection Timeline .............................................45

Figure 3: Distribution of Language Anxiety Levels ....................................56

Figure 4: Distribution of Language Anxiety Levels for Subscale 1 ......................63

Figure 5: Distribution of Language Anxiety Levels for Subscale 2 .......................65 


\section{Chapter 1: Introduction}

\section{Background}

Helping students to become proficient in a foreign language is the primary goal of language educators. As a result, proficiency, defined as the level of competence reached by instruction (Omaggio Hadley, 2001), in all the skills of a language is of capital importance in the field of second language acquisition. Over the years, different approaches have attempted to attain this goal by emphasizing different aspects of language learning.

Traditional approaches such as the grammar-translation method emphasized grammatical accuracy through the explanation of grammar rules and memorization of vocabulary lists (Omaggio Hadley, 2001). Audiolingualism, a traditional method of language teaching based on the behaviorist school of psychology, stressed habit formation and automatic response to linguistic stimuli by means of memorization, repetition, and pattern drills so that the target language reached the unconscious level of the mind (Omaggio Hadley, 2001).

Contrary to these traditional methods, communicative language teaching places the emphasis on meaning and communication in the target language. This approach advocates for the development of communicative competence as the primary goal of language teaching (Omaggio Hadley, 2001). Communicative competence has been defined as the specific skills of good communicators, such as negotiation of meaning or the use of appropriate context-specific register and style in both written and spoken language (Savignon, 1997). Because of its emphasis on communication, this approach encourages attempts to communicate in the target language from the earliest stages of instruction (Omaggio Hadley, 2001). It is therefore essential for language educators following this approach to provide learners with as many opportunities as possible to communicate in the target language, in both its written and oral forms. 
Oral proficiency, or communicative competence in spoken language, is an important objective of language teaching both from the methodological point of view, as stated above, and from the learner's perspective, either because of personal satisfaction, or career interests (Omaggio Hadley, 2001). Ommagio Hadley (2001) points out that it is the task of language teachers to identify some effective strategies for teaching oral skills and to increase the opportunities for developing oral proficiency. However, foreign language educators often experience difficulties in encouraging all students to participate openly in oral activities, thus resulting in a slower development of their communicative competence in spoken language. These professionals feel that the learners' level of anxiety is often to blame for such reluctance to speak in the target language.

Researchers have looked into these anecdotal experiences and have identified speaking as the most anxiety-producing skill from the learners' perspective (Chen, Horwitz, \& Schallert, 1999; Ellis, 1994; Horwitz, Horwitz, \& Cope, 1986; Young, 1990). Additionally, theorists have claimed that anxiety is associated with several constructs related to interaction in a foreign language, such as communication apprehension (Horwitz et al., 1986), willingness to communicate (MacIntyre, Clément, Dörney \& Noels, 1998), sociability, and risk-taking (Ely, 1986). In view of this research, it becomes clear that there is a strong relationship between anxiety and risk-taking in oral participation in a foreign language.

The source of this relationship does not lie in the act of speaking itself, but rather in a fear of self-exposure, and of being negatively evaluated by others when making errors in the target language (Chen et al., 1999; Young, 1990). Consequently, if foreign language educators can provide an environment where students can concentrate on language and meaning, rather than on 
fear of failure and negative evaluation, their level of anxiety will be lowered, and they will be able to speak more often and openly in the target language.

Computer conferencing technologies such as email, chat rooms, or bulletin boards have the potential of providing a low-anxiety environment for oral interaction. The special features of these technologies eliminate the learner's exposure to the physical presence of others that might negatively evaluate his/her performance at the moment of speaking.

Computer conferencing technologies are increasingly being used in the field of second language acquisition. They have expanded the communicative reach of the foreign language classroom by breaking the time and space barriers typical of that environment. Additionally, as a result of technological advances in the past few years, it is now possible to add the dimension of voice to these text-based technologies. Therefore, it is likely that they will break yet another barrier of the classroom environment, namely the high level of anxiety that students experience when participating in oral interaction in the target language.

\section{Rationale}

Text-based computer conferencing technologies, both synchronous and asynchronous, have been used as a teaching tool in foreign language courses since the early nineties. This trend has been supported by a body of research that has found numerous benefits for the learners. These benefits include a reduction of anxiety (Beauvois, 1994, 1996, 1999; Kivela, 1996; Lee, 2004; Meunier, 1998; Skinner \& Austin, 1999; Warschauer, 1996a), and a more equal interaction which, together with an increased production, indicate a higher level of student empowerment and risk-taking (Beauvois, 1992, 1994, 1999; Blake, 2000; Chun, 1994; Kamhi-Stein, 2000; Kelm, 1992; Kern, 1995; Kroonenberg, 1995; Meunier, 1998; Pelletieri, 2000; Schultz, 2000; Sengupta, 2001; Shetzer \& Warschauer, 2000; Skinner \& Austin, 1999; Toyoda, 2002; 
Warschauer, 1996a; Weasenforth; Biesengach-Lucas \& Meloni, 2002). Finally, some researchers have reported a diminished fear of negative evaluation in the electronic medium (Beauvois, 1996; Chun, 1994; Kelm, 1992; Kivela, 1996).

However, in spite of their conversational nature, these text-based technologies lack the voice element that is essential for the improvement of oral communication skills. Research on these technologies has failed to make a clear distinction regarding the type of skills, either writing or speaking, that these technologies support. As new technologies are being developed, opportunities have become available for interaction in a new environment that supports the use of voice. In view of that, research needs to move a step forward and investigate the effects of these new tools on the acquisition of oral skills in a foreign language.

In her definition of the research agenda for networked classroom interaction, Ortega (1997) emphasized the need for more studies on the relationship between computer conferencing technologies and affective variables, such as attitudes towards the use of the computer and computer anxiety. Most studies conducted to date have concentrated on the influence of computer conferencing on combinations of affective factors such as motivation, student attitudes, or personality. Consequently, it is necessary to conduct studies that improve our understanding of the effects of computer voice conferencing technologies specifically on language anxiety, given the importance of this affective variable in the development of oral proficiency in a foreign language.

This study attempted to provide insights on the use of computer voice conferencing technologies in oral communication in a foreign language, and more specifically on the impact of those technologies on learners' anxiety when speaking in the target language on a voice web board. 


\section{Problem Statement and Purpose of the Study}

In order to address this manifest need of the field, the results of the present research increase our understanding of how new technological advances can support methodological principles of second language acquisition. In particular, this study provides insights on how networked communication technologies can facilitate oral interaction by providing the possibility of using voice conferencing in a low-anxiety environment.

The purpose of this study was therefore to investigate the influence of asynchronous computer voice conferencing on learners' anxiety when speaking in a foreign language. The following research questions were addressed for this purpose:

\section{Research Questions}

1. What is the learners' perception of their language anxiety when speaking in the asynchronous computer voice conferencing environment?

2. How empowered do the learners feel to take risks in the asynchronous computer voice conferencing environment?

3. How concerned are the learners about being evaluated by others when making oral mistakes in the foreign language in the asynchronous computer voice conferencing environment?

\section{Definition of Terms}

The following terms are used in this study as defined below:

Communication: "The expression, interpretation, and negotiation of meaning" (Savignon, 1997). 
Anxiety: An emotional state characterized by the arousal of feelings of tension and increased activity of the nervous system (Spielberger \& Gaudry, 1971). These feelings are the response of a human being to fear, either real or perceived (Horwitz, 2002).

Foreign language anxiety: A type of situation-specific anxiety associated with attempts to learn a foreign language and communicate in it (Ellis, 1994). It is a distinct combination of feelings, self-perception, and convictions caused by the language learning process and based on a fear of performance evaluation in academic and social contexts (Horwitz et al.).

Asynchronous computer-mediated voice conferencing: The technology that will be used in the present study is a voice web board provided by Wimba. One of the co-founders and former CEO of the company, K. W. Ross (2003), defined this technology as follows: "Asynchronous voice is the interactive communication process of people leaving voice messages for other people and the other people responding to their voice messages" (p. 60). 


\section{Chapter 2: Literature Review}

\section{Language Anxiety}

The variable of anxiety is included in the Learner-Centered Psychological Principles of the American Psychological Association (1997). According to these principles, the learner's anxiety level can enhance the quality of learning when it is mild, and hinder it when it is an intense and negative emotion. Therefore, it becomes clear that anxiety can be both beneficial and detrimental for learning. In the first review of the literature regarding anxiety and language learning, Scovel (1978) points to this distinction between facilitating and debilitating anxiety as the proper direction for language anxiety research. Keeping that distinction in mind, and given the difficulties found by language educators to facilitate oral interaction, and the findings of subsequent research on anxiety and speaking, it is important to point out that the anxiety addressed in this study was that of the debilitating kind.

The most significant distinction regarding anxiety in psychology differentiates between trait anxiety, a natural proneness of an individual to be anxious, and state anxiety, a transitory emotion that is experienced at a specific point in time (Spielberger \& Gaudry, 1971). In addition to these two types, researchers of the effects of anxiety on language acquisition have been interested in a third kind, which has been called situation specific anxiety (Ellis, 1999; Horwitz et al.; MacIntyre \& Gardner, 1991). This is a specific anxiety reaction that is aroused by welldefined situations such as speaking in pubic or participating in class. It is in this third category that language anxiety is included.

Language anxiety has been considered a conceptually distinct variable since the work of Horwitz el al. According to these authors, the anxiety experienced by the language learning process entails a separate combination of feelings and behaviors that are produced by this specific 
situation. The rationale provided by these authors is that this anxiety is related to the difficulty of expressing ideas in a channel that is not completely mastered by the speaker. They affirm that communicating in a second language requires a greater amount of risk-taking and uncertainty than communicating in the first language. Horwitz et al. also suggest that the language classroom situation, where the speaker is constantly being monitored by the instructor and peers, intensifies this feeling of anxiety.

The significance of language anxiety in the process of second language learning is brought out in one of the most influential models of second language acquisition developed to this day, the Monitor Theory (Krashen, 1982). The affective filter hypothesis, the last of the five hypotheses that comprise this model, states that the linguistic input needed for language acquisition will not be assimilated by the human brain if the affective filter, a combination of anxiety, self esteem, and motivation, is high. In other words, unless the anxiety level of the learner, or acquirer in Krashen's terms, is low, language acquisition cannot take place. According to this hypothesis, it is the task of language educators to create environments that promote a low affective filter and to provide comprehensible input, or language to which the learner can attach some real-world meaning (VanPatten \& Lee, 2003), in a low-anxiety atmosphere.

Given the theoretical implications of anxiety in language learning, a body of research has been conducted over the past three decades whose objective was to find relationships between anxiety and achievement in second and foreign language courses. As we saw earlier in this chapter, Scovel (1978) provides the first review of the literature regarding the role of anxiety in language learning. In this work, he refers to the mixed and conflicting results on the effects of anxiety on language achievement. However, he attributes this lack of conclusive findings, not to a lack of a relationship between both variables, but to the difficulty in defining the variable of 
anxiety, and the failure of previous research to distinguish between facilitating and debilitating anxiety.

In the same line, Horwitz et al. mention the issue of the inconclusive findings of previous research, and again, they do not attribute it to the lack of a relationship between anxiety and achievement, but to the non existence of a unified measure of language anxiety. In order to address that need, they developed the Foreign Language Classroom Anxiety Scale (FLCAS), an instrument that was designed to identify anxious students in language classrooms.

Subsequent research on the subject of language anxiety and achievement has yielded more consistent results. MacIntyre and Gardner (1989) found that vocabulary test scores in both oral and written tests decreased as language anxiety increased. Phillips (1992) found that the FLCAS correlated negatively with oral test scores. Aida (1994) found that anxiety was negatively related to performance in a Japanese course. Further, Ehrman and Oxford (1995) found strong correlations between anxiety about speaking a foreign language and speaking and reading success. In this study, anxiety, together with motivation, was the most important affective factor influencing success. Soon after, Gardner, Tremblay, and Masgoret (1997) found a strong negative correlation between French achievement and language anxiety. Finally, Onwuegbuzie, Bailey, and Daley (2000) identified foreign language anxiety as the second predictor, after general academic achievement, of foreign language achievement.

With regard to content and complexity of language and ideas, Phillips (1992) observed that students with high anxiety tended to produce shorter communicative units, and use less complex structures in the target language. In other words, they tended to say less, and in a simpler language, than non-anxious students. This finding supported the research by Steimberg and Horwitz (1986), who observed that language students exposed to conditions that foster high 
language anxiety used less interpretive language, with less personal contributions, than those exposed to more relaxed conditions.

Other effects of language anxiety that may hinder achievement were found by Dörney, Clément, and Noels (1994). They conducted a study using questionnaires about attitude, motivation, and anxiety that were given to secondary school teachers and students learning English in Budapest. The study revealed that language anxiety was related to variables such as motivation, activity in the classroom, attitude and effort, student status in the classroom, and involvement in learning English.

Although the above-mentioned research showed strong correlations between language anxiety and achievement in all skills, in the experience of language educators it is oral communication that causes the highest levels of anxiety. Language teachers often find difficulties in facilitating oral participation because the students feel nervous about speaking in the target language in the classroom. To these experiences of language educators, Horwitz et al. add the reports of school counselors that point to speaking and listening as the most anxiety-producing skills in a second language, with special emphasis on speaking.

A tradition of research has followed these anecdotal reports, which confirms what educators and counselors had been experiencing in the language classrooms. Young (1986) found that there was a negative relationship between oral proficiency ratings and anxiety. Ehrman and Oxford (1995) found that anxiety about speaking in another language strongly correlated with speaking and reading success. Following this line of research, Ellis (1994) concluded in his work about second language acquisition that language anxiety appears to be limited to the skills of speaking and listening. Moreover, other researchers have found that it is not the act of speaking itself that arouses language learners' anxiety, but a fear of performing in front of others who may 
negatively evaluate them. Young (1990) found that four out of five activities that caused the highest level of anxiety in language learners were speaking oriented, but also involved exposure of the learners to the rest of the class. She concluded that language students have a fear of selfexposure, rather than of the mere act of speaking in the language.

Chen et al. reached similar conclusions when they found that classroom performance anxiety was one of the best predictors of speaking course grades. The authors further analyzed this performance-based language anxiety and found that it was grounded on the students' low level of confidence when speaking in the target language. It was also based on fear of the possibility of failure, that is, of making errors in the performance that may lead to the negative evaluation of others. In a later study, Young (1990) found evidence of the same sources of anxiety. The findings of this study revealed that making errors when speaking and getting in front of the class were causes of language anxiety. Aida (1994) also found that fear of negative evaluation was an important component of language anxiety in students of Japanese. These findings confirm the personal experience in a French class related by Bailey (1983). She reports feeling panic about making mistakes out loud in front of her classmates, but she grounds this fear, not on speaking itself, but on a sense of competitiveness with respect to her peers.

Horwitz (2002) suggests that a common reaction to this fear is the learner's avoidance of those situations that can cause anxiety. This reaction can act as a detriment to oral communicative competence, since it prevents the learners from participating in oral communication. In psychology, this reaction is called communication apprehension and it works together with fear of negative evaluation and test anxiety in the conceptualization of language anxiety by Horwitz et al. The concept of communication apprehension was introduced by McCroskey (1984) as the anxiety related to oral communication. It is related to communication in the first language and it 
includes interaction with individuals or groups, stage fright, and receiver anxiety. Horwitz et al. believed communication apprehension to be a strong element of their concept of language anxiety. The research by MacIntyre \& Gardner (1989) supports this claim since they found that communicative anxiety, a concept that they claim bears an obvious similarity to McCroskey's communication apprehension, was the only factor that influenced the acquisition and production of French vocabulary.

As a final point on the issue of language anxiety, it is important to refer to the relationship between this variable and other constructs that are closely related to the concept of communication apprehension, namely willingness to communicate, sociability, and risk-taking. MacIntyre et al. (1998) define willingness to communicate as the likelihood of choosing to take part in communication in a second language. In the model that they propose for the conceptualization of this construct, they include anxiety as an underlying factor that causes lack of self-confidence, which, in turn, influences an individual's promptness to enter into communication.

Concerning sociability and risk-taking in a second language, Ely (1986) situated anxiety as part of the notion of discomfort. In this study, he found a chain reaction that started with discomfort reducing risk-taking and sociability among the participants, which, in turn, reduced participation. Ely (1986) further claimed that this reduction in student participation in the language classroom had a negative influence on second language proficiency.

Given the great impact of anxiety on language achievement in general, and oral proficiency in particular shown by research, it is crucial for language educators to find ways to reduce anxiety so that the learners are willing to communicate in the target language and acquisition can take place. Computer conferencing technologies have the potential of providing a 
low-anxiety environment for oral interaction in a second language because they eliminate social cues and the physical presence of instructors and peers who may negatively evaluate performance, thus reducing the main sources of language anxiety, namely fear of negative evaluation and fear of self exposure.

\section{Text-based computer conferencing technologies and learning}

Before focusing on the specific effects of computer conferencing technologies on second language acquisition, it is important to provide a brief summary of the findings of educational research that bear importance for second language acquisition.

Collins \& Berge (1996) include computer conferencing as one of the uses of computermediated communication in education and they define it as the type of interaction in which the computer acts as an impersonal communication device that can be used synchronously and asynchronously. Additionally, these authors point out advantages and disadvantages of computer conferencing such as its equalizing effect on the interaction, and the notion of "flaming." The equalizing effect refers to the fact that, because of the lack of social cues that characterizes computer conferencing, people with disabilities and those who would otherwise be reticent to participate in the communication act feel more inclined to take part in the interaction. As a result, a wider variety of voices can be heard. On the other side, and due to that same lack of social cues, more aggressive participants may become overly zealous, and the language and tone of the conversation may reach undesirable levels. This phenomenon is called "flaming."

In a previous study, Bump (1990) also revealed a more egalitarian and student-centered interchange in which shy students were encouraged to participate. Ellsworth (1995) also referred to the equalizing effect of bulletin boards. She found that interaction of introverts with peers and professors was facilitated by this environment. She also found that computer-mediated 
communication alleviated stress by the increased use of humor. Additionally, Scarce (1997)

studied the use of email discussion groups in a sociology class. He found that $96 \%$ of the students felt that the experience had been worthwhile from an educational standpoint.

Finally, a comparison between email, chat rooms, and bulletin boards was made by Irvine (2000). She found that bulletin boards were the preferred form of computer conferencing among the students, closely followed by email. In addition, students were more likely to use quotes from the textbook, give examples and links to other sources, and make reference to others' comments using the asynchronous technologies.

In light of this research, we can conclude that computer conferencing technologies have some impacts on communication in general educational settings that are also significant to the study of foreign languages and to the purpose of this research. The alleviation of anxiety produced by the reduction of social cues in these communication media may generate overzealousness and flaming on occasions, but mostly promotes a more equal and studentcentered interaction, coupled with richer communication in terms of the content that is expressed, all in an environment that is valued by the learners.

\section{Text-based computer conferencing technologies and second language acquisition}

The research that has been carried out in the area of computer conferencing and the learning of foreign languages is included within the scope of the more general domain of computer assisted language learning (CALL) (Chapelle, 2000), which refers to the ways in which computers can support language learning. Given the fast pace of technological innovation, the area of CALL is constantly evolving and, as new technologies emerge, educators and scholars have taken on the task of exploring how they can make use of those innovations for the advantage of the language learners. 
Computer networks have enormous potential to enhance the language learning experience, since they provide new opportunities for communication (Chun \& Plass, 2000). Moreover, this communication takes place at the learner's convenience, and without any time constraints (Walther, 1996). Scholars have been aware of the communication capabilities of computer networks for some time and extensive research has been conducted since the early nineties in order to examine the impact of these technological innovations on language learning. Since then, numerous benefits have been found for learners of foreign languages. For the purpose of this research, these benefits will be organized in the following sections according to how they provide insights into the research questions of the present investigation. Learners' Perceptions of their Language Anxiety in Computer Conferencing Environments.

Beauvois (1994) experimented with the use of a chat room in a class of intermediate French students in order to determine the attitude of the students towards learning a foreign language in this environment. She found that the network was perceived not only as a strong motivating factor, but also as a low-stress atmosphere that facilitated self-expression in French. In a later study, Beauvois (1996) reiterated this finding in a French conversation and composition course. She found that students felt less anxious and enjoyed the experience because they had more time to think in the network than in regular face-to-face discussions. Similarly, Warschauer (1996a) compared face-to-face and electronic discussions via chat room in an English as a second language (ESL) class. He found that students felt less stress in the computer-mediated environment than in the traditional face-to-face classroom.

In a study about synchronous computer conferencing and writer apprehension at the Chinese University of Hong Kong, Kivela (1996) found that as many as $72 \%$ of the students felt more confident about expressing their ideas in the electronic environment because they had more 
time to think and organize their ideas before sharing them with their peers. However, some students did not take advantage of the opportunity to practice oral skills, due to the text-based nature of the technology.

Meunier (1998) studied French and German classes that were using synchronous computer conferencing and found that students soon overcame their initial computer anxiety and the great majority of them reported a low level of stress that contributed to a better atmosphere during class discussions. The students generally showed a positive attitude towards the use of the technology, with the exception of the instances when activities were not fully integrated into the course, or topics did not appeal to them. She suggests that both instructor and learners must control the functions of the technology and that computer conferencing activities should not be a superfluous addition, but should be carefully integrated in the course.

Likewise, Skinner \& Austin (1999) remark upon the importance of appropriate integration of computer conferencing activities into the course. In this study, English as a foreign language (EFL) students from different nationalities reported an enhancement of personal confidence, compared to other situations where they had to use English. Yet, this was not possible until they became familiar with the technology. Apart from the importance of proper integration in the curriculum of these activities, the findings of this research show the importance of providing training to the students so that the technology does not become an additional source of anxiety that may hinder language learning.

In agreement with these researchers and with Meunier (1998), Beauvois (1999) advocates for the appropriate integration of the activities that involve the use of the network. She also agrees with Skinner \& Austin (1999) when she recommends that an initial session must be dedicated to the students' familiarization with the technology. The study conducted by Beauvois 
(1999) focused specifically in the reduction of anxiety among students of different levels of French using synchronous computer conferencing. The findings indicated that none of the students interviewed reported anxiety in the computer conferencing environment at any level of proficiency. Moreover, they described the medium as a stress-free atmosphere that helped to create a sense of community.

The most recent study regarding the issue of learners' perspectives on interaction in a foreign language via computer conferencing is Lee (2004). Using a chat room as the communication environment between native and nonnative speakers of Spanish, this research revealed that, although it was an overall positive experience for both groups, students still felt anxious and afraid of making mistakes when talking to people who speak the language natively. The author points to the learners' level of proficiency in the language, their computer skills, and age differences as factors that may have influenced those results.

In view of the findings of these studies, and for the purpose of the present investigation, we can conclude that language learners perceive low levels of anxiety when communicating via computer conferencing. Additionally, the researchers highlight the importance of appropriate integration of the computer conferencing activities into language courses, as well as the key role of training in the effectiveness of such integration.

\section{Risk-Taking in Computer Conferencing Environments.}

Greatly due to the above-mentioned reduction of anxiety among the learners, computer conferencing has been shown to empower students to take risks with the target language. Research has found that the computer environment promotes increased participation in the target language both in quantitative and qualitative terms. In other words, the number of contributions per student increases and the learners are more forthcoming about themselves, express their 
opinions more freely, and negotiate meaning in this medium. The result is an equalization of the communication in which students that would not normally participate in traditional face-to-face discussions are empowered to contribute their ideas in the computer conferencing environment. Conversely, the interaction becomes more student-centered, as opposed to the teacher-centered nature of traditional classroom discussions. The remainder of this section will present the specific research studies that focus on those benefits of computer conferencing.

In his preliminary report on the use of synchronous computer conferencing in language instruction, Kelm (1992) analyzed transcripts of student contributions in a synchronous computer environment by college students of fourth semester Portuguese. This researcher observed an increase in student participation in Portuguese, with a larger number of messages per student than during regular classroom discussions. This author also observed that shy students spoke up, while more dominant types did not stand out as much, hence the equalizing effect of the computer environment. He also noticed an increase in the honesty and "candidness" of the opinions that the students expressed and he concluded that the environment provided greater freedom, which allowed for a greater flexibility for self-expression. On the negative side, Kelm (1992) also observed that, although flaming was not an issue, some students pushed the limits to see how far they could go in the computer environment. However, Kelm (1992) does not provide details of what the students said to push those limits. Another disadvantage was the use of English words in parenthesis, a habit that was difficult for the instructor to control.

Using the data from Kelm (1992), Beauvois (1992) reached the same conclusions, and she draws emphasis to the fact that nobody dominated the discussion, everyone, even the teacher, had equal control over the conversation. In addition, she conducted a case study on a student of French and she also found an increase in language production, due to the flexible atmosphere 
provided by the computer medium and the fact that this mode of communication slowed down the pace of interaction into what Beauvois (1992) called "conversation in slow motion."

These findings were corroborated in her later study, Beauvois (1994), which targeted third-semester French students. The results of this study also indicated that there was increased output in the target language, thanks to the same reduction of the speed of the interaction that reduced the level of anxiety and allowed them to monitor their grammar and better express their opinions. However, the students could not say that participating in the network activities improved their oral skills, but many pointed out that the network had increased their confidence in speaking French. The author's explanation for this last finding is that it is yet unclear how computer conferencing affects reading, writing, and speaking.

Similar results were found by Kroonenberg (1995), who investigated the use of both synchronous and asynchronous computer conferencing technologies in grades 9 to 12 English as a foreign language (EFL) classes to native speakers of Cantonese in Hong Kong. She found that bulletin boards allowed for all opinions to be heard and that conversations in chat mode were beneficial because of the slower pace of the interaction.

A later study by Skinner \& Austin (1999) yielded analogous results when studying the online behavior of intermediate to upper intermediate ESL students from different nationalities in an intensive six-week module. These researchers found that computer conferencing helped to overcome writer apprehension in EFL students. The medium enhanced the confidence of those learners who are generally not strong in classroom discussions and most felt that they were able to produce a larger number of messages in the computer conferencing environment than face-toface. 
With regard to the types of ideas expressed by the students and their role in the interaction in computer conferencing environments, several studies have shown numerous benefits of these technologies for language learners. Kern (1995) found that the use of real-time computer conferencing promoted greater interaction among second-level college students of French, with a larger number of words and sentences between students than in face-to-face conversations. The students were also more confident about themselves and the ideas that they expressed in the computer medium and there was much more student-to-student interaction, without intervention of the teacher. Regarding discourse functions such as greetings, questions, commands, assertion of personal opinions, and so forth, the transcripts showed a greater variety of functions in the computer environment than in face-to-face conversations, where functions like questions and assertions were mostly produced by the teacher. In terms of morphosyntactic characteristics, Kern (1995) found that the students produced a greater variety of verb forms, with all tenses and moods being represented in the computer conference and not in the face-toface conversations. They also produced greater grammatical complexity, that is, a larger number of subordinating clauses, if clauses, and negative clauses in the computer conference.

Similarly, Warschauer (1996a) found that students in an advanced ESL composition class in a community college in Hawaii expressed themselves more freely, comfortably, and creatively in electronic discussion than face-to-face. The results of this study indicate that students who consider themselves not fluent in the target language participate more equally in electronic conversations than they do face-to-face.

Beauvois (1999) also observed that in the chat room, students of all levels of French at different universities dealt with subjects that they would not discuss face-to-face. She also observed the equalizing benefit of computer conferencing. Chun (1994) found that her first and 
second-semester German learners took the initiative more than they would in regular classroom discussions, and the instructor's role was decentralized. This study confirms the findings of previous research in that the quieter students become the most prolific in the chat room. Finally, the participants asked more questions to peers and occasionally to the teacher, they gave feedback and requested clarification, which denotes negotiation of meaning.

Pelletieri (2000) and Blake (2000) also found that the UNIX-based synchronous computer conferencing software Ytalk had the capability to promote negotiation of meaning. According to Pelletieri (2000), undergraduate students of Spanish were paying attention to form, therefore monitoring their speech, and providing feedback to each other about errors in grammar. In addition, Pelletieri (2000) provides some suggestions for the design of computer conferencing activities. These activities must be goal-oriented, and they must be designed so that all participants have to pay attention to the ideas and information provided by others in the class in order to complete the task assigned in the activity.

Toyoda (2002) investigated negotiation of meaning between native speakers and advanced learners of Japanese in a chat room. The findings of this study revealed that negotiation of meaning did indeed take place between the participants in order to facilitate mutual understanding.

Shetzer \& Warschauer (2000) point out that the cause of the equalizing effect and the increased production that has been found consistently in previous research is due to the reduction of social context by computer-mediated communication. According to these authors, the social cues such as gender, race, or handicap status can delimit communication. The result of the elimination of social cues is freer communication that, if it is run well can produce a rewarding exchange of ideas, and can result in aggressive outbreaks if run poorly. 
In contrast to the findings of most researchers in this field, Meunier (1998) found that, although they appreciated participating at their own pace in the computer network, third year German and French writing students did not take the risk to experiment with the language in the computer conferencing environment. Similar results were found by Schultz (2000), who investigated the use of computers in collaborative writing in French. The study compared the process of peer editing in a face-to-face environment with the same process in a synchronous computer conferencing environment. The results of this study indicated that there were more and more extensive changes in the content and style of the written pieces in the face-to-face environment than in the computer medium. This occurred because students deviated from task more in the computer medium than face-to-face. Student reactions to the computer medium ranged from very positive to very negative. The format that combined face-to-face and computer-mediated collaboration had the highest average of changes in content and style.

It is important to point out that most of the studies referred to in this section used synchronous computer conferencing, i.e. chat rooms, as the communication medium. While the results of those studies are highly relevant to the present investigation, since both synchronous and asynchronous environments share the potential of reducing language anxiety, there are a number of studies that deal exclusively with asynchronous computer conferencing, which is the medium used in the present research.

Kamhi-Stein (2000) investigated the use of bulletin boards in a language teaching methods course. The findings of this study revealed that the face-to-face discussions showed a consistent pattern of teacher initiation, student response, and teacher evaluation, whereas the bulletin board discussions were much more student-centered, with the teacher posting a much lower number of initiations and responses than the students. Moreover, the instructor's postings 
were often overlooked. In addition, the electronic format allowed for more students to be heard and the asynchronous nature of the software promoted self-paced learning. Finally, the absence of social cues allowed the learners to participate more freely in the discussions.

Sengupta (2001) examined the perceptions of ESL learners, working towards a bachelor's degree, about the use of different computer-mediated communication technologies such as a bulletin board, online materials, student web pages with personal logs, a tasks web page, and web resources. The most common discourse functions found in the electronic medium were agreeing and praising and the students were clearly trying to build a classroom community through the use of computer-mediated communication.

Weasenforth et al. (2002) studied the achievement of constructivist objectives through the use of threaded discussions in a bulletin board in an advanced university ESL reading and writing course. They found that the technology encouraged the participation of those students that rarely contributed in the face-to-face classroom. At the same time, the asynchronous nature of the technology and the logical structure of the thread promoted coherent discussions. However, the long-term nature of the assignment reduced student motivation, as they saw it as an add-on module that increased the amount of work that they already had to do for the class.

The findings of this research are relevant to the present investigation since, as mentioned in previous sections, empowerment and risk taking are closely related to the notion of communication apprehension and anxiety. Although some studies show contradicting results, the vast majority of the research that has been conducted in the topic of computer conferencing and language learning has consistently found an increase in risk-taking. Student participation increases both in terms of the number and linguistic complexity of the sentences and the ideas expressed. At the same time, negotiation of meaning increases, and there is an equalization of the 
interaction, since students who would not normally participate in face to face conversations do so in the computer environment. Finally, the interaction becomes student centered, with fewer interventions from the teacher. Although the majority of these studies have been conducted using synchronous computer conferencing, the same results have been found in studies that use asynchronous environments, which is the type of technology that will be used in the present study.

A final conclusion of the literature, that is relevant to the present research, is the importance of good instructional design for activities that involve computer conferencing technologies. The activities should be goal-oriented and should require the students to pay attention to the opinions of others.

\section{Concern about negative evaluation in computer conferencing environments.}

As mentioned previously, much of the anxiety that learners feel when they have to speak in the foreign language is grounded on a fear of negative evaluation by their instructor or peers (Aida, 1994; Bailey, 1983; Chen et al.; Horwitz et al.; Young, 1990). Computer conferencing technologies have been shown to reduce that fear of being "on the spot," and making errors in front of the whole class.

The participants in Kelm (1992) reported being able to communicate without the pressure of the classroom. Chun (1994) and Beauvois (1996) corroborated this finding in that they concluded that the computer environment freed the learners from time pressure and the fear of making a mistake while the whole class is watching.

The Chinese undergraduates that participated in Kivela (1996) reported that electronic communication was relaxing and less embarrassing than face-to-face discussions. However, this fear of negative evaluation was found to be relative to personality types by Meunier (1998). She 
found that thinking students were less worried than feeling students about posting their ideas for others to read.

Contrary to preceding research, Sengupta (2001) reported conflicting findings regarding the issue of negative evaluation. On the one hand, the students liked the electronic format of the bulletin boards and the student pages that included personal logs because it helped them to learn from their peers. On the other hand, some students did not like the sense of responsibility that the public and archived nature of the technologies involved.

In view of these studies, we can conclude that computer conferencing technologies have the potential to reduce fear of negative evaluation among language learners, since students communicate without the pressure of the class and are less afraid of making mistakes in front of their classmates. However, the archived nature of technologies like bulletin boards can create a sense of accountability that is sometimes not appreciated by the students.

\section{Computer Voice Conferencing Technologies and Second Language Acquisition}

In recent years, the Open University of the United Kingdom has made an effort to find ways to provide opportunities for oral interaction to distance learners of foreign languages. Stevens and Hewer (1998) reported how the Center for Modern Languages at that university addressed this need by the use of telephone audio conference during 1995 and 1996. The purpose of Stevens and Hewer (1998) was to examine student perceptions regarding the value of activities that involved audio conference. They found that students concentrated on the message, rather than on grammatical errors, and that the majority of students and tutors perceived the audio conferencing activities as critical for language learning.

The next step taken by the Open University of the United Kingdom was to create an electronic learning environment for the facilitation of communication among foreign language 
learners. This new environment consisted of a synchronous audio conferencing client, email, and web pages with information about activities and technical support. Kötter, Shield \& Stevens (1999) reported on the initial steps of this project, which did not yield very positive results. The students remained reserved and insecure about communicating in the environment and, since it was easy to hide, they did not take risks in the foreign language. In addition, difficulties were found in turn-taking routines, since the students were not yet familiarized with the technology.

Hampel (2003) reports on how, continuing their attempt to provide quality of spoken communication to their distance learners, the Open University of the United Kingdom implemented synchronous communication software that involved the use of audio and graphics in 2002, after several pilot trials in 1999 and 2001. This study found that quieter students were not more likely to participate in the audio-graphic environment and that technical problems and difficulties in determining a consistent turn-taking policy made the communication less spontaneous than regular discussions. However, some students and tutors felt that their oral skills had been improved and overall, students were more in control of the conversation, as opposed to the traditional teacher-centered classroom discussions.

The latest study on the use of voice conferencing in foreign language classes, Hampel \& Hauk (2004), was carried out at Open University of the United Kingdom, with the same synchronous audio-graphic software used in Hampel (2003) as the object of study. The students reported problems with the quality of the audio and numerous technical difficulties. In addition, it was easy for quieter students to hide and not participate in the discussions, allowing the dominant students to take control of the conversations.

To the knowledge of the researcher, only two studies have looked into the use of the Wimba voice board in foreign language teaching. Cho \& Carey (2001) observed that the Wimba 
technology reduced anxiety in students of Korean. The benefits for the use of this technology were its handiness, since students did not need to use any equipment such as cassette tapes or tape recorders; and increased accuracy ad fluency in listening and speaking. Wimba was also used in this study for oral interviews, which constituted the oral examination for the course. Students had more time to listen to questions and reply; they could repeat the recordings as many times as they needed, they did not feel the pressure of having an interviewer in front of them. This helped to reduce student anxiety about the test. A limitation of this study is that it the report does not describe the instruments used to determine the benefits of the technology.

McIntosh Braul, \& Chao (2003) evaluated the viability of Wimba's voice board as a learning environment for enhancing listening and speaking skills in an English for academic purposes course at the University of Alberta. They found that after two or three sessions, the students lost their shyness to record their voices and the majority perceived the voice board as a non-threatening environment that improved their speaking and listening skills. On the other hand, some students did not feel comfortable posting their voices on line for others to listen and others felt that Wimba made the pace of interaction too slow. The reason for this last finding is that the Wimba voice board, an asynchronous technology, was used synchronously by students, who were interacting through this medium in one location and at the same time.

In summary, contrary to the consistency of the findings of the literature regarding textbased computer conferencing, the studies that have been conducted using voice conferencing have yielded mixed and, often, conflicting results. On the one hand, the first attempt by Open University to provide voice to their online language learners proved to be successful in terms of the benefits that it provided to the students. Further attempts by Open University to provide synchronous interaction through the computer network have not proved to be as effective as their 
initial report. Students in general did not feel that their anxiety was reduced by the technology. Moreover, more reserved students used the special properties of the computer environment to hide and let more confident students dominate the interaction. As a result of this behavior, the student empowerment, equalization of the communication, and increased risk-taking did not occur in these studies.

In light of this, it becomes necessary that more studies are conducted in order to shed more light to the issue of affective factors in general, and anxiety in particular, when the element of voice is added to computer conferencing environments. Additionally, the technology provided by Wimba has been shown to be highly beneficial to the students, but there are not many studies that have used this environment as the means for communication. However, those studies looked at a variety of benefits of the technology for language learning, involving a combination of both affective and achievement factors. No studies have been conducted to date that investigate the influence of this medium on specific variables, such as language anxiety. For that reason, more research is needed on the use of the Wimba voice board in order to establish its usefulness as a language learning tool that reduces language anxiety. 


\section{Chapter 3: Methods}

\section{Design}

The influence of the asynchronous computer voice conferencing technology on student anxiety when speaking in Spanish was analyzed by means of a study that combined quantitative data in the form of questionnaires and an evaluation rubric, and qualitative data in the form of interviews. The use of interviews in addition to the quantitative data served to provide further insights and in-depth understandings of the learners' anxiety when speaking on the Wimba voice board. An additional rationale for the use of a mixed methods design was provided by previous research on communication apprehension, which advocates for the use of self-reported measures, such as questionnaires or interviews, as the only valid indicators of this variable (Daly, 1991; McCroskey, 1984). In addition, McCroskey (1984) advocates for the use of behavior measures, like the rubric used in the present research, only when combined with self-reported measures.

\section{Figure 1}

Concurrent Triangulation Strategy
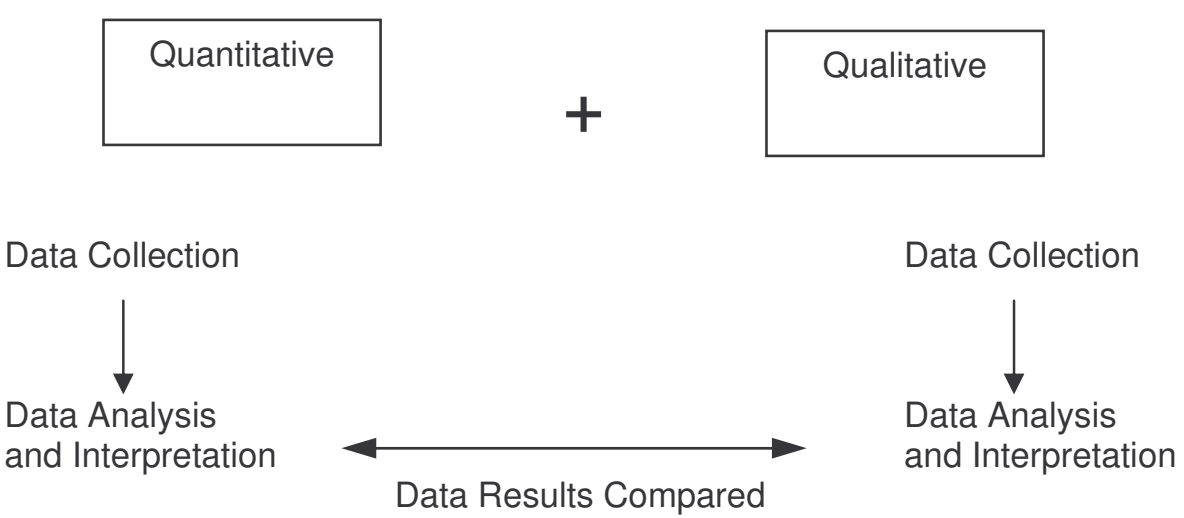

Note: Adapted from Research Design: Qualitative, Quantitative, and Mixed Method Approaches, Creswell, 2003 
Figure 1 illustrates concurrent triangulation, the mixed methods strategy that was employed for the integration of the quantitative and qualitative data in this study (Creswell, 2003). According to Creswell (2003), this approach consists of collecting the quantitative and qualitative information concurrently at one phase of the study, and then integrating both types of data during the phase of analysis and interpretation. It is in this phase when the convergence or divergence of the data is noted and interpreted. The rationale for the use of this model is that it was anticipated that once the course had finished, the availability of potential participants for the interviews would be very limited. In addition, this strategy allows for confirmation and corroboration of findings from different data sources, quantitative and qualitative, and this triangulation of methods yields better validated results (Creswell, 2003).

The present investigation consisted of the development and integration of specific Wimba activities, together with a training session, and the collection and analysis of data from different sources in two Intermediate Spanish 2 sections taught by the researcher. For this purpose, specific sampling methods, data gathering instruments, research procedures, and data analysis techniques were used. The Wimba activities and their integration in the course syllabus are described in the remainder of this section. The participants of the study, instruments of data collection, procedures, and data analysis are discussed in subsequent sections. Asynchronous Computer Voice Conferencing Activities.

Specific activities that use the Wimba voice board as the medium of communication were developed by the researcher (see Appendix A). These activities, together with a training session, constituted the treatment of the present investigation. It is important to point out that these are by no means stand-alone activities. To the contrary, they were designed as part of an overall plan for chapters 4 and 6 of the Spanish textbook, Punto y Aparte. In this manner, the content of the 
textbook and the activities that took place in class served both as preparation and follow-up exercises for the communication that took place on the voice board.

Regarding their theoretical background, the asynchronous computer voice conferencing activities were designed in accordance with previous research in the areas of second language acquisition and instructional technology, as well as the suggestions made by Pelletiery (2000) on the use of networks in language teaching and learning. According to this author, the activities created for network-based language learning should be goal-oriented, and the design should be such that the participants must have a reason to access and take notice of the information provided by others so that real communication takes place. Following these guidelines, the Wimba activities were designed so that the students must go back to the voice board and listen and react to each other's opinions.

As far as previous research on second language acquisition is concerned, the Wimba activities were designed in agreement with the ideas presented by Omaggio Hadley (2001) regarding the creation of speaking activities in a proficiency-oriented approach to language learning. For that reason, the activities were personalized and dealt with topics that are meaningful to the students; they integrated practice in other skills such as writing, or listening; and both pre-communicative practice and follow-up exercises were included in the design. Thanks to that previous practice, the students received the necessary input and guidance that aided them when communicating on the voice board, and thanks to the follow-up exercises, the activities were task-based and required students to listen to each other in order to be prepared for a task that took place during the following class period.

Finally, and taking instructional technology research as a basis, the Wimba activities can be classified within the genre of interpersonal exchanges, according to the categorization of 
network-based educational activities proposed by Harris (2000). More specifically, in the Wimba activity corresponding to chapter four, the activity structures within the interpersonal exchanges genre that were used are impersonations and questions and answers. In the case of the Wimba activity corresponding to chapter six, the activity structure that was used is questions and answers.

Integration of the Activities in the Spanish 204 Syllabus.

Several researchers have emphasized the importance of properly integrating computer conferencing activities into language courses in order to obtain the maximum benefits from this technology (Beauvois, 1999; Meunier, 1998; Skinner \& Austin, 1999; Warschauer, 1996b). Following the recommendations of this research, the activities of the present investigation were integrated into the course syllabus so that they were not seen by the students as a gratuitous and burdensome addition to the class.

The Spanish 204 syllabus allots ten percent of the final grade to the completion of homework exercises to be assigned by the instructor. The Wimba activities were assigned and graded together with other homework exercises in chapters four and six of Punto y aparte. The messages were posted outside of class time, at the L.L.R.C. laboratory, which makes headsets and microphones available to all foreign languages students. However, students who owned the necessary equipment and wished to post their messages from home were allowed to do so. In addition to the Wimba activities, and following the suggestions provided by previous research (Beauvois, 1999; Skinner \& Austin, 1999), the instructor conducted a training session in which the students were shown how to use the Wimba voice board. 


\section{Data Collection Methodology}

\section{Participants}

The participants of this study (potentially $\mathrm{N}=48$ ) were the students enrolled in two sections of Intermediate Spanish 2 taught by the researcher, at the Department of Foreign Languages at West Virginia University during the fall 2004 semester. In terms of their oral skills, the majority of these students resembled the level between the novice high and intermediate low levels of the ACTFL Proficiency Guidelines. At this stage, they still used memorized linguistic material and formulaic speech, typical of the novice level, but they were able to be creative with the target language, and participate in conversations by asking and answering questions, although still strongly influenced by their first language (Breiner-Sanders, K. E., Lowe, P., Miles, J., \& Swender, E., 1999). These latter characteristics are distinctive of the intermediate level of proficiency.

Typically, the students take this course as a requirement for other majors, but there are a number of students who plan to either major or minor in Spanish in the future, or who have a personal or career interest in the language. All of them were U.S.-born undergraduate students whose first language was English. The course was taught using the communicative method of language teaching, and the great majority had taken the previous levels, namely Spanish 101, 102, and 203, at West Virginia University and were accustomed to this methodology.

For the qualitative component of this study, purposeful sampling procedures were used. In particular, the qualitative sampling strategy that was employed in this study was criterion sampling, by which all cases that met specific predetermined criteria were selected (Patton, 2001). In the case of the present investigation, the selection criterion was based on the participants' involvement in both Wimba and face-to-face discussions. In this way, only those 
students who participated in the discussions taking place in both environments were selected. A total of four students, two for each section taught by the researcher, were chosen to participate in the interviews. In addition, the participants were selected based on either a personal communication to the researcher expressing high levels of anxiety, or the researcher's observation of their behavior during class discussions.

\section{Instruments}

In order to provide a more accurate analysis of the capability of asynchronous computer voice conferencing technologies to reduce anxiety, and also to increase internal validity, as suggested by Ortega (1997), a number of different data sources were used in this research. The remainder of this section is a description of the instruments, which will be later matched to the research questions that guide the data collection. Additionally, a set of instruments was used in this research that were aimed, not only at answering the research questions, but also at describing the participants in depth by providing demographic information, as well as data regarding their level of computer anxiety, and anxiety when speaking a foreign language in the classroom. The data obtained from these data sources helped to better explain the results of the study. Finally, some of the data collected in the interviews was used to account for other variables that may influence the results, such as attitude towards the assignment, access to hardware, userfriendliness of the software, and perceived value of the activity.

A demographic survey was developed by the researcher which included information about learner characteristics such as age, gender, first language, reasons for taking the course, level of motivation, number of Spanish courses taken to date, whether those courses were taken at West Virginia University or at another institution, and the amount of effort allotted to the course (see Appendix B for complete survey). Content validity of the survey was established in 
order to ensure that the wording of the individual items was clear for the target population, and the items were representative of the purpose of the questionnaire as well as the typical characteristics of intermediate Spanish 2 students. A panel of three experts was selected for determining the content validity of the survey. Expert selection was based on their experience as instructors of intermediate Spanish 2 or Spanish 200 at the Department of Foreign Languages at West Virginia University.

Expert participation was solicited in person, and packages that included the demographic survey and a response form for the rating of the items were given to each member of the panel upon acceptance. The response form was adapted from Rubio, Berg-Weger, Tebb, \& Rauch (2003) and it requested the experts to rate each item for clarity and representativeness on a fourpoint scale, as well as to provide comments that explained their ratings and items that should be added to or deleted from the survey (see Appendix $\mathrm{C}$ for response form). Following a period for completion, individual meetings were held between the researcher and each member of the panel in order to discuss the results of the content validity process.

Two types of data analyses were performed on the content validity data provided by the experts (see Appendix D for complete content validity data of the demographic survey). First, interrater reliability was computed in order to determine expert ratings consistency. Interrater reliability was computed for each item as well as for the whole measure and was calculated according to Rubio et al. (2003). In order to calculate the interrater reliability for each item, values one and two were combined, and so were three and four (Rubio et al.). After that, the number of experts that rated the item the same was divided by the total number of experts. Interrater reliability for the whole measure was calculated by dividing the number of items that had $100 \%$ agreement by the total number of items. 
Item Interrater Reliability $=$ number of experts that rated the item the same total number of experts

Scale Interrater Reliability $=$ Number of items with $100 \%$ agreement total number of items

All operations were performed for both representativeness and clarity. It was decided that any score below 0.67 , which indicates the agreement of two of the three experts, would be regarded as lack of agreement among the experts. If that was the case, the item would be brought up in the final meetings in order to reach consensus.

The second type of data analysis that was performed in order to determine the content validity of the demographic survey was the content validity index (CVI), which determines the representativeness and clarity of a measure. The CVI for each item was calculated by counting the number of experts that rated the item as 3 or 4 , and dividing the resulting number by the total number of experts (Rubio et al.). This operation was performed for representativeness as well as for clarity. The CVI for the survey was determined by calculating the average CVI of the individual items (Rubio et al.). As with interrater reliability, all CVI operations were performed for both representativeness and clarity.

Item CVI $=\frac{\text { number of experts that rated the item as } 3 \text { or } 4}{\text { total number of experts }}$

Survey CVI $=$ average CVI of the individual items

It was decided that any score below 0.67 , which would mean that two experts rated the item 3 or 4, would be regarded as a low CVI. If that was the case, the item would be brought up in the final meetings for revision. As a final analysis, interrater reliability and CVI were also calculated for the clarity of the instructions to the participants. 
The results of the process (see Appendix D) show an interrater reliability of $1.0(100 \%)$ for both representativeness and clarity of each item, as well as the survey as a whole. For that reason, consistency among the experts was not an issue in the rating of the items. The CVI for the individual items, as well as the scale as a whole, was 1.0 (100\%) for both representativeness and clarity. Despite the high CVI obtained, two of the three experts were consistent in their qualitative comments regarding previous Spanish courses possibly taken at high school, as well as the inclusion in the survey of the placement test that most foreign language students take during their first semester of language learning at West Virginia University. Consequently, the specification that participants should include courses taken at high school was added to item 7. In addition, two new items which queried the students about the placement test were added to the original survey.

The second questionnaire that was administered to the participants was the Computer Anxiety Index (CAIN) developed by Simonson, Maurer, Montag-Torardi, \& Whitaker (1987) as part of a standardized test of computer literacy. The CAIN uses a six-point Likert scale with higher scores indicating a higher level of computer anxiety (See Appendix E for complete questionnaire). The CAIN has been tested and shown to have a reliability of approximately .90 (Simonson et al., 1987).

The third questionnaire that was used in this study was the Foreign Language Classroom Anxiety Scale (FLCAS). This scale was created by Horwitz et al. in order to provide researchers with a valid measure of the anxiety specific to language learning. It was intended that this measure would be the standard scale for determining the relationship between language anxiety and achievement. The authors claimed that highly anxious students identified by the FLCAS score high in items related to speaking the foreign language, and they concluded that these 
students feel self-conscious about taking risks when speaking the target language. In light of these claims, it was concluded that the FLCAS measures mostly the anxiety related to the skill of speaking the foreign language and was therefore appropriate for the present research. The scale uses a five-point Likert scale with higher scores indicating a higher level of language anxiety.

There were a number of items of the FLCAS that were not relevant to the present investigation and were therefore removed. More specifically, items related to test anxiety were eliminated, since the study was concerned exclusively with the anxiety produced by speaking the language. In the same way, items related to fear of not being prepared for class, or anxiety about failing the course were eliminated, since they also fell out of the scope of the present research. As a result of this elimination process, 18 of the 33 items of the original FLCAS were used in this study (See Appendix F for resulting scale). The original scale has been tested and was shown to be reliable at .93 (Horwitz, 1986).

The FLCAS created by Horwitz et al. measures the learners' anxiety level when communicating in the foreign language in the context of the classroom. For the purpose of this research, a modified version of the FLCAS was also used that fit the context of the Wimba web environment. Like the FLCAS, the Wimba Anxiety Scale uses a five-point Likert scale with higher scores indicating higher levels of anxiety (see Appendix $G$ for complete scale). In order to examine test-retest reliability, a sample of 6 ESL students that use Wimba for their class were given the Wimba Anxiety Scale twice, with both administrations occurring two weeks apart from each other. This class was chosen because it was the only one offered at West Virginia University which used Wimba for the purpose of language learning. The test-retest reliability coefficient obtained was .5 . This relatively low reliability coefficient should be considered in 
light of the small sample size and the limited English ability of the participants that caused some problems to fully comprehend the items of the scale.

Additionally, content validity of the adapted scale was established in order to ensure that the wording of the individual items as well as the instructions to participants were clear for the target population, and the items were representative of the research questions that they are intended to address. A panel of three experts was selected for determining the content validity of the Wimba Anxiety Scale. Expert selection was based on familiarity with the present research, background, work experience, and publications in the areas of second language acquisition, technology education and instructional technology, and computer assisted language learning (C.A.L.L.).

Expert participation was solicited via email prior to the initial meeting, and packages that included the Wimba Anxiety Scale and a response form for the rating of the items were sent to each member of the panel upon acceptance. The response form was adapted from Rubio, BergWeger, Tebb, \& Rauch (2003). This form contained the research questions being measured by the Wimba Anxiety Scale, and requested the experts to rate each item for clarity and representativeness on a four-point scale, as well as to provide comments that explained their ratings. For the present study, clarity was defined as the capacity of the items to elicit feelings that the participants have felt, or they know they are capable of feeling during their experience in the Wimba environment. As far as the instructions are concerned, clarity was defined as their capacity to let the participants know what is expected of them. In addition to the dimensions of representativeness and clarity, the experts were requested to evaluate the comprehensiveness of the whole scale by indicating items that should be deleted or added, and to evaluate the level of clarity of the instructions to the participants (see Appendix $\mathrm{H}$ for response form). Following a 
period for completion, a meeting was held between the researcher and the members of the panel in order to discuss the results of the content validity process and reach consensus about the content validity of the scale.

As with the demographic survey, interrater reliability and the content validity index were calculated in order to determine content validity of this scale. The results of the process (see Appendix I) show an interrater reliability of 1.0 (100\%) for both representativeness and clarity of each item of the scale, as well as the scale as a whole. For that reason, consistency among the experts was not an issue in the rating of the items. However, concerning the instructions to the participants, the interrater reliability score was 0.67 , indicating that two of the three experts agreed in their ratings. Although this score did not fall below the threshold that was previously established for low interrater reliability, the instructions to participants were brought up in the final meeting, due to the fact that they also showed a CVI that was lower than that of the individual items (0.67). Following the qualitative comments of one of the experts, and the consensus reached during the meeting, the instructions were reworded in a way that would link the students' previous experience with the Wimba activities with the items of the scale.

The CVI for the individual items, as well as the scale as a whole, was 1.0 (100\%) for both representativeness and clarity. However, since all three experts agreed on this particular point either in qualitative comments or at the final meeting, the items were revised and Spanish was specified as the language of interaction of the Wimba postings.

As a final point, the researcher and the experts reached consensus about which items were to address each of the research questions that the Wimba Anxiety Scale is designed to measure. It was decided that items $1,3,4,7,8,11,15$, and 16 would address research question 1 , since they refer specifically to anxiety when speaking Spanish, and items 2, 5, 6, 9, 10, 12, 13, 
14, and 17 would address research question 3 , since they refer to anxiety caused by the presence of others that may evaluate negative performance when speaking Spanish. In this way, the Wimba Anxiety Scale was divided into two subscales following the recommendations of the experts during the content validity process.

The final step aimed at ensuring content validity was to give the Wimba Anxiety Scale to a Spanish 200 instructor who had used Wimba in the past, and to a former student who had taken that instructor's class. They both found that the items were worded in a clear manner.

Additionally, the instructor was in agreement with the three experts in pointing out the fact that some items were similar to one another.

A fifth source of data, interviews with selected participants, was used in order to provide more in-depth insights and understandings about the Spanish 204 students'́ level of anxiety. The interviews were conducted by the researcher and scheduled with a subsample of four selected participants. More specifically, the interviews followed the general interview guide approach proposed by Patton (2001). According to this approach, the main issues to be addressed by the interview are listed as questions. The interview guide includes topics and subtopics that need to be covered, but it is flexible enough so that the interviewer can elaborate on or ask for further detail of a particular insight provided by the participant in the course of the interview (Patton, 2001). In the case of the present investigation, interview questions addressed student perceptions about their anxiety in the Wimba environment, their willingness to take risks, their concern about negative evaluation by others, as well as their attitude towards the assignment, access to hardware, user-friendliness of the software, and perceived value of the activity (see Appendix $\mathbf{J}$ for complete interview guide). 
The sixth and final data source that was used in this research is a rubric for the evaluation of the linguistic output produced during communication about a selected topic of Wimba postings and classroom discussions (see Appendix K). The purpose of this rubric was to address research question 2 of this study, since it assessed the amount of risk taking by the students during their interactions in the Wimba voice board. Student contributions to the discussion topic in both environments were analyzed and evaluated by the use of this rubric. The development of this measure was based on Ortega (1997), who advocates for the use of multiple outcome instruments in the study of participation patterns and linguistic output. According to this author, such measures should not be limited to the quantity of the output produced by the learners, but should include other outcomes that are motivated by second language acquisition research. In the case of the present study, the outcomes included in the evaluation rubric are based on the literature on the relationship between language anxiety and variables like achievement, complexity of language, and willingness to participate in oral communication. Additionally, some of the criteria included in the rubric are based on the findings of the literature on computer conferencing technologies and language acquisition, such as increased participation and negotiation of meaning, and a more student-centered interaction. The resulting rubric included the following criteria: Quantity of linguistic output, measured by the number of words, sentences, and occasions in which English was used per student contribution in the Wimba and face-to-face environments; complexity of linguistic output, measured by the number of simple and complex sentences and questions that the participants have provided in each discussion; accuracy of linguistic input, measured by the number of grammatical errors per student contribution in each environment; negotiation of meaning, measured by the number of requests for clarification, the number of instances in which feedback was given to other students, and the 
number of elaborations and expansions of previous contributions made by the participants; and finally, teacher versus student-centered interaction, measured by the number of interventions by the instructor in the discussion. The linguistic output that was evaluated by the use of this rubric was taken from transcripts of student contributions posted in Wimba on a selected discussion topic, as well as from a tape-recorded classroom discussion about the same topic. The results of the evaluation rubric for both environments were compared during the data analysis process of the present research.

Table 1

Relationship between Instruments and their Purpose in this Study:

Instruments

Demographic Survey

FLCAS

CAIN

Wimba Anxiety Scale (subscale 1)

Evaluation rubric

Wimba Anxiety Scale (subscale 2)

Interview questions
Purpose

Description of participants.

Possible influence on Wimba anxiety.

RQ 1: What is the learners' perception of their language anxiety when speaking in the asynchronous computer voice conferencing technology environment?

RQ 2: How empowered do the learners feel to take risks in the asynchronous computer voice conferencing environment?

RQ 3: How concerned are the learners about being evaluated by others when making mistakes in the foreign language in the asynchronous computer voice conferencing environment?

Research questions.

Other variables that might influence the results: Attitude towards the assignment, user-friendliness of the software, access to hardware, and perceived value of the activity. 


\section{Procedures}

The study took place over a six-week period during the fall semester of 2004. In terms of course content, this time frame corresponded to the time period when chapters four and six of the textbook Punto y Aparte, for which the Wimba activities were designed, was covered as scheduled in the course calendar. Before data collection, Institutional Review Board (IRB) review took place.

The first data collection point of this research corresponded to the first day of chapter four. On this date, the demographic survey, the FLCAS, and the CAIN were administered to both Spanish 204 sections. This was done on the grounds that these measures were aimed at describing the participants before the treatment had taken place, so that the later familiarization with the technology would not bias the results. Since the researcher was the participants' instructor, all questionnaires that were used in this study were administered by a person other than the researcher instructor, in order to comply with IRB regulations. A cover letter was read to the students previous to the administration of the questionnaires (See Appendix L).

The training session took place for 20 minutes after the questionnaires had been administered. During this session, the instructor demonstrated the use of Wimba and how to find it on the course web site. The Wimba activity that corresponded to chapter four was assigned at the end of this training session.

The two Wimba activities continued to be assigned as part of the course until the end of chapter 6 . In addition, a tape-recorded class discussion that took place during the same period was selected and evaluated by means of the rubric designed for this investigation. The criterion for the use of this specific classroom discussion over the other discussion that was part of the activities was the better quality of the recording. Finally, in order to compare both environments, 
the electronic discussion dealing with the same topic as the one selected for the classroom was evaluated using the same instrument.

With the purpose of providing more accurate results from the evaluation rubric, a number of random classes were tape recorded by the researcher after the training session had taken place. This was done so that the participants could get accustomed to this procedure and the tape recorder did not become an additional source of anxiety that could influence the findings of this research.

The second data collection point took place during the last week of classes, after the content of the textbook chapters had been covered and the largest possible number of students had had the opportunity of using the Wimba voice board. On this date, the participants were administered the Wimba Anxiety Scale. It was also during this last phase of the data collection that the interviews were scheduled, in accordance with the concurrent triangulation strategy of mixed methods research that guided the design of this investigation. Figure 2 illustrates the data collection procedures of this study.

Figure 2

Data Collection Timeline

\begin{tabular}{llcc} 
Oct. 25 & Oct. $25-$ Dec. 8 & Dec. 8 & Dec. $10-17$ \\
\hline $\mid$ & & Wimba Anxiety Scale & Interviews \\
$\begin{array}{l}\text { Demographic Survey } \\
\text { FLCAS }\end{array}$ & Wimba activities & & \\
CAIN & & & \\
Wimba training & & &
\end{tabular}


Methods of Data Analysis

Analysis of the quantitative data involved descriptive statistics, including measures of central tendency, variability, and percentages. In addition, correlation coefficients were obtained between the scores of the FLCAS and CAIN and both subscales of the Wimba Anxiety Scale. Table 2 is an overview of the data analysis methods and their purpose. 
Table 2

Overview of Quantitative Data Analysis Methods for the Description of the Participants and

Research Questions

\begin{tabular}{ll}
\hline \multicolumn{1}{c}{ Purpose } & \multicolumn{1}{c}{ Analysis } \\
\hline Description of the participants. & Percentages of demographic data. \\
Possible influence on research questions. & $\begin{array}{l}\text { Range, } M, \text { and } S D \text { of CAIN index scores (baseline: } \\
\text { published means). }\end{array}$ \\
& $\begin{array}{l}\text { Range, } M, \text { and } S D \text { and distribution of anxiety levels of } \\
\text { FLCAS scores. }\end{array}$
\end{tabular}

Percentages and descriptive data of student selections for each item of FLCAS.

RQ 1: What is the learners' perception of their language anxiety when speaking in the asynchronous computer voice conferencing technology environment?
Range, $M, S D$ and distribution of anxiety levels of Wimba subscale 1 scores.

Percentage and descriptive data of students' selections for each item of the Wimba subscale 1 .

Correlations of the CAIN and FLCAS and Wimba subscale 1 .

RQ 2: How empowered do the learners feel to take risks in the asynchronous computer voice conferencing environment?
Numeric values: Contributions by instructor and students and contributions in English.

Numeric values: Negotiation of meaning in both environments.

$M$ and $S D$ of words, sentences, simple sentences, complex sentences, and errors per contribution in both environments.

Independent samples $t$-tests on words, sentences, simple sentences, complex sentences, and errors.

Range, $M, S D$ and distribution of anxiety levels of the Wimba subscale 1 .

Percentage and descriptive data of students' selections for each item of the Wimba subscale 2 .

Correlations of the CAIN and FLCAS and Wimba subscale 2 . 
The participants' demographic information from the demographic survey is presented in the form of percentages. Other data about the participants that may have influenced their level of anxiety was measured by the CAIN and the FLCAS. The CAIN index was computed by totaling all items scores (M. R. Simonson, personal communication, April 28, 2004), and descriptive data, namely the mean and the standard deviation, was derived from the index scores. The range of possible scores for this instrument is 26 to 156 , with a higher index indicating higher anxiety (Simonson et al.). In order to determine if the participants of this study had a high or low computer anxiety level, compared to other students, the mean computer anxiety index of the participants was contrasted with the mean index for college students reported by Simonson et al. $(M=62.33, S D=17.76)$.

The FLCAS also was computed by totaling all items scores, and the mean and standard deviation of those final scores was calculated. Moderately high and low anxious students were identified by their scoring one standard deviation above and below the mean respectively. In the same way, very high and very low anxious students were identified by their scoring two standard deviations above and below the mean respectively (E. Horwitz, personal communication, May 3rd, 2004). Percentages of students who fell under each category were calculated and used to create a distribution of the participants' language anxiety levels. Finally, and in order to determine which aspects of oral communication produced higher anxiety, mean scores and percentages of agreement were computed for each item of the FLCAS.

Since the Wimba Anxiety Scale was used to address two different research questions, the researcher, together with the panel of experts for content validity, selected the items that were used to measure each research question. For that reason, only scores from the Wimba subscale 1 were analyzed to answer research question 1, and scores from the Wimba subscale 2 were 
analyzed to answer research question 3. The range of scores for the Wimba subscale 1 was $8-40$, and the range for subscale 2 was 14- 36. The range, mean and standard deviation of the scores from the selected items for the Wimba subscale 1 were calculated in order to determine the participants' level of anxiety when speaking in Spanish in the Wimba voice board. As with the FLCAS, moderately high and low anxious students were identified by their scoring one standard deviation above and below the mean respectively. In the same way, very high and very low anxious students were identified by their scoring two standard deviations above and below the mean respectively. The same operations were performed for the items of subscale 2 , which addressed research question 3. Additionally, and in order to determine the relationship between the anxiety experienced in the Wimba voice board and the variables of computer anxiety and language classroom anxiety, correlation coefficients were obtained between the scores of each subscale of the Wimba Anxiety Scale and those of the CAIN and FLCAS.

The analysis of the evaluation rubric that measured the level of risk-taking during the Wimba sessions in comparison with classroom discussions consisted of conducting descriptive statistics on the number of words, sentences, complex sentences, simple sentences, and errors in each contribution. Independent samples $t$-tests were conducted on these variables to determine significant differences between environments. Finally, numeric values indicated teacher and student contributions, contributions in English, questions, and amount of negotiation of meaning.

With regard to the qualitative data for this research, the analysis was carried out in a series of steps. First, the interviews were tape-recorded and transcribed by the researcher, and field notes were taken during interview sessions. The field notes included the participants' answers, as well as the researcher's observations regarding participant behaviors during the interviews. 
The second step involved organizing the data into workable units by looking for themes and categories in the transcripts. A preliminary list of categories was created which was guided by the research questions and the other variables of this study that were addressed by the interview data. Whenever new themes emerged, they were added to the list of categories. In order to increase the accuracy of the coding system, one of the interviews was coded by an expert in qualitative research. A meeting was held between the researcher and the expert in order to reach final consensus about the list of categories for the coding of the qualitative data (see Appendix M for final list of categories). The data were color coded based on these themes and categories. At the same time, the researcher checked the data thoroughly for information that was discrepant with the categories. This was done in order to increase the reliability of the findings (McMillan, 2000).

Finally, the data were interpreted by looking for relationships or discrepancies between the categories or themes and the findings from the quantitative data. Both data gathering sources were checked against each other at this interpretation phase, as indicated by the concurrent triangulation strategy which guided the design of this research (Creswell, 2003). The findings were matched in search for either corroboration of the results, or disagreement between both kinds of data. Additionally, only interview data were used to account for other variables that may influence the findings of this research, as mentioned previously.

\section{Limitations of the Study}

The principal limitations of this study are:

1. Regarding the qualitative findings, generalizability is weak, this being a characteristic of the nature of qualitative research, whose purpose is to provide insights into a specific phenomenon by using methods that are unique to that study (McMillan, 2000). 
2. Since this study has focused on the use of the Wimba voice board, the results are limited to this specific technology. 


\section{Chapter 4: Results}

The purpose of this study was to investigate the influence of asynchronous computer voice conferencing on student anxiety when speaking in a foreign language. The technology chosen was the Wimba voice board. Data were collected to address the following research questions:

1. What is the learners' perception of their language anxiety when speaking in the asynchronous computer voice conferencing environment?

2. How empowered do the learners feel to take risks in the asynchronous computer voice conferencing environment?

3. How concerned are the learners about being evaluated by others when making oral mistakes in the foreign language in the asynchronous computer voice conferencing environment?

In order to fully answer these questions, data were also collected to describe the participants in depth, and to account for other variables that may influence or explain the results of the study. Both quantitative and qualitative research methods were used, in the form of questionnaires, interviews, and transcripts of student oral contributions. Results are presented following the chronological order in which the data were collected.

\section{Results by Data Collection Points}

\section{First Data Collection}

The first data collection of this study was conducted prior to the assignment of the Wimba activities to the students. At this point, the demographic survey, the FLCAS, and the CAIN were administered to both Spanish 204 sections. A total of 35 students (73\% of the potential 48) responded to the questionnaires. The results are as follows: 


\section{Demographic survey}

The participants' age ranged from 19 to 35 years old, with a group mean of 22 years old. Thirteen (37.1\%) of them were male, and $22(62.9 \%)$ were female. All students majored in areas related to the arts, sciences, business, and education, and none had Spanish as their major. One person had Spanish as a minor, and the majority (91.4\%) of the students took Spanish as a requirement for other majors. Finally, five participants took Spanish out of personal interest. All the participants had taken at least three previous Spanish courses. More specifically, 17.6\% had taken three previous Spanish courses, $11.8 \%$ had taken four courses, $29.4 \%$ had taken five courses, $11.8 \%$ had taken six courses, $20.6 \%$ had taken seven courses, and $8.8 \%$ had taken eight courses prior to Spanish 204. Of these, only $22.9 \%$ had taken the placement test offered by the Foreign Languages Department with the purpose of placing students who have had Spanish before at the appropriate course level. Finally, 91.4\% had taken Spanish 101 to 203 at West Virginia University.

Regarding their motivation, most participants (57.1\%) described it as medium, 31\% described it as high, and $11.4 \%$ described it as low. On the other hand, when asked about the amount of effort that they had put into the course, the majority (80\%) reported to have put the same effort into Spanish 204 as in other classes, $8.6 \%$ reported having put more effort than in other classes, and 11.4\% reported having put less effort into Spanish 204 than in other classes.

These results indicate that the participants of this study are representative of other Spanish 204 students at West Virginia University. According to the researcher's experience at the institution, they are comparable in terms of age, reason for taking the course, number of previous courses taken, motivation, and effort put into the course. 


\section{Computer anxiety: CAIN}

The CAIN measured the participants' level of computer anxiety. An independent samples $t$-test was conducted in order to determine if there was any significant difference between the two Spanish 204 sections that participated in the study. Since no statistically significant difference was found, the scores of the two sections were combined and treated as a single group. The mean computer anxiety index of the participants was computed and contrasted with the mean index for college students reported by Simonson et al. This was done in order to determine if the participants of the study were similar to other college students in terms of computer anxiety. The mean and standard deviation of the participants of this study, in contrast with those reported by Simonson et al., are presented in Table 3

\section{Table 3}

Descriptive Statistics of the CAIN for the Two Studies

\begin{tabular}{lcc}
\hline & Present Study & Simonson et al. \\
\hline$N$ & 35 & 545 \\
$M$ & 53.1 & 62.33 \\
$S D$ & 13.3 & 17.76 \\
\hline
\end{tabular}

Note. Possible range 26-156. A higher mean indicates a higher level of anxiety.

These results indicate that the level of computer anxiety of the participants of this study was lower than that reported by Simonson et al. for college students. This was considered as an indication that the participants of the present study had a relatively low level of computer anxiety. In view of this, it can be determined that computer anxiety was not a significant influencing factor in the student's language anxiety in the voice board. 


\section{Foreign language classroom anxiety: FLCAS}

The participants' level of language anxiety in the classroom was measured by the FLCAS. An independent samples $t$-test was conducted in order to determine if there was significant difference between the two Spanish 204 sections that participated in the study. Since statistically significant difference was not found, the scores for the two sections were combined and treated as a single group. The possible range of scores for the FLCAS was 18-90, with higher numbers indicating a higher level of anxiety. The mean score for the FLCAS was 53.3 $(S D=4.329)$, and the range was 20-89.

In order to determine the percentage of anxious and non anxious students, the participants were also grouped by levels of anxiety, according to their scores in the FLCAS. Students experiencing moderately high and low anxiety were identified by their scoring one standard deviation above and below the mean respectively. Students experiencing very high and low anxiety were identified by their scoring two standard deviations above and below the mean respectively. Figure 3 illustrates the distribution of the participants by levels of language anxiety. 
Figure 3

Distribution of Language Anxiety Levels

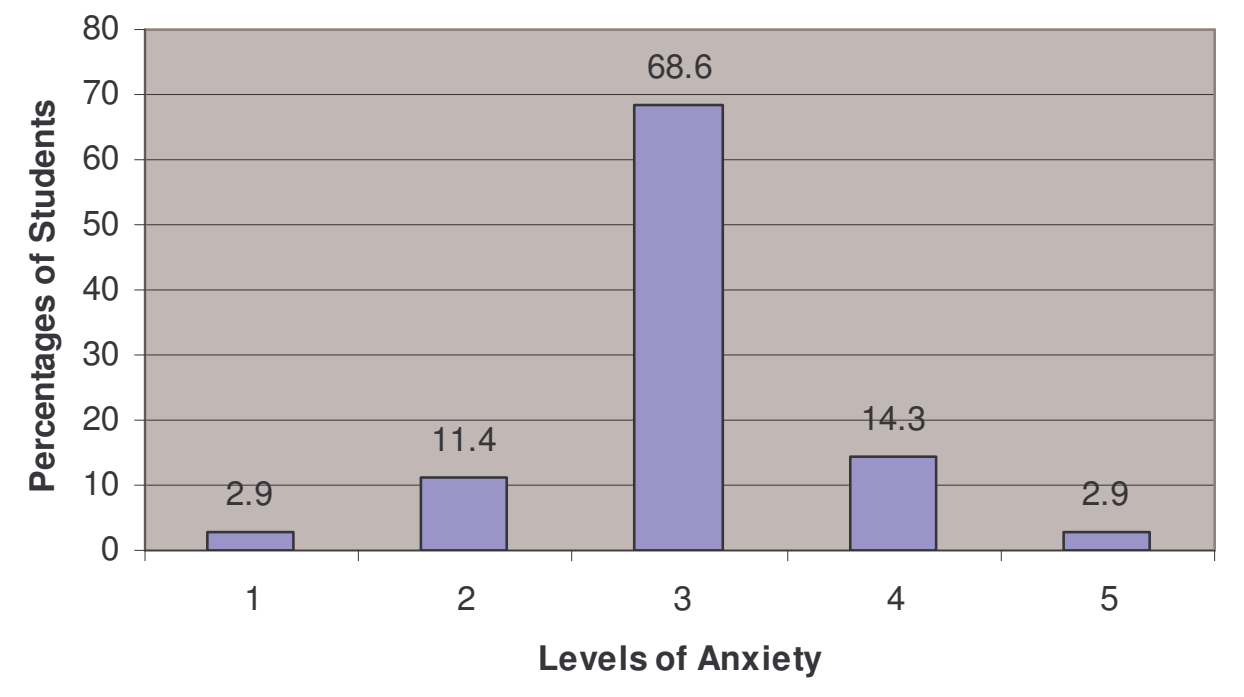

$$
\begin{aligned}
& 1=\text { very low anxiety }(2 S D \text { above the mean }) \\
& 2=\text { moderately low anxiety ( } 1 S D \text { above the mean) } \\
& 3=\text { average anxiety } \\
& 4=\text { moderately high anxiety }(1 S D \text { below the mean }) \\
& 5=\text { very high anxiety }(2 S D \text { below the mean) }
\end{aligned}
$$

The data presented in Figure 3 shows that there was a slightly greater percentage of moderately high classroom language anxiety than moderately low classroom language anxiety. Conversely, there were equal percentages of students with very high and very low levels of classroom language anxiety. As a result, the total percentage of students experiencing high levels of anxiety (17.2\%) was slightly lower than the percentage of those experiencing low levels of anxiety (14.3\%).

In order to determine which aspects of oral communication produced higher anxiety, means and percentages of agreement were computed for each item of the FLCAS. Table 4 shows the percentages of participants that selected each category of agreement. 
Table 4

FLCAS Items with Percentages of Selections for Each Alternative, and Means of Scores

\begin{tabular}{|c|c|c|c|c|c|c|c|}
\hline & Strongly Agree & Agree & $\begin{array}{l}\text { Neither Agree, } \\
\text { nor Disagree }\end{array}$ & Disagree & $\begin{array}{l}\text { Strongly } \\
\text { Disagree } \\
\end{array}$ & $M$ & $S D$ \\
\hline $1 *$ & \multicolumn{7}{|c|}{ I never feel quite sure of myself when I'm speaking in my foreign language class } \\
\hline & $26 \%$ & $51 \%$ & $0 \%$ & $20 \%$ & $2.9 \%$ & 3.77 & 1.140 \\
\hline $2 \dagger$ & \multicolumn{7}{|c|}{ I don’t worry about making mistakes in language class. } \\
\hline & $8.6 \%$ & $8.6 \%$ & $23 \%$ & $51.4 \%$ & $8.6 \%$ & 3.43 & 1.065 \\
\hline 3 & \multicolumn{7}{|c|}{ I tremble when I know I'm going to be called on in language class. } \\
\hline & $5.7 \%$ & $14.3 \%$ & $28.6 \%$ & $45.7 \%$ & $5.7 \%$ & 2.69 & .993 \\
\hline 4 & \multicolumn{7}{|c|}{ It frightens me when I don't understand what the teacher says in the foreign language. } \\
\hline & $8.6 \%$ & $28.6 \%$ & $22.9 \%$ & $34.3 \%$ & $5.7 \%$ & 3.00 & 1.111 \\
\hline $5 \dagger$ & \multicolumn{7}{|c|}{ I keep thinking that the other students are better at languages than I am. } \\
\hline & $14.3 \%$ & $40 \%$ & $8.6 \%$ & $34.3 \%$ & $2.9 \%$ & 3.29 & 1.178 \\
\hline 6 & \multicolumn{7}{|c|}{ I don't understand why people get so upset over foreign language classes. } \\
\hline & $5.7 \%$ & $25.7 \%$ & $31.4 \%$ & $34.3 \%$ & $2.9 \%$ & 3.03 & .985 \\
\hline 7 & \multicolumn{7}{|c|}{ In language class, I can get so nervous I forget things I know. } \\
\hline & $8.6 \%$ & $20 \%$ & $22.9 \%$ & $37.1 \%$ & $11.4 \%$ & 2.77 & 1.165 \\
\hline 8 & \multicolumn{7}{|c|}{ It embarrasses me to volunteer answers in my language class. } \\
\hline & $8.6 \%$ & $31.4 \%$ & $11.4 \%$ & $37.1 \%$ & $11.4 \%$ & 2.89 & 1.231 \\
\hline $9 \dagger$ & \multicolumn{7}{|c|}{ I would not be nervous speaking the foreign language with native speakers. } \\
\hline & $11.4 \%$ & $14.3 \%$ & $14.3 \%$ & $42.9 \%$ & $17.1 \%$ & 3.40 & 1.265 \\
\hline $10 \dagger$ & \multicolumn{7}{|c|}{ I feel confident when I speak in foreign language class. } \\
\hline & $2.9 \%$ & $20 \%$ & $28.6 \%$ & $40 \%$ & $8.6 \%$ & 3.31 & .993 \\
\hline 11 & \multicolumn{7}{|c|}{ I am afraid that my language teacher is ready to correct every mistake I make. } \\
\hline & $5.7 \%$ & $11.4 \%$ & $14.3 \%$ & $51.4 \%$ & $17.1 \%$ & 2.37 & 1.087 \\
\hline 12 & \multicolumn{7}{|c|}{ I can feel my heart pounding when I'm going to be called on in language class. } \\
\hline & $5.7 \%$ & $20 \%$ & $17.1 \%$ & $45.7 \%$ & $11.4 \%$ & 2.63 & 1.114 \\
\hline $13+$ & \multicolumn{7}{|c|}{ I always feel that the other students speak the foreign language better than I do. } \\
\hline & $8.6 \%$ & $40 \%$ & $17.1 \%$ & $28.6 \%$ & $5.7 \%$ & 3.17 & 1.124 \\
\hline 14 & \multicolumn{7}{|c|}{ I feel very self-conscious about speaking the foreign language in front of other students. } \\
\hline & $8.6 \%$ & $37.1 \%$ & $14.3 \%$ & $28.6 \%$ & $11.4 \%$ & 3.03 & 1.224 \\
\hline $15+$ & \multicolumn{7}{|c|}{ I feel more tense and nervous in my language class than in my other classes. } \\
\hline & $8.6 \%$ & $42.9 \%$ & $11.4 \%$ & $25.7 \%$ & $11.4 \%$ & 3.11 & 1.231 \\
\hline 16 & \multicolumn{7}{|c|}{ I get nervous and confused when I'm speaking in my language class. } \\
\hline & $5.7 \%$ & $31.4 \%$ & $14.3 \%$ & $42.9 \%$ & $5.7 \%$ & 2.89 & 1.105 \\
\hline 17 & \multicolumn{7}{|c|}{ I get nervous when I don't understand every word the language teacher says. } \\
\hline & $5.7 \%$ & $17.1 \%$ & $25.7 \%$ & $48.6 \%$ & $2.9 \%$ & 2.74 & .980 \\
\hline 18 & \multicolumn{7}{|c|}{ I'm afraid that the other students will laugh at me when I speak the foreign language. } \\
\hline & $2.9 \%$ & $14.3 \%$ & $8.3 \%$ & $51.4 \%$ & $22.9 \%$ & 2.23 & 1.060 \\
\hline
\end{tabular}

Note. ${ }^{*}$ Item with highest anxiety. $\dagger$ Item with high anxiety.

The findings shown in Table 4 reveal that the majority of the students showed high levels

of anxiety in items relating to speaking Spanish in the classroom (items 1 and 10). Other items

that yielded high scores refer to anxiety about making mistakes, anxiety about speaking to native 
speakers of the language, and thinking that the other students are better at languages (items 2, 5, 9 and 13 respectively). An additional aspect of language anxiety that was indicated by a relatively large number of students refers to being more anxious in language class than in other classes (item 15).

Second Data Collection: Evaluation Rubric

The students' contributions to selected discussions that took place in the classroom and computer environments were analyzed by the use of an evaluation rubric (see Appendix K). The rubric measured the amount of risk-taking in the linguistic output produced during selected discussions in the classroom and asynchronous computer environments for the two sections that took part in this study. An independent samples $t$-test was conducted to determine if there was significant difference between both sections. Since no significant difference was found, both sections were treated as a single group. Independent samples $t$-tests were also conducted to see if there were significant differences between the Wimba and classroom environments regarding the number of words, sentences, simple and complex sentences, and errors uttered in student contributions. The results for both environments are presented in Tables 5 and 6. 
Table 5

Evaluation of Classroom and Wimba Discussions

\begin{tabular}{|c|c|c|}
\hline & Classroom & Wimba \\
\hline Student contributions & 176 & 66 \\
\hline Instructor contributions & 249 & 2 \\
\hline $\begin{array}{l}\text { Number of contributions in } \\
\text { English }\end{array}$ & 23 & 0 \\
\hline Questions in the discussion & 7 & 0 \\
\hline $\begin{array}{l}\text { Requests for clarification by } \\
\text { students }\end{array}$ & 2 & 0 \\
\hline $\begin{array}{l}\text { Occasions in which feedback } \\
\text { was given to other students }\end{array}$ & 14 & 26 \\
\hline $\begin{array}{l}\text { Elaborations and expansions of } \\
\text { previous contributions }\end{array}$ & 27 & 5 \\
\hline
\end{tabular}

Table 6

Evaluation of Student Contributions

\begin{tabular}{llccc}
\hline & & & & \\
& Environment & $N$ & $M$ & $S D$ \\
\hline \multirow{3}{*}{ Words per contribution } & & & & \\
& Classroom & 176 & 3.9 & 4.852 \\
& Wimba & 66 & 29 & 15.33 \\
\hline Sentences per contribution & Classroom & 176 & .39 & .564 \\
& Wimba & 66 & 2.38 & 1.298 \\
\hline Simple sentences per contribution & Classroom & 176 & .09 & .288 \\
& Wimba & 66 & 1.24 & .860 \\
\hline Complex sentences per contribution & Classroom & 176 & .3 & .505 \\
& Wimba & 66 & 1.18 & 1.252 \\
\hline Errors per contribution & Classroom & 176 & .09 & .288 \\
& Wimba & 66 & .92 & 1.244 \\
& & & & \\
\hline
\end{tabular}


The results of the evaluation rubric shown in table 5 indicate that the instructor's contributions in classroom conversations were $58.6 \%$ of the total number of contributions. On the contrary, the instructor contributed to $2.9 \%$ of the discussions on the voice. In view of this, it can be concluded that the instructor played a much more central role in the classroom than on the voice board in both sections.

The findings of the evaluation of the amount of negotiation of meaning in both environments show a very small number of requests for clarification by students. In contrast, more feedback was given to other students during the discussions on the voice board than in the classroom. This can be attributed to the nature of the activities designed for the computer environment, which required the students to react to the opinions of their classmates, according to the suggestions of Pelletiery (2000). On the contrary, the data show that there were more elaborations and expansions of previous contributions by students in the classroom than in the computer environment. However, the elaborations and expansions that occurred in class were not spontaneous, but requested by the instructor, as opposed to those on the voice board, which occurred in spite of the design of the activities, which did not require them. In light of these findings, it becomes clear that regardless of the environment, most negotiation of meaning in the selected discussions occurred when requested by the instructor. Spontaneous negotiations of meaning were rare in the discussions of this study, and they were not environment-related.

With regard to the quantity and quality of the linguistic output in the foreign language, as shown in table 5 the students tended to turn to English in classroom conversations, a tendency that did not occur in the computer environment. Furthermore, since all $t$-values found by the independent samples $t$-tests are negative, the mean of the Wimba environment was in all cases significantly higher then in the classroom, therefore, the students produced significantly longer 
and more complex contributions in terms of words and sentences on Wimba. Specifically, an independent samples $t$-test on words showed significant differences between both environments: $t=-13.057(\mathrm{p}<.01)$. Additionally, an independent samples $t$-test on sentences showed significant differences between both environments: $t=-12.050(\mathrm{p}<.01)$. In light of these findings, it becomes clear that students produced more and longer sentences in Spanish in the asynchronous computer environment than in the classroom.

Concerning the complexity of the output, independent samples $t$-test on simple sentences showed significant differences between both environments: $t=-10.651(\mathrm{p}<.01)$. Additionally, independent samples t-test on complex sentences also showed significant differences between both environments: $t=-5.585(\mathrm{p}<.01)$. The students produced a significantly greater number of both simple and complex sentences in the asynchronous environment. The data also show that the average number of sentences uttered during classroom discussions was significantly smaller than one, indicating that there were a number of contributions in these conversations that did not constitute a full sentence. In effect, there was a large amount of one-word contributions in the classroom, as opposed to the voice board, where each posting included at least one full sentence. Finally, as shown in table 5, more questions were asked in the classroom than on the voice board by the students from both sections. These findings not only show a greater quantity, but also a greater complexity of output in the asynchronous voice computer conferencing environment. In terms of the accuracy of the output, the data indicate that the students made more errors in the asynchronous environment than during classroom discussions. Independent samples $t$-test on errors showed significant differences between the environments: $t=-5.387(\mathrm{p}<.01)$. This increased number of errors can be attributed to the greater accuracy and complexity of output in the voice board contributions. 


\section{Third Data Collection: The Wimba Anxiety Scale}

The third data collection point of the study was the administration of the Wimba Anxiety Scale to the participants, after the Wimba activities had taken place. The scale measured the students' level of language anxiety when speaking in the asynchronous computer voice conferencing environment. A total of 29 (60.4\% of the potential 48$)$ participants took the Wimba Anxiety Scale. After the content validity process, this scale was divided into two subscales, subscale 1 and subscale 2, each of which addressed research questions 1 and 3 respectively. An independent samples $t$-test was conducted in order to determine if there was significant difference between the means of the two Spanish 204 sections that participated in the study for each of the subscales. Since statistically significant difference was not found, the scores for the two sections were combined and treated as a single group.

Language anxiety in the asynchronous computer voice conferencing environment: Wimba Anxiety subscale1

The possible range of scores for subscale 1 was 8-40, with higher values indicating a higher level of anxiety. The mean score for this subscale was $19.07(S D=6.761)$, and the range was 8-36. Additionally, as was done with the FLCAS, the participants were grouped by levels of anxiety, according to their scores in subscale 1. Figure 4 illustrates the distribution of the participants by levels of language anxiety. 
Figure 4

Distribution of Language Anxiety Levels for Wimba Subscale 1

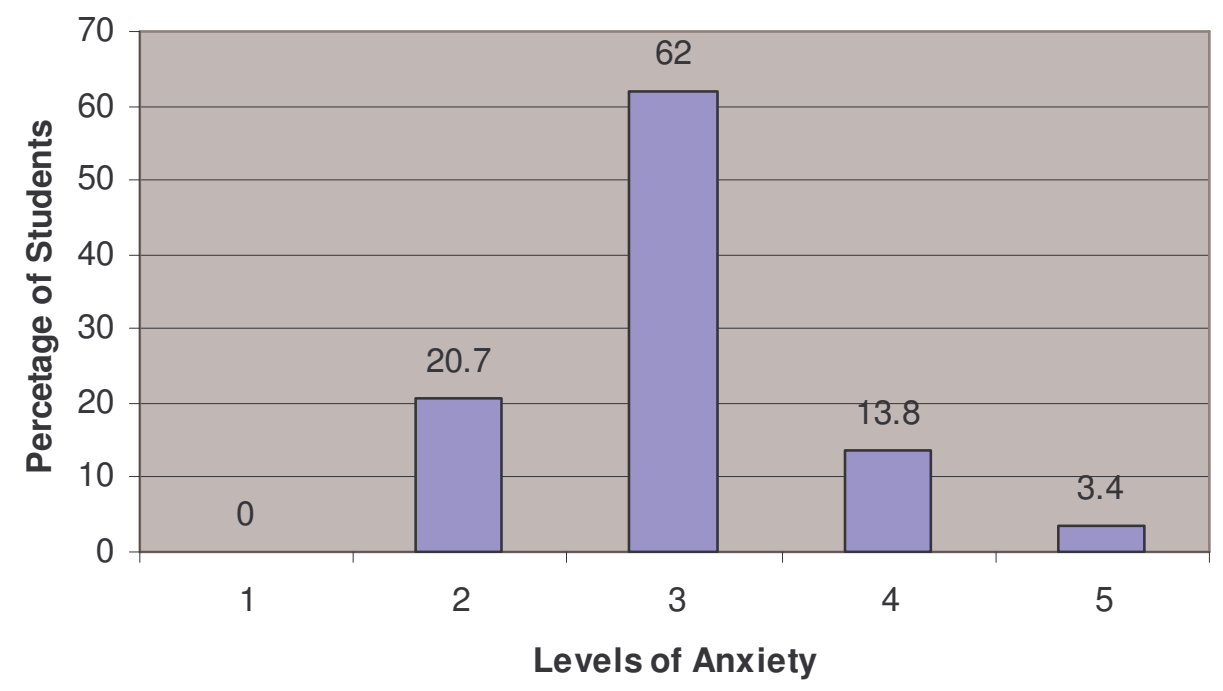

$$
\begin{aligned}
& 1=\text { very low anxiety ( } 2 S D \text { above the mean }) \\
& 2=\text { moderately low anxiety ( } 1 S D \text { above the mean) } \\
& 3=\text { average anxiety } \\
& 4=\text { moderately high anxiety ( } 1 S D \text { below the mean }) \\
& 5=\text { very high anxiety }(2 S D \text { below the mean })
\end{aligned}
$$

The data presented in figure 4 shows a greater percentage of moderately low versus moderately high anxiety in the asynchronous computer voice conferencing environment. On the other hand, there was a low percentage of very high anxiety when speaking in the asynchronous computer voice conferencing environment and none of the participants fell in the very low anxiety category. We can also conclude that the total percentage of students experiencing low levels of anxiety (20.7\%) was only slightly higher than the percentage of those experiencing high levels of anxiety (17.2\%).

In order to determine which aspects of oral communication produced higher anxiety in the asynchronous computer conferencing environment, means and percentages of agreement 
were computed for each item of subscale 1 . Table 7 shows the percentages of participants that selected each category of agreement.

Table 7

Wimba Subscale 1 Items with Percentages of Students Selections for Each Alternative, and Means of Scores

\begin{tabular}{|c|c|c|c|c|c|c|c|}
\hline & $\begin{array}{l}\text { Strongly } \\
\text { Agree }\end{array}$ & Agree & $\begin{array}{l}\text { Neither Agree, } \\
\text { nor Disagree }\end{array}$ & Disagree & $\begin{array}{l}\text { Strongly } \\
\text { Disagree } \\
\end{array}$ & $M$ & SD \\
\hline 1 & \multicolumn{7}{|c|}{ I never feel quite sure of myself when I'm speaking Spanish in the Wimba voice board. } \\
\hline & 10.3 & 17.2 & 24.1 & 27.6 & 20.7 & 2.69 & 1.285 \\
\hline $3 \dagger$ & \multicolumn{7}{|c|}{ I tremble when I know I have to speak Spanish in the Wimba voice board. } \\
\hline & 3.4 & 3.4 & 17.2 & 34.5 & 41.4 & 1.93 & 1.033 \\
\hline 4 & \multicolumn{7}{|c|}{ It frightens me when I don't understand what the teacher says in Spanish in the Wimba voice board. } \\
\hline & 3.4 & 24.1 & 17.2 & 24.1 & 31 & 2.45 & 1.27 \\
\hline 7 & \multicolumn{7}{|c|}{ It embarrasses me to answer in Spanish to other students' comments in the Wimba voice board. } \\
\hline & 0 & 20.7 & 17.2 & 31 & 31 & 2.28 & 1.131 \\
\hline $8^{*}$ & \multicolumn{7}{|c|}{ I would not be nervous speaking Spanish with native speakers in the Wimba voice board. } \\
\hline & 6.9 & 17.2 & 20.7 & 37.9 & 17.2 & 3.41 & 1.181 \\
\hline $11 \dagger$ & \multicolumn{7}{|c|}{ I can feel my heart pounding when I'm going to speak Spanish in the Wimba voice board. } \\
\hline & 0 & 3.4 & 6.9 & 44.8 & 44.8 & 1.69 & .761 \\
\hline 15 & \multicolumn{7}{|c|}{ I get nervous and confused when I'm speaking Spanish in the Wimba voice board. } \\
\hline & 0 & 10.3 & 31 & 20.7 & 37.9 & 2.14 & 1.060 \\
\hline 16 & \multicolumn{7}{|c|}{$\begin{array}{l}\text { I get nervous when I don't understand every word the language teacher says in Spanish in the Wimba } \\
\text { voice board. }\end{array}$} \\
\hline & 0 & 24.1 & 24.1 & 27.6 & 24.1 & 2.48 & 1.122 \\
\hline
\end{tabular}

Note. ${ }^{*}$ Item with highest anxiety. $\dagger$ Items with low anxiety.

As shown in Table 7, the majority of the students indicated a high level of anxiety in the item that refers to speaking to native speakers of the language in the computer environment (item 8). On the contrary, items that refer to physical manifestations of anxiety (items 3 and 11) had the lowest percentages of agreement, indicating low levels of anxiety. Finally, given that the means of scores for the great majority of the items of subscale 1 are lower than 3 , which constitutes the mid-point of possible scores for each item, it can be concluded that the participants did not experience high levels of anxiety about most aspects of speaking in the foreign language referred to by the items of this subscale. 
Anxiety about negative evaluation in the asynchronous computer voice conferencing environment: Wimba Anxiety subscale 2

The possible range of scores for subscale 2 was 9-45, with higher values indicating a higher level of anxiety. The mean score for this subscale was $23.07(S D=6.204)$, and the range was 14-36. The participants were grouped by levels of anxiety, according to these values and their scores in subscale 2. Figure 5 illustrates the distribution of the participants by levels of language anxiety.

Figure 5

Distribution of Language Anxiety Levels for Subscale 2

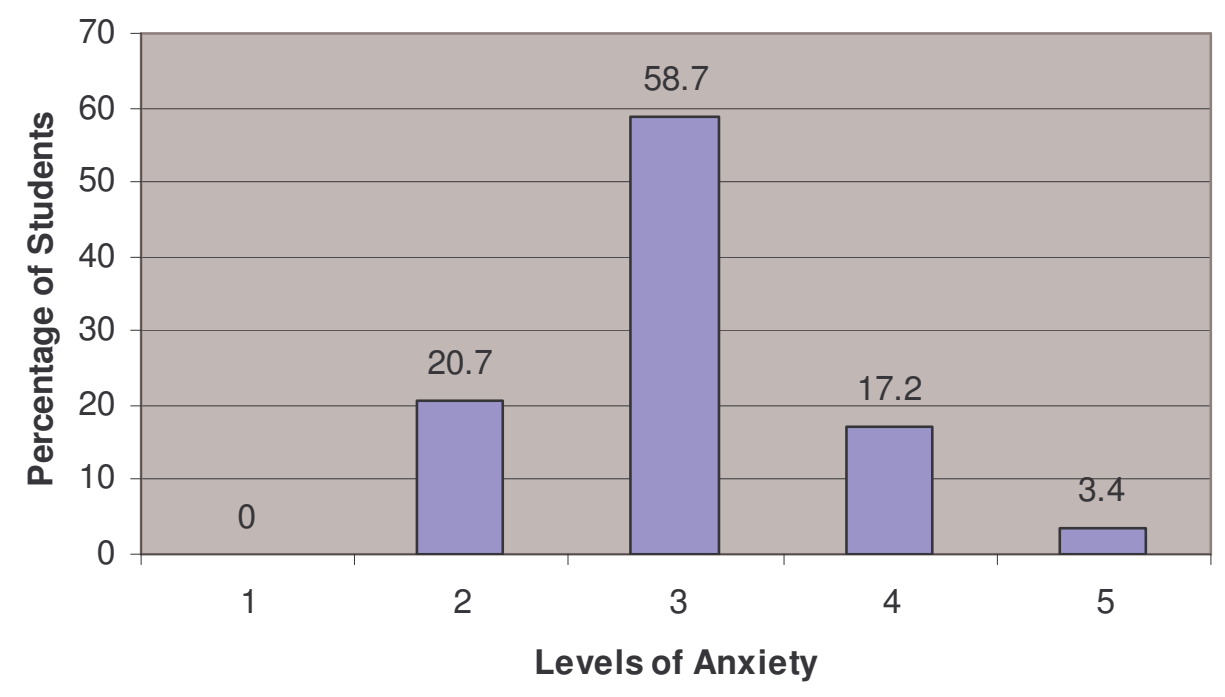

$$
\begin{aligned}
& 1=\text { very low anxiety ( } 2 S D \text { above the mean }) \\
& 2=\text { moderately low anxiety }(1 S D \text { above the mean }) \\
& 3=\text { average anxiety } \\
& 4=\text { moderately high anxiety }(1 S D \text { below the mean }) \\
& 5=\text { very high anxiety }(2 S D \text { below the mean })
\end{aligned}
$$

Figure 5 shows a slightly higher percentage of moderately low anxiety about negative evaluation in the asynchronous computer voice conferencing environment than that of moderately high anxiety. On the other hand, there was a low percentage of very high anxiety, 
and none of the participants fell in the very low anxiety category. It can also be concluded that the total percentages of students experiencing high (20.6\%) and low levels of anxiety $(20.7 \%)$ about negative evaluation in the asynchronous computer environment are virtually equal.

The aspects of negative evaluation that produced higher levels of anxiety in the asynchronous computer conferencing environment were determined by computing the means and percentages of agreement for each item of subscale 2. Table 8 shows the means of scores and percentages of participants that selected each category of agreement.

Table 8

Subscale 2 Items with Percentages of Students Selections for Each Alternative, and Means of Scores

\begin{tabular}{|c|c|c|c|c|c|c|c|}
\hline & $\begin{array}{l}\text { Strongly } \\
\text { Agree }\end{array}$ & Agree & $\begin{array}{l}\text { Neither Agree, } \\
\text { nor Disagree }\end{array}$ & Disagree & $\begin{array}{l}\text { Strongly } \\
\text { Disagree }\end{array}$ & $M$ & $S D$ \\
\hline $2^{*}$ & \multicolumn{7}{|c|}{ I don't worry about making mistakes in Spanish in the Wimba voice board. } \\
\hline & 0 & 31 & 13.8 & 41.4 & 13.8 & 3.38 & 1.083 \\
\hline 5 & \multicolumn{7}{|c|}{$\begin{array}{l}\text { I keep thinking that the other students are better at Spanish than I am when I listen to their } \\
\text { postings. }\end{array}$} \\
\hline & 0 & 24.5 & 17.2 & 24.1 & 24.1 & 2.62 & 1.208 \\
\hline 6 & \multicolumn{7}{|c|}{ In the Wimba voice board, I can get so nervous I forget things I know about Spanish. } \\
\hline & 0 & 13.8 & 17.2 & 34.5 & 34.5 & 2.10 & 1.047 \\
\hline 9 & \multicolumn{7}{|c|}{ I feel confident when I speak Spanish in the Wimba voice board. } \\
\hline & 13.8 & 34.5 & 24.1 & 27.6 & 0 & 2.66 & 1.045 \\
\hline $10 \dagger$ & \multicolumn{7}{|c|}{$\begin{array}{l}\text { I am afraid that my Spanish teacher will correct every mistake I make in the Wimba voice } \\
\text { board. }\end{array}$} \\
\hline & 0 & 0 & 17.2 & 48.3 & 34.5 & 1.83 & .711 \\
\hline 12 & \multicolumn{7}{|c|}{$\begin{array}{l}\text { I always feel that the other students speak Spanish better than I do when I listen to their } \\
\text { postings. }\end{array}$} \\
\hline & 0 & 34.5 & 13.8 & 24.1 & 27.6 & 2.55 & 1.242 \\
\hline 13 & \multicolumn{7}{|c|}{$\begin{array}{l}\text { I don't feel very self-conscious about speaking Spanish in the Wimba voice board because } \\
\text { the teacher is not present. }\end{array}$} \\
\hline & 0 & 37.9 & 24.1 & 34.5 & 3.4 & 3.03 & .944 \\
\hline 14 & \multicolumn{7}{|c|}{$\begin{array}{l}\text { I don't feel very self-conscious about speaking Spanish in the Wimba voice board because } \\
\text { other students are not present. }\end{array}$} \\
\hline & 3.4 & 44.8 & 24.1 & 27.6 & 0 & 2.76 & .912 \\
\hline 17 & \multicolumn{7}{|c|}{ I'm afraid that the other students will laugh at me when they listen to my postings. } \\
\hline & 3.4 & 13.8 & 17.2 & 24.1 & 41.4 & 2.14 & 1.217 \\
\hline
\end{tabular}

Note. *Item with highest anxiety. †Item with lowest anxiety. 
The results shown in Table 8 reveal that the majority of the students were worried about making mistakes in the asynchronous computer voice conferencing environment (item 2). However, the data indicate that the students were the least anxious about the possibility of the instructor correcting their mistakes (item 10). Finally, given that the means of scores for the great majority of the items of subscale 2 are lower than 3, which constitutes the mid-point of possible scores per item, it can be concluded that the participants did not experience high levels of anxiety about the aspects of fear to negative evaluation referred to by most items of this subscale.

\section{Correlational analyses}

A series of Pearson product moment byvariate correlational analyses were performed in order to answer the research questions. A total of four correlational analyses were conducted to investigate the relationship between each subscale of the Wimba Anxiety Scale and the CAIN on the one hand, and the FLCAS on the other.

The results indicated that there was not a statistically significant relationship between computer anxiety, measured by the CAIN, and any of the Wimba anxiety subscales. Similarly, there was not a statistically significant relationship between classroom language anxiety, measured by the FLCAS, and anxiety caused by fear of negative evaluation, measured by subscale 2 of the Wimba Anxiety Scale. In contrast, classroom language anxiety was found to be positively correlated with anxiety about speaking the language on the voice board, measured by the Wimba subscale 1. According to this, anxiety on Wimba increased as classroom anxiety increased. Therefore, from a quantitative perspective, the environment did not make a difference in terms of language anxiety.

$(r=.626, p<.01)$. Table 9 shows the results of the Pearson product moment bivariate correlational analyses. 
Table 9

Correlations of the CAIN and FLCAS with the Wimba Anxiety Subscales

Wimba Anxiety Subscale 1 Wimba Anxiety Subscale 2

\begin{tabular}{lll} 
CAIN & .223 & .278 \\
FLCAS & $.626^{* *}$ & .376 \\
\hline
\end{tabular}

Note. ** Correlation is significant at the 0.01 level (2-tailed)

\section{Summary of Quantitative Findings}

Overall, the participants of this investigation felt relatively low levels of computer anxiety, compared to other college students, as published by Simonson et al. The findings also revealed that there was not a statistically significant correlation between the computer anxiety and the anxiety experienced in the asynchronous computer voice conferencing environment. In the same way, there was not a statistically significant relationship between fear of negative evaluation and computer anxiety. It was therefore concluded that computer anxiety did not constitute an influencing factor in the students' level of anxiety when speaking in the computer environment.

Concerning language anxiety in the classroom, there was only a slightly higher percentage of participants that reported feeling high levels of anxiety than those who reported feeling low levels of anxiety. The majority of those who felt anxious were concerned about the general act of speaking Spanish in the classroom, speaking to native speakers of the language, and thinking that the other students in the class were better at the language than they were. For that reason, the majority reported feeling more anxious in their language class than in other classes. Since most participants showed an average level of anxiety, with similar percentages for 
high and low anxiety, it can be concluded that the participants of this study showed a normal distribution of anxiety levels. It can also be concluded that despite the normal distribution of anxiety levels, the scores for the specific items indicate that there was in fact a certain amount of language anxiety among the participants of this study regarding some aspects of oral communication in the classroom environment.

When it comes to speaking in the asynchronous computer voice conferencing environment, similar percentages of high and low anxiety were found. Overall, the participants did not show a high level of anxiety about most items of the Wimba subscale 1 . The majority of the participants were still concerned about speaking to native speakers of the language, and the lowest levels of anxiety were related to the physical manifestations of anxiety, such as trembling or strong heart pounding. Finally, a statistically significant relationship was found between language anxiety in the classroom, and the anxiety experienced about speaking in the asynchronous computer conferencing environment. This indicates that, as far as quantitative data is concerned, the levels of language anxiety felt by students on the voice board was very similar to those felt in the classroom. Anxiety for speaking occurred regardless of the environment, according to the quantitative data of this study.

Regarding the amount of risk-taking shown in the students contributions, the discussions that took place in the asynchronous computer voice conferencing environment were found to be more student-centered, with a smaller amount of teacher interventions. Similarly, the quantity of the output produced by students was significantly larger in the asynchronous computer voice conferencing environment with a significantly greater number of words and sentences per contribution. In addition, the significantly greater numbers of both simple and complex sentences together with the fact that all contributions constituted a sentence in the voice board are 
indicators of a greater complexity of output in this environment. Regarding accuracy, significantly more mistakes were made in the asynchronous computer voice conferencing environment, the reason being the greater quantity and complexity of the output. Finally, as regards the negotiation of meaning, the findings suggest that regardless of the environment, most negotiation was prompted by the instructor. Spontaneous negotiations of meaning were rare and not environment-related. In conclusion, the quantitative findings reveal that the asynchronous computer voice conferencing environment fostered risk-taking in the target language in terms of a more student-centered interaction, with longer and more grammatically complex student contributions.

Virtually equal percentages of high and low levels of anxiety were found regarding fear of the participants to negative evaluation by their instructor or peers. Overall, the participants did not show a high level of anxiety about most items of the Wimba subscale 2. Making mistakes in the asynchronous computer voice conferencing environment was the aspect that caused higher levels of anxiety. Interestingly, the aspect that produced lowest levels of anxiety was the possibility of the instructor correcting the mistakes that the students made in the computer environment. Finally, there was not a statistically significant correlation between the language anxiety experienced in the classroom and that caused by concern of negative evaluation in the computer environment. In light of this, it can be concluded that the participants were not anxious about negative evaluation from their instructor or peers in the computer environment. Although there was a concern for correctness among the students in this environment, this concern was not based on fear of negative evaluation, since the participants were the least worried about the instructor's corrections. Finally, since a relationship was not found between language anxiety in the classroom and fear of negative evaluation by the instructor or peers in the computer 
environment, it can be concluded that the environment did make a difference when it comes to this kind of anxiety.

\section{Results of the Interviews}

\section{Description of Participants Interviewed}

Four of the students, two from each section taught by the researcher, were selected to participate in the interviews that constitute the qualitative data of this study. Purposeful sampling procedures were used for the selection of these four participants. In particular, the qualitative sampling strategy that was employed in this study was criterion sampling. The selection criterion was the participants` involvement in both Wimba and face-to-face discussions. Only students who fully participated in the discussions taking place in both environments were selected for the interviews. In addition, the participants were selected based on either a personal communication to the researcher expressing high levels of anxiety, or the researcher's observation of their behavior during class discussions. Their names were changed to other names of their choice, in order to protect their anonymity. These four students were very different from one another, and they constitute a representative subsample of the two sections used for this study:

1. Anita: She was 19 years old and was taking Spanish as a requirement for her major. She described her motivation for the course as high, and said to have put the same effort into Spanish 204 as the rest of her classes. She had taken seven Spanish courses prior to Spanish 204, and she had taken the placement test, after which she placed at Spanish 203. Her CAIN index indicated that she had a low level of computer anxiety. Her language anxiety, showed by her score in the FLCAS, was moderately high, although, prior to the interview, she reported to the researcher that the reason why she did not volunteer in class 
was a very high level of anxiety. On the contrary, her score on the Wimba Anxiety Scale was moderately low.

2. Robert: He was 20 years old and was taking Spanish as a requirement for his major. He described his motivation as low, and said to have put less effort in Spanish 204 than into other classes. He had taken five courses prior to Spanish 204, and he had not taken the placement test. His CAIN index indicated that he had a high level of computer anxiety. His language anxiety, showed by his score in the FLCAS, was average. He was selected because of his apparent reluctance to volunteer during oral discussions in class, which was probably due to his low level of motivation. Finally, his anxiety on Wimba, as indicated by his score in the Wimba Anxiety Scale, was moderately high.

3. Marly: She was 23 years old and was taking Spanish as a requirement for her major. She described her motivation for the course as low, and said to put the same effort into Spanish 204 as the rest of her classes. Her CAIN index indicated that she had a low level of computer anxiety. Her language anxiety, showed by her score in the FLCAS, was average. However, prior to the study, she had verbally reported to the researcher about being nervous during oral discussions in class. Finally, her level of anxiety on Wimba, as indicated by her score on the Wimba Anxiety Scale, was also average.

4. Jane: She was 23 years old and was taking Spanish as a requirement for her major. She described her motivation for the course as medium, and said to have put the same effort into Spanish 204 as the rest of her classes. Although she had taken five Spanish courses prior to Spanish 204, she had not taken the placement test. Her CAIN index indicated that she had a low level of computer anxiety, and her score in the FLCAS indicated that her language anxiety was average. In spite of this data, she was selected because of her 
apparent reluctance to volunteer during oral discussions in class. Finally, her level of anxiety on Wimba, as indicated by her score on the Wimba Anxiety Scale, was also average.

Computer Anxiety and Classroom Language Anxiety

The results of the interviews regarding computer anxiety and classroom language anxiety are summarized in Table 10. 
Table 10

Summary of Interview Data about Computer Anxiety and Classroom Language Anxiety

\begin{tabular}{|c|c|c|c|c|}
\hline Theme & Anita & Robert & Jane & Marly \\
\hline $\begin{array}{l}\text { Computer } \\
\text { Anxiety }\end{array}$ & Not reported. & $\begin{array}{l}\text { High. "I hate } \\
\text { computers. [...] } \\
\text { Technology and I } \\
\text { don't get along } \\
\text { very well so..." }\end{array}$ & $\begin{array}{l}\text { Low. "Most people } \\
\text { in college should } \\
\text { know how to use a } \\
\text { computer by now, } \\
\text { so it shouldn't be a } \\
\text { problem." }\end{array}$ & $\begin{array}{l}\text { Low. "Students } \\
\text { should feel fine } \\
\text { too, because I } \\
\text { think most college } \\
\text { students have to } \\
\text { use a computer..." }\end{array}$ \\
\hline $\begin{array}{l}\text { Perception of } \\
\text { language anxiety. }\end{array}$ & $\begin{array}{l}\text { High. "Not } \\
\text { because I don't } \\
\text { know what to say } \\
\text { [...] but I feel very } \\
\text { anxious." "On a } \\
\text { scale of } 1 \text { to } 10 \text {, in } \\
\text { class, it's about a } \\
9,8 \text { or } 9 . "\end{array}$ & $\begin{array}{l}\text { Low: "I feel pretty } \\
\text { confident..., ahh, } \\
\text { oh, as long as } \\
\text { everybody is about } \\
\text { the same level as } \\
\text { me." }\end{array}$ & $\begin{array}{l}\text { High: "It makes } \\
\text { me nervous } \\
\text { because I'm not } \\
\text { that good at } \\
\text { Spanish." }\end{array}$ & $\begin{array}{l}\text { Medium: "I'm not } \\
\text { necessarily shy, } \\
\text { I'm not a shy } \\
\text { person, but, ahh, I } \\
\text { just think... I don't } \\
\text { know a lot." }\end{array}$ \\
\hline $\begin{array}{l}\text { Attitude towards } \\
\text { being called on. }\end{array}$ & $\begin{array}{l}\text { Worried about the } \\
\text { number of people } \\
\text { listening. }\end{array}$ & Not worried. & $\begin{array}{l}\text { Worried about the } \\
\text { pressure of having } \\
\text { to come up with an } \\
\text { answer fast. }\end{array}$ & $\begin{array}{l}\text { Worried about the } \\
\text { pressure of having } \\
\text { to come up with an } \\
\text { answer fast. No } \\
\text { time to think. }\end{array}$ \\
\hline Volunteering. & $\begin{array}{l}\text { Not anxious when } \\
\text { volunteering. }\end{array}$ & $\begin{array}{l}\text { Does not volunteer } \\
\text { often. }\end{array}$ & $\begin{array}{l}\text { Only if she knows } \\
\text { that she is correct. }\end{array}$ & $\begin{array}{l}\text { Does not } \\
\text { volunteer, unless } \\
\text { she has to. }\end{array}$ \\
\hline $\begin{array}{l}\text { Presence of peers } \\
\text { and instructor }\end{array}$ & $\begin{array}{l}\text { Concerned about } \\
\text { everybody } \\
\text { listening. Not } \\
\text { concerned about } \\
\text { the instructor. } \\
\text { Worried about } \\
\text { making a mistake, } \\
\text { or not giving a } \\
\text { complete enough } \\
\text { answer. }\end{array}$ & $\begin{array}{l}\text { "It actually kind of } \\
\text { helps me because } \\
\text { everybody else is } \\
\text { at the same level as } \\
\text { me." The } \\
\text { instructor is a } \\
\text { higher level, but } \\
\text { "you talk down to } \\
\text { our level." }\end{array}$ & $\begin{array}{l}\text { Not a problem, it } \\
\text { was a nice group } \\
\text { of people: } \\
\text { "They're very nice } \\
\text { and they don't } \\
\text { make fun of you or } \\
\text { anything." The } \\
\text { instructor and } \\
\text { peers can help. } \\
\text { Worried about } \\
\text { mistakes: "I want } \\
\text { to say everything } \\
\text { correctly." }\end{array}$ & $\begin{array}{l}\text { Not worried about } \\
\text { criticism. Worried } \\
\text { about being in } \\
\text { front of a teacher } \\
\text { that is a native } \\
\text { speaker: Feels that } \\
\text { the standard is } \\
\text { higher: "It's not } \\
\text { like you require us, } \\
\text { but it's, it feels like } \\
\text { we have a higher } \\
\text { standard." }\end{array}$ \\
\hline
\end{tabular}

The findings shown in Table 10 reveal that two of the three participants that were asked about computer anxiety described it as low, and referred to the extensive use of computers in today's higher education as the cause. In the case of language anxiety, three of the four 
participants interviewed had experienced a medium or high level. The main cause of anxiety as revealed by the interviews is the participants' lack of confidence in their overall skills in Spanish. Even when the anxiety was described as low, as in the case of Robert, he expressed a concern about his level of Spanish compared with that of other students in the class.

An additional source of anxiety when speaking in the foreign language in the classroom was the prospect of being called on by the instructor, expressed by three of the four students interviewed. The causes of this anxiety reported by the participants were the number of people listening, and the pressure of having limited class time, which forces the students to produce answers fast. This anxiety towards being called on disappears in the case of Anita when she volunteers. This can be due to the fact that students, as in the case of Jane, only volunteer in the classroom when they know that they are correct.

The presence of the instructor was not a source of anxiety for three of the four participants. However, the fact that the instructor was a native speaker of the language was seen by Marly as a source of anxiety, since she felt that the standard was higher when speaking to a native speaker. Regarding the presence of their peers, three of the four students reported not experiencing anxiety for this aspect of the classroom environment. The main explanation being that the peers can actually help, as long as "they are a nice group of people", or they are all at the same level. However, in the case of Anita, the presence of the peers was a significant source of anxiety, since she felt that everybody was listening to her when speaking in the foreign language. A final point revealed by the interviews is that two of the participants were concerned about making mistakes, or not giving satisfactory enough answers, when speaking in the classroom. 
Anxiety in the Asynchronous Computer Voice Conferencing Environment

Anxiety towards speaking

All four participants described their level of anxiety when speaking in the asynchronous computer voice conferencing environment as low. Three of the four participants shared that their level of anxiety was lower than that of the classroom. As Anita described:

In... On a scale of one to ten, in class, it's about a nine, eight or nine, but on Wimba, it's four at the most.

The main reason for this decrease in the level of anxiety mentioned by three of the four participants was that the asynchronous environment freed them from the time pressure of the classroom. As Marly said:

Yeah, that's... that's different because it's in front of the whole class and then you, you're you know, you don't have time for me, sitting there, like, taking five, six minutes to answer a question. Wimba... you can take as long as you need... to design your sentence that you're gonna say, and listen to as many people as you want, over and over again. I mean, you have all the time in the world, but when you are in a class setting, you've got fifty minutes with all those other students, and then you're called on, you really don't know what to say.

The asynchronous nature of the voice board, coupled with the possibility to replay people's contributions and edit their own was a key factor in the reduction of anxiety that the participants reported to have experienced in this environment. Additionally, there were a series of consequences linked to the asynchronous nature of the computer voice conferencing environment. Two of the four students said that they wrote their answers down first, and then read them out loud on the voice board. As Anita said: 
But on Wimba, like the way I do it, I listen to what you say and what I'm supposed to respond to, and write out a response.

Sometimes contributing to the conversations on the voice board became a group effort:

I always brought someone else there. That's why I'd rather bring, you know, cause you can help, students can help each other out.

Clearly, the students were taking an approach to the completion of the Wimba activities that very much resembles that of other homework assignments. Writing answers down and collaborating with classmates and friends are common practices in the homework assigned in foreign language classes.

An additional aspect of oral communication in the asynchronous computer voice conferencing environment that emerged in the interviews was the importance of the physical setting surrounding the technology. The characteristics of this physical setting were found to be a determining factor in the students' anxiety about speaking in the computer environment. Some participants were concerned, even anxious, about the physical setting where the communication took place. Anita said:

I like it better when I'm in the lab; I've only gone in in the lab once. Other times, I've been in my room and I've had to get every one out because they don't speak Spanish and I feel kind of weird speaking Spanish in front of them into a microphone ahh mainly because they don't really know what I'm saying and I feel kind of bad doing that, and... but when I'm in the computer lab, it's either just me, or there is one other person who is in your class, and they know what I'm saying so... 
The laboratory setting was more conducive to the reduction of anxiety for this student because the room was empty at the time when she posted her contribution to the discussion. Clearly, the setting surrounding the technology constituted a source of anxiety for Anita. Moreover, the specific time of the day when the students chose to post their contributions at the lab made a difference in their level of anxiety. Jane described her experience talking in a crowded laboratory:

I remember trying to talk low like, I had the microphone right to my mouth and I was like talking like this because I didn't want everyone to hear it in case I messed up and I had to re... redo my reply... do that again. Ahh I didn’t want people to... hear my Spanish, honestly, so I was kind of leaning forward to the computer and doing the... speaking into the microphone really low.

In view of this, it can be concluded the properties of the asynchronous computer voice conferencing environment that are conducive to the reduction of anxiety can be eliminated by the circumstances surrounding the technology itself. These circumstances are added to the technology in order to create a whole new environment that may not be as beneficial to the reduction of anxiety as the technology alone would be. Consequently, the asynchronous environment would likely be conducive for the reduction of anxiety if the physical setting surrounding the technology were controlled.

Risk-taking

All four participants agreed to have taken more risks with the foreign language in the asynchronous computer voice conferencing environment. As Robert shared: 
I would be more likely to say something that I wasn't sure about on Wimba, as opposed to the classroom, probably. [...] I would be more likely to say something... difficult or... that I really wasn't sure if it was right... just like on a homework assignment, because... you are not in front of the class.

Two of the students referred mainly to the grammatical complexity of their contributions in the asynchronous environment. As Anita said:

Well... the positive part is that you could think about what you're saying before hand so that you can develop your larger sentence... more complex sentences and such, and you can get your message across better, as opposed to only using simple sentences, like you usually use in class when you are called on and you can't think of all the other stuff.

Undoubtedly, freedom from the time constrains of the classroom, coupled with the absence of the instructor and peers facilitated an increase in the amount of risk-taking in the asynchronous environment. The students were more daring when it came to saying something that they were not sure about, and they produced longer and more complex sentences in this environment.

\section{Anxiety towards negative evaluation}

Three of the four students that were interviewed agreed that the absence of the instructor and peers in the asynchronous computer voice conferencing environment helped to reduce anxiety. Marly said:

Yeah, I... I enjoyed being able to do that on your own time, and not worrying about others, what others are thinking, or you know, if you sound not that great 
for a Spanish four student or, yeah I, I like that you can go... and be by yourself or be with friends and you can feel much more comfortable.

In addition, the fact that both their instructor and their classmates would listen to them at some point did not make a difference in their anxiety, as expressed by Jane when asked about this possibility:

I didn't... I didn't even think about it, honestly, cause I was just like... it just... it didn't bother me and I wasn't worried because ahh there ... I don't know, I don't really have a reason. I just, it just didn't bother me as much as it would if I was in class and having to respond because I wrote it out and then I read it, I read it and tried to pronounce it the best I could and then... you know, that's better than I could do in class at times.

Clearly, the fact that the students were free from the time limits of the classroom and the opportunity of writing their answers contributed to a reduction of the fear of negative evaluation experienced in the asynchronous environment. By having more time to prepare their answers, the students gained a sense of security about the quality and accuracy of their output. This improvement in the output was also ensured by the possibility offered by the technology of editing and recording their contributions as many times as they needed. As Jane said:

When I made mistakes, I started laughing and just started it over, because ahh because I knew I could start over and, you know, make up another reply, so I just ahh I just kind of laughed and started. It didn't really bother me because I knew I could correct it, fix it, and start again. 
In effect, none of the students interviewed expressed a concern about making mistakes in the asynchronous computer voice conferencing environment; even if a mistake was found after they had already posted their contribution. As Robert said:

If I made a mistake, unless it was something serious, like the sentence didn't make sense, I generally just left it out there.

This lack of anxiety about making mistakes indicates a reduction in the fear of negative evaluation in the asynchronous computer voice conferencing environment. The possibility that the instructor and peers would eventually listen to their contributions, and to possible mistakes, did not make a difference in the students' anxiety about negative evaluation. Other Variables Addressed by the Interviews

The results of the interviews regarding the students' attitude towards the assignment, perceived value of the activity, and access to hardware and user-friendliness of the software are summarized in Table 11. 
Table 11

Summary of Interview Data about Other Variables that May Influence the Results

\begin{tabular}{|c|c|c|c|c|}
\hline Theme & Anita & Robert & Jane & Marly \\
\hline $\begin{array}{l}\text { Attitude } \\
\text { towards the } \\
\text { assignment }\end{array}$ & $\begin{array}{l}\text { Her first reaction } \\
\text { was "how am I } \\
\text { going to do this, I } \\
\text { don't have a } \\
\text { microphone." }\end{array}$ & $\begin{array}{l}\text { Good and bad: "It } \\
\text { wasn't as difficult } \\
\text { as I thought it } \\
\text { would be, I mean, } \\
\text { I still, it's kind of } \\
\text { a pain to do it, but } \\
\text { it's kind of nice to } \\
\text { hear other people } \\
\text { talking." }\end{array}$ & $\begin{array}{l}\text { Bad first reaction: "I } \\
\text { wasn't like excited } \\
\text { about it, because it's } \\
\text { just something else } \\
\text { that I had to do." } \\
\text { It improved after } \\
\text { doing the activities: "I } \\
\text { actually liked to do } \\
\text { it." }\end{array}$ & $\begin{array}{l}\text { Good: "I enjoyed } \\
\text { it, I mean; I } \\
\text { thought it was a } \\
\text { good assignment." }\end{array}$ \\
\hline $\begin{array}{l}\text { Perceived } \\
\text { value of the } \\
\text { activity }\end{array}$ & $\begin{array}{l}\text { Positive: } \\
\text { - You can see } \\
\text { oral progress. } \\
\text { - You can listen } \\
\text { to others and } \\
\text { evaluate each } \\
\text { other. You can } \\
\text { get help from } \\
\text { your peers. } \\
\text { Negative: } \\
\text { - Not } \\
\text { conversational. } \\
\text { You don't } \\
\text { develop the skill } \\
\text { of immediacy. } \\
\text { - Lack of non- } \\
\text { verbal cues. }\end{array}$ & $\begin{array}{l}\text { Positive: } \\
\text { - You learn to } \\
\text { understand } \\
\text { Spanish } \\
\text { without seeing } \\
\text { it written. } \\
\text { - More exposure } \\
\text { helps to } \\
\text { reinforce the } \\
\text { language. } \\
\text { Negative: } \\
\text { - Lack of non- } \\
\text { verbal cues. } \\
\text { - Wimba should } \\
\text { start to be used } \\
\text { earlier. }\end{array}$ & $\begin{array}{l}\text { Positive: } \\
\text { - } \quad \text { It helped to learn } \\
\text { vocabulary. } \\
\text { - } \\
\text { It helped to hear } \\
\text { others. }\end{array}$ & 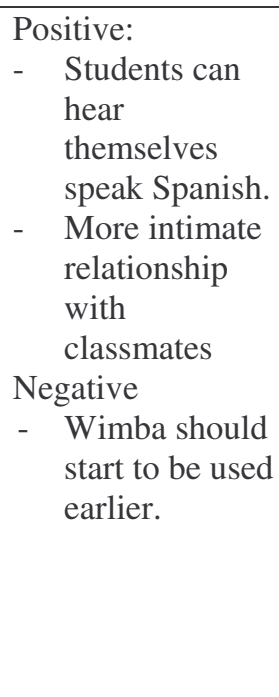 \\
\hline $\begin{array}{l}\text { Access to } \\
\text { hardware }\end{array}$ & $\begin{array}{l}\text { The laboratory: } \\
\text { "Going to Eiesland } \\
\text { was not a } \\
\text { problem." } \\
\text { Technical problems } \\
\text { at the language } \\
\text { laboratory: } \\
\text { "Occasionally, the } \\
\text { microphone would } \\
\text { be messed up." }\end{array}$ & $\begin{array}{l}\text { The laboratory: } \\
\text { "The worst thing } \\
\text { is having to go to } \\
\text { the computer lab. } \\
\text { [...] I don't think } \\
\text { it would be so bad } \\
\text { if the lab was } \\
\text { open all the time." }\end{array}$ & $\begin{array}{l}\text { The laboratory: "The } \\
\text { worst thing would be } \\
\text { the lab hours." "If the } \\
\text { computers were not so } \\
\text { close together, I'd be } \\
\text { better." } \\
\text { Technical problems: } \\
\text { "Sometimes, the } \\
\text { computers didn't' } \\
\text { work that well." }\end{array}$ & $\begin{array}{l}\text { The laboratory: } \\
\text { "The worst is } \\
\text { having probably to } \\
\text { go to the lab." } \\
\text { Technical } \\
\text { problems: "the } \\
\text { microphones } \\
\text { are...poor." }\end{array}$ \\
\hline $\begin{array}{l}\text { User- } \\
\text { friendliness of } \\
\text { the software }\end{array}$ & $\begin{array}{l}\text { Easy: "As long as } \\
\text { your Java is } \\
\text { enabled, it's very } \\
\text { easy.” }\end{array}$ & $\begin{array}{l}\text { Easy: "It's not } \\
\text { complicated at all. } \\
\text { [...] I don't see } \\
\text { anything wrong } \\
\text { with it." }\end{array}$ & $\begin{array}{l}\text { Easy: "It was actually } \\
\text { pretty easy like to } \\
\text { catch on." }\end{array}$ & $\begin{array}{l}\text { Easy: "I think the } \\
\text { structure of it was } \\
\text { pretty decent." } \\
\text { "That was pretty } \\
\text { self-explanatory." }\end{array}$ \\
\hline
\end{tabular}


Based on the data displayed in Table 11, it can be concluded that most students had a generally good attitude towards the assignment. However, some did not have a positive initial reaction to the activity because it can be an extra burden to the work that they already have to do, or because of the difficult of access to microphones. Even if, like in the case of Robert, the attitude towards the assignment was not totally positive, all the students perceived the value of the activity to language learning. The participants interviewed listed a series of benefits of the technology that outnumbered the drawbacks that they also mentioned. One disadvantage of the implementation of the technology that was mentioned by two of the participants was the short amount of time in the semester that was allotted to the Wimba activities. This indicates that the students valued the technology for language learning and thought that its benefits would be increased if implemented over a longer period of time.

Additionally, since most students had to do this activity at the language laboratory, due to the limited access to microphones, all four participants mentioned their attitude towards this means of accessing the computer environment. Three of the four participants reported to have a negative attitude towards the language laboratory and described it as the worst aspect of the activities. The main reason provided for this attitude was the inconvenience of the laboratory hours. In addition, most students reported to have experienced technical difficulties at the language laboratory during the Wimba activities. Finally, the Wimba software was described as easy and straight-forward by all four participants.

In light of this, we find that variables such as attitude towards the assignment, perceived value of the activity, or user-friendliness of the software did not have a negative effect in the students' perceptions of their anxiety when speaking in Spanish in the asynchronous computer environment. However, the negative attitude towards going to the language laboratory, coupled 
with the technical difficulties had a negative effect on the level of student anxiety in the asynchronous environment.

\section{Summary of Interview Data}

Three of the four students interviewed reported to have a low level of computer anxiety. However, when it comes to language anxiety in the classroom, the majority of the students described it as medium or high. The main causes of anxiety revealed during the interviews were the participants' lack of confidence in their skills in Spanish, and a concern about the level of the other students. An additional source of anxiety when speaking in the foreign language in the classroom was the prospect of being called on by the instructor. The causes of this anxiety were the number of people listening, and the pressure of having limited class time. In addition, two of the students were concerned about making mistakes, or not giving satisfactory enough answers, when speaking in the classroom. The anxiety towards being called on sometimes disappeared when the student volunteered.

The presence of the instructor was not a source of anxiety. However, the fact that the instructor was a native speaker of the language was seen by one of the students as a source of anxiety, since she felt that the standard was higher when speaking to a native speaker. Three of the four students reported that they did not anxiety about the presence of their peers in the classroom environment. However, in the case of one student, the presence of the peers was a significant source of anxiety. Her case may be representative of a number of the participants of this study.

All participants described their level of anxiety when speaking in the asynchronous computer voice conferencing environment as low and three shared that it was lower than that of the classroom. The main reason for this decrease in the level of anxiety was that the 
asynchronous environment freed them from the time pressure of the classroom, coupled with the possibility of replaying people's contributions and editing their own. Additionally, there were a series of consequences linked to the asynchronous nature of the computer voice conferencing environment. Two of the four students said that they wrote their answers down first, and then read them out loud on the voice board. Sometimes contributing to the conversations on the voice board became a group effort. This indicates that the students were taking an approach to the completion of the Wimba activities that very much resembles that of written homework assignments.

Freedom from the time constrains of the classroom, together with the absence of the instructor and peers facilitated an increase in the amount of risk-taking in the asynchronous environment. The students were more daring when it came to saying something that they were not sure about, and they produced longer and more complex sentences in this environment.

Regarding the absence of the instructor and peers in the asynchronous computer voice conferencing environment, three of the four students that were interviewed agreed that it helped to reduce anxiety. In addition, the fact that both their instructor and their classmates would listen to them at some point did not make a difference in their anxiety. The reason for this perception was that the students were free from the time limits of the classroom and the possibility of writing their answers contributed to a greater sense of security in the accuracy of their output which in turn resulted in less fear of negative evaluation. This could explain why none of the students interviewed expressed a concern about making mistakes in the asynchronous computer voice conferencing environment; even if a mistake was found after they had already posted their contribution. 
An interesting finding of the interview data is that the properties of the asynchronous computer voice conferencing environment that are likely to reduce anxiety can be eliminated by the circumstances surrounding the technology itself. This creates a whole new environment that, added to the voice board, may not be as beneficial to the reduction of anxiety as the technology alone.

As a final point, variables such as attitude towards the assignment, perceived value of the activity, or user-friendliness of the software did not have a negative effect on the students' perception of their anxiety when speaking in the computer environment. On the other hand, a negative attitude towards going to the language laboratory, coupled with the technical difficulties and the activities being implemented over a short time may have caused anxiety to increase in this environment.

\section{Discussion}

Research Question 1: What Is the Learners' Perception of Their Language Anxiety When Speaking in the Asynchronous Computer Voice Conferencing Environment?

From a quantitative perspective, the environment did not make a difference in terms of the general feeling of anxiety towards oral communication in the foreign language, based on the positive relationship between both environments shown by the quantitative analysis. However, the data from the interviews showed that students did experience a reduction in the level of anxiety when speaking in the computer environment. This reduction of the level of anxiety was due to the elimination of the time constraints of the classroom, coupled with the possibility of replaying and editing contributions to the voice board. 
Research Question 2: How Empowered Do the Learners Feel to Take Risks in the Asynchronous

Computer Voice Conferencing Environment?

Both quantitative and qualitative data reveal that the asynchronous computer voice conferencing environment facilitated a greater amount of risk-taking among the students. The students produced not only a greater number, but also longer and more complex sentences in the computer environment than in the classroom discussions. The only exception was the negotiation of meaning, which was mostly prompted by the instructor regardless of the environment. In addition, the participants reported being more daring when it came to saying something that they were not sure about in the computer environment. They also reported that the asynchronous nature of this environment in terms of the freedom from the time constrains of the classroom together with the absence of instructor and peers favored this increased risk-taking.

Research Question 3: How Concerned Are the Learners about Being Evaluated by Others When Making Oral Mistakes in the Foreign Language in the Asynchronous Computer Voice Conferencing Environment?

The asynchronous computer voice conferencing environment had a positive effect on the students' concern about negative evaluation by their instructor and peers. This conclusion is supported by both quantitative and qualitative data. The majority of the students felt that the absence of their instructor and peers in the computer environment helped to reduce anxiety.

The increased amount of time provided by the asynchronous technology helped to reduce fear of negative evaluation, since the students were more confident about the quality of their output. For that reason, the students were not concerned about the fact that both instructor and peers would eventually listen to their contributions. In effect, the students were the least concerned about the possibility that the instructor would correct their mistakes on the voice 
board. However, making mistakes was the aspect of negative evaluation that caused the highest levels of anxiety among the participants of this study. A possible explanation for this apparent contradiction is that, regardless of the environment, students were concerned about the accuracy of their output in the foreign language. The source of this concern does not lay in a concern of negative evaluation by their instructor or peers, but rather on a desire to speak the language correctly and thus improve the quality of their output. 
Chapter 5: Conclusions, Implications, and Recommendations

In order to address a specific need in the field of second language acquisition to provide students with opportunities for oral communication in a low-anxiety environment, this study looked into asynchronous computer voice conferencing as an environment with the potential to reduce spoken language anxiety. More specifically, the purpose of the study was to investigate the influence of asynchronous computer voice conferencing on student anxiety when speaking in a foreign language. The technology chosen for the study was the Wimba voice board.

Based on previous research on the relationship between language and anxiety, which identified speaking as the most anxiety-producing skill in a foreign language (Chen, Horwitz, \& Schallert, 1999; Ellis, 1994; Horwitz et al.; Young, 1990), a general research question was formulated about the students' perceptions of their anxiety when speaking a foreign language. This question was also grounded in research on the use of computer conferencing technologies for language learning, which revealed the potential for reducing student anxiety (Beauvois, 1994, 1996, 1999; Kivela, 1996; Lee, 2004; Meunier, 1998; Skinner \& Austin, 1999; Warschauer, 1996a). As a result, Research Question 1 was formulated as follows: What is the learners' perception of their language anxiety when speaking in the asynchronous computer voice conferencing technology environment?

Previous research has linked anxiety with a reduction of participation in foreign language courses. More specifically, this research has found a relationship between anxiety and communication apprehension (Horwitz et al.), willingness to communicate (MacIntyre et al.), sociability, and risk-taking (Ely, 1986). Regarding this last construct of risk-taking, it has been found that anxiety is related to the production of shorter and less complex communicative units, the use of less interpretive language with less personal contributions, and a tendency to avoid 
participating in oral communication (Horwitz, 2002; Phillips, 1992; Steimberg \& Horwitz, 1986).

In contrast, research has also found that computer conferencing empowered the learners to take more risks with the target language in terms of an increased participation, an equal and more student-centered interaction, and a greater array of the ideas expressed (Beauvois, 1992, 1994, 1999; Blake, 2000; Chun, 1994; Kamhi-Stein, 2000; Kelm, 1992; Kern, 1995; Kroonenberg, 1995; Meunier, 1998; Pelletieri, 2000; Schultz, 2000; Sengupta, 2001; Shetzer \& Warschauer, 2000; Skinner \& Austin, 1999; Toyoda, 2002; Warschauer, 1996a; Weasenforth; Biesengach-Lucas \& Meloni, 2002). In response to these findings, Research Question 2 of this study was formulated as follows: How empowered do the learners feel to take risks in the asynchronous computer voice conferencing environment?

Furthermore, the literature also indicated that language anxiety did not reside in the act of speaking itself, but on a fear of negative evaluation by instructor and peers when making mistakes in the target language (Chen et al., 1999; Young, 1990). Therefore, Research Question 3 was formulated as follows: How concerned are the learners about being evaluated by others when making oral mistakes in the foreign language in the asynchronous computer voice conferencing environment?

The design of the present investigation was set up as a mixed methods study. The combination of quantitative and qualitative data proved to be appropriate for providing a greater understanding of the students' perceptions of their anxiety in the Wimba environment.

\section{Conclusions}

Conclusions are organized around the issues that arose from the findings of the study. These issues will be used to address the research questions that guided the investigation. 


\section{Participants' Perception of Their Anxiety}

Analysis of the quantitative data revealed that the anxiety experienced on Wimba increased as classroom anxiety increased. Consequently, from a quantitative perspective, the analysis demonstrated that regardless of the place of oral interaction, students continued to experience language anxiety when engaging in oral communication in the target language. On the contrary, the qualitative data did in fact indicate that a number of students experienced reduced anxiety attributable to both the elimination of the time pressure of the classroom, as well as the opportunity to edit their contributions before posting them to the voice board. Qualitative comments indicated that the limited availability of response time in face-to-face oral interactions in the classroom was a cause of anxiety in that environment. The elimination of the time constraints of the classroom resulted in lower levels of anxiety in the Wimba environment. Additionally, qualitative analysis indicated that the opportunity to edit their contributions gave the students greater confidence in the quality of their output, which also resulted in a lower level of anxiety.

Given this data, we can conclude that for Research Question 1, which inquired about learners' perception of their language anxiety when speaking in the asynchronous computer conferencing voice environment, Wimba involves features that promote a reduction of anxiety, namely the increased response time provided by the asynchronous nature of the technology, and the opportunity to edit student contributions but participants of this study did not fully benefit from these features of the technology. This is attributable to a number of issues that emerged in the qualitative analysis and that caused an increase in the level of anxiety: The conditions of the place where Wimba is used, access and technical support, and instruction. Wimba has the capability to reduce anxiety if these issues are controlled: 


\section{Conditions of the place where Wimba is used}

An explanation for the divergence between quantitative and qualitative data regarding learners' perception of their anxiety is the characteristics of the physical setting where the Wimba communication technology is actually used. The interviews revealed that some participants were concerned, even anxious, about the physical setting where the communication took place. The fact that the language laboratory was crowded when some students posted their contributions to the voice board, or the use of the technology in a shared dormitory room were environmental conditions, mentioned by the participants, that caused students to be anxious while using the technology. Therefore, because of these physical conditions of the point of access, students did not benefit from the anxiety-reducing features of the Wimba technology.

\section{Access and technical support}

In addition to the barriers imposed by the physical conditions, the interviews indicated a general negative attitude towards going to the language laboratory, which was the major place of access provided for this study. Going to the language laboratory was in several cases described as "the worst" aspect of the activity, primarily due to the limited hours in which the facility was available to students. The students interviewed also mentioned experiencing technical difficulties at the laboratory during the Wimba activities. The negative attitude towards the laboratory and the technical difficulties are added to the physical conditions of the point of access to negate the anxiety reducing potential of the voice board. As a conclusion, qualitative analysis showed the need to control for the characteristics of the point of access in order to achieve the maximum benefit of online environments to reduce language anxiety. 


\section{Instruction}

Only two activities, which involved a total of four contributions to the Wimba voice board, were designed and implemented for the purpose of this study over a six-week period. Analysis of the qualitative data indicated that this was seen as a disadvantage by the students, who felt that they did not have enough time to benefit from the technology. As a result, the interviews revealed that there was a strong connection between instructional time and the anxiety reducing benefits of the technology.

\section{Risk-taking}

The ability of the Wimba technology to reduce language anxiety was demonstrated by the amount of student risk-taking in that environment. Data collected through the evaluation rubric indicated that students were empowered to take more risks in the computer environment. Students produced a significantly greater quantity and complexity of output in a more student-centered interaction on the voice board. The analysis of the interviews provided further explanations for this increased risk-taking. Interview data showed that in the computer environment students were more daring to make statements that they were not confident in being accurate than would have occurred in the face-to-face classroom. Students attributed this increased risk-taking to two causes. First, the reduced response time typical of oral interaction in the classroom was eliminated and more time was allowed to prepare their contributions to the voice board. Second, the typical pressure of being in front of the class was also eliminated by the technology and favored an increase of risk-taking.

Therefore, we can conclude that based on the data analyzed to address Research Question 2, which inquired about student empowerment to take risks in the asynchronous computer voice conferencing environment, students took more risks in the Wimba voice board than in the face- 
to-face environment. This is consistent with the results reported by Beauvois (1992), Chun (1994), Kamhi-Stein (2000), and Kern (1995) in that they found that the quantity and quality of the output increased in the computer medium and the instructor's role was decentralized.

\section{Fear of Negative Evaluation}

Correlational analysis indicated that there was not a relationship between the level of anxiety about negative evaluation in the Wimba and classroom environments. Analysis of the qualitative data further substantiated these results. These data demonstrated that the reduced fear of negative evaluation is attributable to the absence of the instructor and peers in this environment. Moreover, the fact that their instructor and peers would eventually listen to their contributions did not constitute an additional source of anxiety. Finally, interviews indicated that because students were free from the time constraints of the classroom and because they had the opportunity of editing their answers there was a reduction of the fear of negative evaluation. These two features of the technology provided students with a greater sense of security about the quality and accuracy of their output leading to a reduction of the fear towards negative evaluation.

In view of this, we can conclude that for Research Question 2, which inquired about learners' concern about being evaluated by others when making oral mistakes in the foreign language in the Wimba environment, the voice board decreased fear of negative evaluation. This is consistent with previous research in the use of computers as communication media for language courses (Beauvois, 1992, 1994; Skinner and Austin, 1999; Kern, 1995), which found that students produced a greater amount and complexity of output in the computer environment.

Collectively, data gathered to investigate students' perceptions of their anxiety, risktaking, and fear of negative evaluation on the Wimba voice board lead to the general conclusion 
that asynchronous computer voice conferencing technologies have the potential to reduce anxiety associated with speaking a foreign language. Specifically, the Wimba voice board, as one example of this technology available for oral communication in foreign language courses, demonstrated a strong potential for the reduction of language anxiety. This is consistent with the findings of previous research on the use of the Wimba voice board for language classes. According to Cho and Carey (2001), the use of the voice board reduced anxiety because of the increased time to listen and respond and the possibility of repeating recordings and replaying others' contributions. The findings are also consistent with those of McIntosh, Braul and Chao, who also found that the Wimba voice board was a non threatening environment for the students.

\section{Implications}

From a practitioner's standpoint, a number of implications stem from the findings of this research. When integrating this technology in intermediate language courses, educators should consider the following implications in order to achieve the maximum benefit for reducing anxiety during oral communication:

1. To promote low anxiety, the physical conditions of the place of access to the technology must be controlled. These conditions must be such that the students have easy access to the technology and are not exposed to the presence of others that may hear their contributions to the voice board.

2. To avoid negative attitudes regarding such environments, the technology must be made available to the students without time or space limitations.

3. For that same reason, every effort should be made to minimize technical difficulties.

4. To obtain greater benefits in the reduction of anxiety, the technology should be implemented as an instructional strategy over a long period of time. 


\section{Recommendations for Further Research}

There is little doubt that more research is needed in the future to investigate the integration of asynchronous computer voice conferencing technologies such as Wimba in foreign language courses. Recognizing the limitations of this study, further attention should be given to better understanding the impact of the physical conditions of the point of access to the technology on anxiety. Additionally, the ability of these technologies to lower language anxiety needs to be investigated when integration takes place over long periods of time. 


\section{References}

American Council for the Teaching of Foreign Languages (1999). ACTFL Proficiency

Guidelines. Retrieved, March 5, 2004, from the ACTFL Web site:

http://www.actfl.org/files/public/Guidelinesspeak.pdf

Aida, Y. (1994). Examination of Horwitz, Horwitz, and Cope's construct of foreign language anxiety: The case of students of Japanese. The Modern Language Journal, 78, 155-168.

American Psychological Association (1997, November). Learner-centered psychological principles: A framework for school redesign and reform. Retrieved March 5, 2004, from the American Psychological Association Web site: http://www.apa.org/ed/lcp.html

Bailey, K. M. (1983). Competitiveness and anxiety in adult second language learning: Looking at and through the diary studies. In H. W. Seliger \& M. H. Long (Eds.), Classroom oriented research in second language acquisition (pp. 67-102). Rowley, MA: Newbury House Publishers Inc.

Beauvois, M. H. (1992). Computer-assisted classroom discussion in the foreign language classroom: Conversation in slow motion. Foreign Language Annals, 25, 455-463.

Beauvois, M. H. (1994). E-talk: Attitudes and motivation in computer-assisted classroom discussion. Computers and the Humanities, 28, 177-190. Retrieved January 25, 2004, from the Kluwer Online database.

Beauvois, M. H. (1996). Personality types and megabytes: Student attitudes toward computermediated communication (CMC) in the language classroom. CALICO Journal, 13, 26-45.

Beauvois, M. H. (1999). Computer-mediated communication: Reducing anxiety and building community. In D. J. Young (Ed.), Affect in Foreign Language and Second Language 
Learning: A Practical Guide to Creating a Low Anxiety Classroom Atmosphere (pp. 144165). Boston: McGraw Hill.

Blake, R. (2000). Computer-mediated communication: A window in L2 Spanish Interlanguage. Language Learning and Technology, 4, 120-136. Retrieved March 5, 2004 from http://llt.msu.edu/vol4num1/blake/default.html

Breiner-Sanders, K. E., Lowe, P., Miles, J., \& Swender, E. (1999). ACFL Proficiency Guidelines: Speaking Revised 1999. Foreign Language Annals, 33, 13-18.

Bump, J. (1990). Radical changes in class discussion using networked computers. Computers and the Humanities, 24, 49-65. Retrieved January 25, 2004, from Kluwer Online database.

Chapelle, C. (2000). Is network-based learning CALL? In M. Warshauer \& Kern, R. G. (Eds.), Network-Based Language Teaching: Concepts and Practice (pp. 205-228). Cambridge: Cambridge University Press.

Chen, Y., Horwitz, E. K., \& Schaller, D. L. (1999). Language anxiety: Differenciating writing and speaking components. Language Learning, 49, 417-447.

Cho, S. P., \& Carey, S. (2001). Increasing Korean oral fluency using an electronic bulletin board and Wimba-based voiced chat. The Korean Language in America, 6, 115-128.

Chun, D. M. (1994). Using computer networking to facilitate the acquisition of interactive comptetence. System, 22, 17-31.

Chun, D. M. \& Plass, J. L. (2000). Networked multimedia environments for second language acquisition. In M. Warshauer \& Kern, R. G. (Eds.), Network-Based Language Teaching: Concepts and Practice (pp. 151-170). Cambridge: Cambridge University Press. 
Collins, M. \& Berge, Z. (1996). Facilitating interaction in computer-mediated online courses. Paper presented at the 1996 FSU/AETC Distance Education Conference. Abstract retrieved March 5, 2004, from http://emoderators.com/flcc.html

Creswell, J. W. (2003). Research Design: Qualitative, Quantitative, and Mixed Method Approaches. Thousand Oaks, CA: Sage Publications.

Daly, J. (1991). Understanding communication apprehension: An introduction for language educators. In E. K. Horwitz \& D. J. Young (Eds.), Language Anxiety: From Theory and Research to Classroom Implications. Englewood Cliffs, NJ: Prentice Hall.

Dörney, Z., Clément, R., \& Noels, K. A. (1994). Motivation, self-confidence, and group cohesion in the foreign language classroom. Language Learning, 44, 417-448.

Ehrman, M. E., \& Oxford, R. L. (1995). Cognition plus: Correlates of language learning success. The Modern Language Journal, 79, 67-89.

Ellis, R. (1994). The Study of Second Language Acquisition. New York: Oxford University Press.

Ellsworth, J. H. (1995). Using computer-mediated communication in teaching university courses. In Z. L. Berge \& M. P. Collins (Eds.), Computer-Mediated Communication (pp. 29-37). Cresskill, NJ: Hampton Press Inc.

Ely, C. M. (1986). Language learning motivation: A descriptive and causal analysis. The Modern Language Journal, 70, 28-35.

Foerster, S. W., Lambright, A., Alfonso-Pinto, F. (2003). Punto y Aparte (2nd ed.). Boston, MA: McGraw-Hill.

Gardner, R. C., Tremblay, P. F., \& Masgoret, A. M. (1997). Towards a full model of second language learning: An empirical investigation. The Modern Language Journal, 81, 344362. 
Hampel, R. (2003). Theoretical perspectives and new practices in audio-graphic conferencing for language learning. ReCALL, 15, 21-36.

Hampel, R. \& Hauk, M. (2004). Towards an effective use of audio conferencing in distance language courses. Language Learning and Technology, 8, 66-82. Retrieved February 27, 2004, from http://llt.msu.edu/vol8num1/hampel/default.html

Harris, J. (2000). Design Tools for the Internet-Supported Classroom (2 ${ }^{\text {nd }}$ ed.). Alexandria, Va.: Association for Supervision and Curriculum Development.

Horwitz, E., Horwitz, M. B., \& Cope, J. (1986). Foreign language classroom anxiety. The Modern Language Journal, 70, 125-132.

Horwitz, E. (1986). Preliminary evidence for the reliability and validity of a foreign language anxiety scale. TESOL Quarterly, 20, 559-562.

Horwitz, B. (2002). Communication Apprehension. Albany, NY:Delmar Singular.

Irvine, S. E. (2000). What are we talking about? The impact of computer-mediated communication on student learning. (ERIC Document Reproduction Service No. ED444404)

Khami-Stein, L. D. (2000). Looking to the future of TESOL teacher education: Web-based bulletin board discussions in a methods course. TESOL Quarterly, 34, 423-455.

Kelm, O. R. (1992). The use of synchronous computer networks in second language instruction: A preliminary report. Foreign Language Annals, 25, 441-454.

Kern, R. G. (1995). Restructuring classroom interaction with networked computers: Effects on quantity and characteristics of language production. The Modern Language Journal, 79, 457-476. 
Kivela, R. J. (1996). Writing on networked computers: Effects on ESL writer attitudes and apprehension. Asian Journal of English Language Teaching, 6, 85-92.

Köter, M. Shield, L, \& Stevens, A. (1999). Real-time audio and email for fluency: Promoting distance language learners' aural and oral skills via the Internet. ReCALL, 11, 55-60. Retrieved February 17, 2004, from http://www.hull.ac.uk/cti/eurocall/recall/r_online.htm

Krashen, S. (1982). Principles and Practice in Second Language Acquisition. New York: Pergamon Press.

Kronenberg, N. (1995). Developing communicative and thinking skills via electronic mail. TESOL Journal. 4, 24-27.

Lee, L. (2004). Learners' perspectives on networked collaborative interaction with native speakers of Spanish in the U.S. Language Learning and Technology, 8, 83-100. Retrieved February 27, 2004, from http://llt.msu.edu/vol8num1/

MacIntyre, P. D., Clément, R., Dörney, Z., \& Noels, K. (1998). Conceptualizing willingness to communicate in a L2: A situational model for L2 confidence and affiliation. Modern Language Journal, 82, 545-562.

MacIntyre, P.D. \& Gardner, R. C. (1989). Anxiety and second language learning: Toward a theoretical clarification. Language Learning, 39, 251-275.

MacIntyre, P. D., \& Gardner, R. C. (1991). Methods and results in the study of anxiety and language learning: A review of the literature. Language Learning, 41, 85-117.

McCroskey, J. C. (1984). The communication apprehension perspective. In J. A. Daly \& J. C. McCroskey (Eds.), Avoiding communication (pp. 78-96). Beverly Hills, CA: Sage Publications. 
McIntosh, S., Braul, B., \& Chao, T. (2003). A case study in asynchronous voice conferencing for language instruction. Education Media International, 40, 63-74.

McMillan, J. H. (2000). Educational Research: Fundamentals for the Consumer ( $3^{\text {rd }}$ ed.). New York: Addison Wesley Longman.

Meunier, L. E. (1998). Personality and motivational factors in computer-mediated foreign language communication (CMFLC). In J.A. Muyskens (Ed.), New ways of learning and teaching: Focus on technology and foreign language education (pp. 145-197). Boston:

Heinle \& Heinle.

Omaggio Hadley, A. (2001). Teaching Language in Context ( $3^{\text {rd }}$ ed.). Boston: Heinle \& Heinle.

Onwuegbuzie, A. J., Bailey, P., \& Daley, C. E. (2000). Cognitive, affective, personality, and demographic predictors of foreign language achievement. Journal of Educational Research, 94, 3-16.

Ortega, L. (1997). Processes and outcomes in networked classroom interaction: Defining the research agenda for L2 computer-assisted classroom discussion. Language Learning and Technology, 1, 82-93. Retrieved December 4, 2002, from http://polyglot.cal.msu.edu/llt/vol1num1/ortega/

Patton, M. Q. (2001). Qualitative Research and Evaluation Methods (3 ${ }^{\text {rd }}$ ed.). London: Sage Publications.

Pelletieri, J. (2000). Negotiation in cyberspace: The role of chatting in the development of grammatical competence. In M. Warshauer \& Kern, R. G. (Eds.), Network-Based Language Teaching: Concepts and Practice (pp. 59-86). Cambridge: Cambridge University Press. 
Phillips, E. M. (1992). The effects of language anxiety on students' oral test performance and attitudes. The Modern Language Journal, 76, 14-26.

Ross, K. W. (2003). Asynchronous Voice: A personal account. IEEE Multimedia, 10, 70-74.

Rubio, D. M., Berg-Weger, M., Tebb, S. S., Lee, E. S., \& Rauch, S. (2003). Objectifying content validity: Conducting a content validity study in social work research. Social Work Research, 27, 94-105. Retrieved May 10, 2004 from the EBSCOhost database.

Savignon, S. J. (1997). Communicative competence: Theory and classroom practice. Texts and contexts in second language learning (2nd ed.). Boston: McGraw Hill.

Scarce, R. (1997). Using electronic mail discussion groups to enhance students' critical thinking skills. The Technology Source. Retrieved March 5, 2004, from http://ts.mivu.org

Schultz, J. M. (2000). Computers and collaborative writing in the foreign language curriculum. In M. Warshauer \& Kern, R. G. (Eds.), Network-Based Language Teaching: Concepts and Practice (pp. 171-185). Cambridge: Cambridge University Press.

Scovel, T. (1978). The effect of affect in foreign language learning: A review of the anxiety research. Language Learning, 28, 129-142.

Sengupta, S. (2001). Exchanging ideas with peers in network-based classrooms: An aid or a pain. Language Learning and Technology, 5, 103-134. Retrieved February 26, 2004, from http://llt.msu.edu/vol5num1/sengupta/default.html

Shetzer, H. \& Warshauer, M. (2000). An electronic literacy approach to network-based language teaching. In M. Warshauer \& Kern, R. G. (Eds.), Network-Based Language Teaching: Concepts and Practice (pp. 171-185). Cambridge: Cambridge University Press. 
Simonson, M. R., Maurer, M., Montag-Torardi, M., \& Whitaker, M. (1987). Development of a standardized test of computer literacy and a computer anxiety index. Journal of Educational Computing Research, 3, 231-247.

Skinner, B., \& Austin, R. (1999). Computer conferencing-does it motivate EFL students? ELT Journal, 53, 270-278.

Spielberger, C. D., \& Gaudry, E. (1971). Anxiety and Educational Achievement. New York: John Wiley \& Sons Australasia Pty. Ltd.

Steinberg, F. S. \& Horwitz, E. K. (1986). The effect of induced anxiety and interpretive content of second language speech. TESOL Quarterly, 20, 131-136.

Stevens, A. \& Hewer, S. (1998). From policy to practice and back. Proceedings of the First LEVERAGE Conference, Cambridge, 7-8. Retrieved March 5, 2004, from http://greco.dit.upm.es/ leverage/conf1/hewer.htm

Toyoda, E. (2002). Categorizationof text chat communication between learners and native speakers of Japanese. Language Learning and Technology, 6, 82-99. Retrieved March, 5, 2004, from http://llt.msu.edu/vol6num1/toyoda/

VanPatten, B. \& James L. (2003). Making Communicative Language Teaching Happen (2 ${ }^{\text {nd }}$ ed.). New York: McGraw Hill, Inc.

Walther, J. B. (1996). Computer-mediated communication: Impersonal, interpersonal, and hyperpersonal interaction. Communication Research, 23, 3-43.

Warschauer, M. (1996a). Comparing face-to-face and electronic discussion in the second language classroom. CALICO Journal, 13, 7-26. 
Warschauer, M. (1996b). Motivational aspecs of using computers for writing and communication. In M. Warschauer (Ed.), Telecollaboration in foreign language learning: Proceedings of the Hawai'i symposium. (Technical report \#12) (pp. 29-46). Honolulu, Hawai'i: University of Hawai'i, Second Language Teaching \& Curriculum Center. Retrieved January 26, 2004, from http://www.nflrc.hawaii.edu/networks/NW01/NW01.pdf

Weasenforth, D., Biesengach-Lucas, S. , \& Meloni, C. (2002). Realizing constructivist objectives through collaborative technologies: Threaded discussions. Language Learning and Technology, 6, 58-86. Retrieved February 4, 2004, from http://lit.msu.edu/vol6num3/weasenforth/

Young, D. J. (1986). The relationship between anxiety and foreign language oral proficiency ratings. Foreign Language Annals, 19, 439-445.

Young, D. J. (1990). An investigation of students' perspectives on anxiety and speaking. Foreign Language Annals, 23, 539-553. 
Appendices 


\section{Appendix A}

\section{Asynchronous Computer Voice Conferencing Activities}

\section{Wimba Activity 1}

\section{Chapter 4: “El trabajo y el ocio; ¿Cómo se relaja usted?” (Work and Leisure: What do you do to relax?)}

Goals (Adapted from course syllabus)

Objectives

Pre-communication activity

Wimba training

Wimba activity (part 1)
Students will speak Spanish well enough to describe, narrate, react and recommend, compare, talk about the future, and hypothesize about most familiar topics and about the resources discussed in this course.

Students will comprehend spoken Spanish with sufficient ability to grasp the main idea and most of the supporting details in short conversations--both prepared and spontaneous--that relate to topics with which you have some degree of familiarity.

Students will speak in Spanish about work and leisure at American universities.

Students will comprehend spoken Spanish about work and leisure at American universities.

Oct. 25 (in class, 15 minutes): Chapter 4 vocabulary about work and leisure.

The students are given sentences expressing opinions about work and leisure at American universities. They react to the opinions and share reactions with the class.

Oct. 25 (in class, 20 minutes): Students receive training in the use of the Wimba voice board.

Oct. 25: Wimba activity is assigned. Activity due on Oct. 29. At their convenience, students access the Wimba voice board and answer a question that the instructor, impersonating a foreign exchange student from Spain that will come to study at WVU, has posted for the class:

"Hi, I'm Alicia and I'm from Spain. I'm planning to spend a year studying psychology at WVU and I would like to have some information about American universities before I get there. I have heard that it is a lot of fun studying in the U.S. The students are always going out to clubs and sports events and don't study much, since these are their last years of 'freedom' before they enter the working world. Is that true? Work or 
leisure, what is more important at U.S. universities?"

Class discussion Oct. 29 (in class, 30 minutes): Classroom discussion about the same topic.

Wimba activity (part 2) Nov. 1: Wimba activity is assigned. Due on Nov. 5.

Students listen to the opinions of the others and determine the opinion of the majority of the class. They also write two characteristics of student life expressed in the postings. Finally, they reply to one of the opinions by saying if they agree or disagree with it, and justify their reaction.

Follow-up Nov. 5 (in class): Students share their notes from the web board postings in order to determine the overall opinion of the class. In groups, they write a letter to the exchange student describing work and leisure at American universities.

\section{Wimba Activity 2}

\section{Chapter 6: "El porvenir." (The Future)}

Goals (Adapted from course syllabus)

Objectives

Pre-communication activities
Students will speak Spanish well enough to describe, narrate, react and recommend, compare, talk about the future, and hypothesize about most familiar topics and about the resources discussed in this course.

Students will comprehend spoken Spanish with sufficient ability to grasp the main idea and most of the supporting details in short conversations--both prepared and spontaneous--that relate to topics with which you have some degree of familiarity.

Students will speak in Spanish about the future.

Students will comprehend spoken Spanish about the future.

Nov. 19 (in class, 50 minutes): Chapter 6 vocabulary about predicting the future and future of the world. The students select words from the list that describe the world in the year 2050. The words are written on the board in order to determine the class's overall opinion about the topic. After that, the students are given a series of controversial opinions to which they have to react. Reactions are shared with the class.

Nov. 29 (in class, 30 minutes): Review of vocabulary. Grammar about the future. In groups, the students draw and 
present to the class future scenes from descriptions given by the instructor, in which verbs in the future are highlighted. The drawings are put on the wall for the students to look at and describe the future of humanity according to those drawings, as well as react to that description. Ideas from the reports are shared with the class.

Wimba activity (part 1) Nov. 29: Wimba activity is assigned. Activity due on Dec. 3. The students answer a question posed by the instructor on the voice board:

"What is your opinion about the future of humanity? Do you think that it will be positive or negative? Justify your answer with predictions for the year 2050."

Class discussion Dec. 3 (in class: 30 minutes): Class discussion about the same topic.

Wimba activity (part 2) Dec. 6: Wimba activity is assigned. Due on Dec. 8. Students listen to the opinions of the others and determine the opinion of the majority about the future of humanity being either positive or negative, and justify their answers with examples from the postings. They bring their reports to the next class. They also reply to one posting either agreeing or disagreeing with the opinions expressed and justifying their reaction.

Follow-up Dec. 8 (in class, 20 minutes): Student reports are shared with the class and conclusions are drawn about the opinion of the majority. 


\section{Appendix B}

\section{Demographic Survey}

1. Date of birth:

2. Gender: $\bigcirc$ Male $\bigcirc$ Female

3. First language:

4. Major:

5. Reason for taking this course (Please, choose one)

$\bigcirc$ Requirement

Major

$\bigcirc$ Minor

$\bigcirc$ Personal interest

$\bigcirc$ Other (Please, specify)

6. How do you consider your motivation for this course? (Please, choose one)

$\bigcirc$ High

$\bigcirc$ Medium

$\bigcirc$ Low

7. How many Spanish courses have you taken before? (include courses taken at high school)

8. Did you take Spanish 101, 102, and 203 at WVU? $\bigcirc$ Yes $\bigcirc$ No

9. Have you ever taken the placement test? $\bigcirc$ Yes $\bigcirc$ No

10. If so, specify the level that you placed into.

11. How much effort are you putting in this course? (Please, choose one)

More than in other courses

About the same as in other courses

$\bigcirc$ Less than in other courses 


\section{Appendix C}

\section{Response Form for the Rating of the Items of the Demographic Survey}

Name:

INSTRUCTIONS: This measure is designed to evaluate the content validity of a demographic survey. Please, rate each item as follows:

- Please, rate the level of representativeness with respect to the purpose of the survey on a scale of $1-4$, with 4 being the most representative. Space is provided for you to comment on the item or suggest revisions.

- Please indicate the level of clarity of each item, also on a four-point scale. Again, please make comments in the space provided.

- Please, evaluate the comprehensiveness of the entire measure by indicating items that should be deleted or added.

Purpose of the Survey

Description of the participants: Spanish 204 students.

Items

1. Date of birth

2. Gender

3. First language.

4. Major

5. Reason for taking this course

6. How do you rate your motivation for this course?

7. How many Spanish courses have you taken before
Representativeness

$1=$ item is not

representative of the

research question

$2=$ item needs major

revisions to be

representative

$3=$ item needs minor

revisions to be

representative

$4=$ item is clear

1234

Comments

1234

Comments

1234

Comments

1234

Comments

1234

Comments

1234

Comments

1234

Comments

\section{Clarity}

$1=$ item is not clear

$2=$ item needs major

revisions to be clear

$3=$ item needs minor

revisions to be clear

$4=$ item is clear

1234

Comments

1234

Comments

1234

Comments

1234

Comments

1234

Comments

1234

Comments

1234

Comments 
8. Did you take Spanish 101, 102, and 301 at WVU?

1234

Comments

9. How much effort are you putting in this course?

1234

Comments
12334

Comments

12334

Comments

Comprehensiveness of the measure:

- Please, indicate which items should be deleted.

- Please, suggest items that should be added. 


\section{Appendix D}

Original Demographic Survey with Content Validity Data and Calculations

\begin{tabular}{|c|c|c|c|c|c|c|c|c|c|c|c|c|c|}
\hline \multirow[t]{2}{*}{ Original items } & \multicolumn{3}{|c|}{ Expert 1} & \multicolumn{3}{|c|}{ Expert 2} & \multicolumn{3}{|c|}{ Expert 3} & \multicolumn{2}{|c|}{$\begin{array}{l}\text { Interrater } \\
\text { Reliability }\end{array}$} & \multicolumn{2}{|c|}{ CVI* } \\
\hline & $\mathbf{R} *$ & $\mathbf{C} *$ & Comments & $\mathbf{R} *$ & $\mathbf{C}^{*}$ & Comments & $\mathbf{R} *$ & C* & Comments & $\mathbf{R} *$ & $\mathrm{C}^{*}$ & $\mathbf{R} *$ & $\mathrm{C}^{*}$ \\
\hline 1. Date of birth & 4 & 4 & & 4 & 4 & & 4 & 4 & & $3 / 3=1$ & $3 / 3=1$ & $3 / 3=1$ & $3 / 3=1$ \\
\hline 2. Gender & 4 & 4 & & 4 & 4 & & 4 & 4 & & $3 / 3=1$ & $3 / 3=1$ & $3 / 3=1$ & $3 / 3=1$ \\
\hline 3. First language & 3 & 3 & $\begin{array}{l}\text { Ambiguous: } \\
\text { some students } \\
\text { don't know } \\
\text { their first } \\
\text { language } \\
\text { (bilingual) }\end{array}$ & 4 & 4 & & 4 & 4 & & $3 / 3=1$ & $3 / 3=1$ & $3 / 3=1$ & $3 / 3=1$ \\
\hline 4. Major & 4 & 4 & & 4 & 4 & & 4 & 4 & & $3 / 3=1$ & $3 / 3=1$ & $3 / 3=1$ & $3 / 3=1$ \\
\hline 5. Reason for taking this course & 4 & 4 & & 4 & 4 & & 4 & 4 & & $3 / 3=1$ & $3 / 3=1$ & $3 / 3=1$ & $3 / 3=1$ \\
\hline $\begin{array}{l}\text { 6. How do you rate your motivation for this } \\
\text { course? }\end{array}$ & 4 & 4 & & 4 & 4 & & 4 & 4 & & $3 / 3=1$ & $3 / 3=1$ & $3 / 3=1$ & $3 / 3=1$ \\
\hline $\begin{array}{l}\text { 7. How many Spanish courses have you taken } \\
\text { before? }\end{array}$ & 3 & 3 & $\begin{array}{l}\text { Does it include } \\
\text { high school? }\end{array}$ & 4 & 3 & $\begin{array}{l}\text { Should include } \\
\text { whether the } \\
\text { classes were @ } \\
\text { WVUor in high } \\
\text { school. }\end{array}$ & 4 & 4 & & $3 / 3=1$ & $3 / 3=1$ & $3 / 3=1$ & $3 / 3=1$ \\
\hline $\begin{array}{l}\text { 8. Did you take Spanish 102, 102, and } 203 \text { at } \\
\text { WVU? }\end{array}$ & 3 & 3 & & 4 & 3 & $\begin{array}{l}\text { What about } \\
\text { those who } \\
\text { tested out of } 1 \\
\text { or } 2 \text { ) }\end{array}$ & 4 & 4 & & $3 / 3=1$ & $3 / 3=1$ & $3 / 3=1$ & $3 / 3=1$ \\
\hline $\begin{array}{l}\text { 9. How much effort are you putting in this } \\
\text { course? }\end{array}$ & 4 & 4 & & 4 & 4 & & 4 & 4 & & $3 / 3=1$ & $3 / 3=1$ & $3 / 3=1$ & $3 / 3=1$ \\
\hline
\end{tabular}


Representativeness Interrater Reliability for the whole scale: $9 / 9=1$

Representativeness CVI for the whole scale: $9 / 9=1$

Clarity Interrater Reliability for the whole scale: $9 / 9=1$

Clarity CVI for the whole scale: $9 / 9=1$

Comprehensiveness of the measure

- Please, indicate which items should be deleted

Rater \#1: None

Rater \#2: No comments

Rater \#3: No comments

- Please, suggest items that should be added

Rater \#1: Maybe you should include a question, or add to item \#8: Did you take the placement exam?

Rater \#2: No comments

Rater \#3: No comments 


\section{Appendix E}

\section{Computer Anxiety Index (CAIN)}

\section{Computer Opinion Survey}

Instructions: Please indicate how you feel about the following statements. Select the appropriate circle after each question to indicate your feelings.

1 Having a computer available to me would strongly agree slightly slightly disagree strongly improve my productivity.

2 If I had to use a computer for some reason, it would probably save me same time and work.

3 If I use a computer, I could get a better picture of facts and figures.

4 Having a computer available would improve my general satisfaction.

$5 \quad$ Having to use a computer could make my life less enjoyable.

6 Having a computer available to me could make things easier for me.

7 I feel very negative about computers in general.

8 Having a computer available to me could make things more fun for me.

9 If I had a computer at my disposal, I would try to get rid of it.

10 I look forward to a time when computers are more widely used.

11 I doubt if I would ever use computers very much.

12 I avoid using computers whenever I can.

13 I enjoy using computers.

14 I feel that there are too many computers around now.

15 Computers are probably going to be an important part of my life.

16 A computer could make learning fun.

17 If I were to use a computer, I could get a lot of satisfaction from it.

18 If I had to use a computer, it would probably be more trouble than it was worth.

19 I am usually uncomfortable when I have to use computers.

20 I sometimes get nervous just thinking about computers.

21 I will probably never learn to use a computer.

22 Computers are too complicated to be of much use to me.

23 If I had to use a computer all the time, I would probably be very unhappy.

24 I sometimes feel intimidated when I have to use a 
computer.

25 I sometimes feel that computers are smarter than I am.

26 I can think of many ways that I could use a computer. 


\section{Appendix F}

\section{Foreign Language Classroom Anxiety Scale and scoring (Only items to be used in this}

\section{study)}

Instructions: Think about your experience in language classes and indicate how you feel about the following statements. Select the appropriate option after each question.

1. I never feel quite sure of myself when I'm speaking in my foreign language class.

2. I don't worry about making mistakes in language class.

3. I tremble when I know I'm going to be called on in language class.

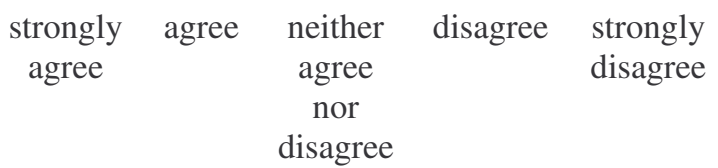

4. It frightens me when I don't understand what the teacher says in the foreign language.

5. I keep thinking that the other students are better at languages than I am.

6. I don't understand why people get so upset over foreign language classes.

7. In language class, I can get so nervous I forget things I know.

8. It embarrasses me to volunteer answers in my language class.

9. I would not be nervous speaking the foreign language with native speakers.

10. I feel confident when I speak in foreign language class.

11. I am afraid that my language teacher is ready to correct every mistake I make.

12. I can feel my heart pounding when I'm going to be called on in language class.

13. I always feel that the other students speak the foreign language better than I do.

14. I feel very self-conscious about speaking the foreign language in front of other students.

15. I feel more tense and nervous in my language class than in my other classes.

16. I get nervous and confused when I'm speaking in my language class.

17. I get nervous when I don't understand every word the language teacher says.

18. I'm afraid that the other students will laugh at me when I speak the foreign language.

\begin{tabular}{|c|c|c|c|}
\hline 5 & 4 & 3 & 2 \\
\hline 1 & 2 & 3 & 4 \\
\hline & 4 & 3 & 2 \\
\hline & 4 & 3 & 2 \\
\hline & 4 & 3 & 2 \\
\hline & 2 & 3 & 4 \\
\hline & 4 & 3 & 2 \\
\hline & 4 & 3 & 2 \\
\hline & 2 & 3 & 4 \\
\hline & 2 & 3 & 4 \\
\hline & 4 & 3 & 2 \\
\hline & 4 & 3 & 2 \\
\hline & 4 & 3 & 2 \\
\hline & 4 & 3 & 2 \\
\hline & 4 & 3 & 2 \\
\hline & 4 & 3 & 2 \\
\hline & 4 & 3 & 2 \\
\hline & 4 & 3 & 2 \\
\hline
\end{tabular}




\section{Appendix G}

\section{Wimba Anxiety Scale and Scoring}

Instructions: During the past weeks, you have participated in oral conversations in Spanish using the Wimba voice board. Think about your experience when speaking in Spanish in that environment and indicate how you feel about the following statements. Select the appropriate option after each question.

1. I never feel quite sure of myself when I'm speaking Spanish in the Wimba voice board.

2. I don't worry about making mistakes in Spanish in the Wimba voice board.

3. I tremble when I know I have to speak Spanish in the Wimba voice board.

4. It frightens me when I don't understand what the teacher says in Spanish in the Wimba voice board.

5. I keep thinking that the other students are better at Spanish than I am when I listen to their postings.

6. In the Wimba voice board, I can get so nervous I forget things I know about Spanish.

7. It embarrasses me to answer in Spanish to other students' comments in the Wimba voice board.

8. I would not be nervous speaking Spanish with native speakers in the Wimba voice board.

9. I feel confident when I speak Spanish in the Wimba voice board.

10. I am afraid that my Spanish teacher will correct every mistake I make in the Wimba voice board.

11. I can feel my heart pounding when I'm going to speak Spanish in the Wimba voice board.

12. I always feel that the other students speak Spanish better than I do when I listen to their postings.

13. I don't feel very self-conscious about speaking Spanish in the Wimba voice board because the teacher is not present.

14. I don't feel very self-conscious about speaking Spanish in the Wimba voice board because other students are not present.

15. I get nervous and confused when I'm speaking Spanish in the Wimba voice board.

16. I get nervous when I don't understand every word the language teacher says in Spanish in the Wimba voice board.

17. I'm afraid that the other students will laugh at me when they listen to my postings.

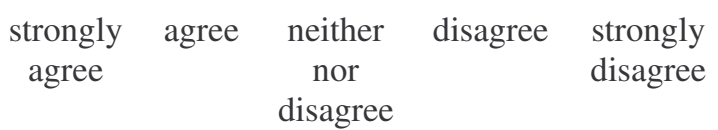

1

5

5

5

5

1

1

5

5

5

1

5

5

5

5

.

5

5

.

更

1

4

3

4

3

$\begin{array}{ll}2 & 1\end{array}$




\section{Appendix H}

\section{Response Form for the Rating of the Items of the Wimba Anxiety Scale}

Name:

INSTRUCTIONS: This measure is designed to evaluate the content validity of a Wimba anxiety measure. Please, rate each item as follows:

- Please, rate the level of representativeness with respect to the research questions being measured on a scale of $1-4$, with 4 being the most representative. Space is provided for you to comment on the item or suggest revisions.

- Please indicate the level of clarity of each item, also on a four-point scale. Again, please make comments in the space provided.

- Please, evaluate the comprehensiveness of the entire measure by indicating items that should be deleted or added.

- Finally, evaluate the level of clarity of the instructions to the participants, also on a four-point scale. Please, make comments in the space provided. Thank you for your time.

Research questions being measured

1. What is the learners' perception of their language anxiety when speaking in the asynchronous computer voice conferencing technology environment?

2. How concerned are the learners about being evaluated by others when making mistakes in the foreign language in the asynchronous computer voice conferencing environment?

\section{Representativeness Clarity}

$1=$ item is not representative $1=$ item is not clear

of the research question $\quad 2=$ item needs major

$2=$ item needs major revisions to be clear

revisions to be representative $3=$ item needs minor

$3=$ item needs minor revisions to be clear

revisions to be representative $4=$ item is clear

$4=$ item is clear 
10. I never feel quite sure of myself when

11. I don't worry about making mistakes in

1234

$\begin{array}{llll}1 & 2 & 3 & 4\end{array}$ the Wimba voice board.

Comments

Comments

12. I tremble when I know I have to speak

1234

1234

in the Wimba voice board.

Comments

Comments

13. It frightens me when I don't understand what the teacher says in the foreign

$\begin{array}{llll}1 & 2 & 3 & 4\end{array}$

1234 language in the Wimba voice board.

Comments

Comments

14. I keep thinking that the other students are $\begin{array}{llll}1 & 2 & 3 & 4\end{array}$ better at languages than I am when I Comments

1234 listen to their postings.

Comments

15. In the Wimba voice board, I can get so $\begin{array}{llll}1 & 2 & 3 & 4\end{array}$

1234

nervous I forget things I know.

Comments

Comments

16. It embarrasses me to answer to other $\quad \begin{array}{llll}1 & 2 & 3\end{array}$

1234

students' comments in the Wimba voice Comments

Comments

board.

17. I would not be nervous speaking the $\quad 1234$

12334

foreign language with native speakers in Comments

Comments the Wimba voice board.

18. I feel confident when I speak in the

$\begin{array}{llll}1 & 2 & 3 & 4\end{array}$

1234 Wimba voice board.

19. I am afraid that my language teacher will $1223 \quad 4$

1234 correct every mistake Comments Comments I make in the Wimba voice board.

20. I can feel my heart pounding when I'm $\quad \begin{array}{llll}1 & 2 & 3 & 4\end{array}$

1234 going to speak in the Wimba voice Comments Comments board.

21. I always feel that the other 1234

1234 students speak the foreign language Comments Comments better than I do when I listen to their postings. 
22. I don't feel very self-conscious about

1234

Comments speaking the foreign language in the Wimba web board because the teacher is not present.

23. I don't' feel very self-conscious about speaking in the Wimba web board because other students are not present.

24. I get nervous and confused when I'm speaking in the Wimba voice board.

25. I get nervous when I don't understand every word the language teacher says in the Wimba voice board.

26. I'm afraid that the other students will laugh at me when they listen to my postings.
1234

1234

Comments
Comments

\section{4}

Comments

1234

Comments

\section{4}

Comments

1234

Comments
1234

Comments
1234

Comments

1234

Comments

\section{Comprehensiveness of the measure:}

- Please, indicate which items should be deleted.

- Please, suggest items that should be added.

\section{$\underline{\text { Instructions to participants }}$}

\section{Clarity}

Please, indicate how you feel about the following statements. Select

1234 the appropriate option after each question.

Comments 


\section{Appendix I}

Wimba Anxiety Scale with Content Validity Data and Calculations

\section{Original items}

10. I never feel quite sure of myself when I'm speaking in the Wimba voice board.

11.I don't worry about making mistakes in the Wimba voice board.

12.I tremble when I know I have to speak in the Wimba voice board.

13. It frightens me when I don't understand what the teacher says in the foreign

language in the Wimba voice board.

14.I keep thinking that the other students are better at languages than I am when I listen to their postings.

15. In the Wimba voice board, I can get so nervous I forget things I know.

16. It embarrasses me to answer to other students' comments in the Wimba voice board.

17.I would not be nervous speaking the foreign language with native speakers in the Wimba voice board.

18. I feel confident when I speak in the Wimba voice board.

19.I am afraid that my language teacher will correct every mistake I make in the Wimba voice board.

20.I can feel my heart pounding when I'm going to speak in the Wimba voice board.

21.I always feel that the other students speak the foreign language better than I do when I listen to their postings. 


\begin{tabular}{|c|c|c|c|c|c|c|c|c|c|c|c|c|c|}
\hline \multirow[t]{2}{*}{ Items } & \multicolumn{3}{|c|}{ Expert 1} & \multicolumn{3}{|c|}{ Expert 2} & \multicolumn{3}{|c|}{ Expert 3} & \multicolumn{2}{|c|}{$\begin{array}{l}\text { Interrater } \\
\text { Reliability }\end{array}$} & \multicolumn{2}{|c|}{ CVI } \\
\hline & $\mathbf{R} *$ & $\mathbf{C}^{*}$ & Comments & $\mathbf{R} *$ & $\mathbf{C}^{*}$ & Comments & $\mathbf{R} *$ & $\mathbf{C}^{*}$ & Comments & $\mathbf{R} *$ & C* & $\mathbf{R} *$ & $\mathrm{C}^{*}$ \\
\hline $\begin{array}{l}\text { 22.I don't feel very self-conscious about } \\
\text { speaking the foreign language in the Wimba } \\
\text { web board because the teacher is not } \\
\text { present. }\end{array}$ & 4 & 4 & $\begin{array}{l}\text { Separate on } \\
\text { the } \\
\text { instrument }\end{array}$ & 4 & 4 & & 4 & 4 & & $3 / 3=1$ & $3 / 3=1$ & $3 / 3=1$ & $\begin{array}{l}3 / 3 \\
=1\end{array}$ \\
\hline $\begin{array}{l}\text { 23.I don't' feel very self-conscious about } \\
\text { speaking in the Wimba web board because } \\
\text { other students are not present. }\end{array}$ & 4 & 4 & $\begin{array}{l}\text { Separate on } \\
\text { the } \\
\text { instrument }\end{array}$ & 4 & 4 & & 4 & 4 & & $3 / 3=1$ & $3 / 3=1$ & $3 / 3=1$ & $\begin{array}{l}3 / 3 \\
=1\end{array}$ \\
\hline $\begin{array}{l}\text { 24.I get nervous and confused when I'm } \\
\text { speaking in the Wimba voice board. }\end{array}$ & 3 & 3 & $\begin{array}{l}\text { Separate on } \\
\text { the } \\
\text { instrument }\end{array}$ & 4 & 4 & Same as 8 & 3 & 4 & Language? & $3 / 3=1$ & $3 / 3=1$ & $3 / 3=1$ & $\begin{array}{l}3 / 3 \\
=1\end{array}$ \\
\hline $\begin{array}{l}\text { 25.I get nervous when I don't understand every } \\
\text { word the language teacher says in the } \\
\text { Wimba voice board. }\end{array}$ & 3 & 3 & $\begin{array}{l}\text { Separate on } \\
\text { the } \\
\text { instrument }\end{array}$ & 4 & 4 & & 4 & 4 & & $3 / 3=1$ & $3 / 3=1$ & $3 / 3=1$ & $\begin{array}{l}3 / 3 \\
=1\end{array}$ \\
\hline $\begin{array}{l}\text { 26.I'm afraid that the other students will laugh } \\
\text { at me when they listen to my postings. }\end{array}$ & 4 & 4 & & 4 & 4 & & 3 & 4 & Language? & $3 / 3=1$ & $3 / 3=1$ & $3 / 3=1$ & $\begin{array}{l}3 / 3 \\
=1\end{array}$ \\
\hline
\end{tabular}

Representativeness Interrater Reliability for the whole scale: $17 / 17=1$

Representativeness CVI for the whole scale: 17/17 = 1

Clarity Interrater Reliability for the whole scale: $17 / 17=1$

Clarity CVI for the whole scale: $17 / 17=1$

*R: Representativeness; C: Clarity; S: Simplicity; CVI: Content Validity Index 


\section{Comprehensiveness of the measure}

- Please, indicate which items should be deleted

Rater \#1: None

Rater \#2: Number 3 and 11 assess the same thing. Is that on purpose?

Rater \#3: No comments

\section{- Please, suggest items that should be added}

Rater \#1: Not sure. Will need more information regarding items addressing each research question.

Rater \#2: No comments

Rater \#3: What role does technophobia play in these anxiety measures?

\section{$\underline{\text { Instructions to participants }}$}

Rater \# 1

Clarity Comments

2 There needs to be more detail in your explanation regarding the target environment (Wimba). Instructions do not indicate the assessment is about Wimba.

\section{Interrater Reliability for the Instructions to Participants}

\begin{tabular}{llll}
\hline & Raters & \\
\hline 1 & 2 & 3 & $\begin{array}{c}\text { Interrater } \\
\text { Reliability }\end{array}$ \\
\hline 2 & 4 & 4 & $2 / 3=0.67$ \\
\hline
\end{tabular}


Clarity CVI for the instructions to participants

\begin{tabular}{|c|c|c|c|}
\hline \multicolumn{3}{|c|}{ Raters } & \multirow{2}{*}{ CVI } \\
\hline 1 & 2 & 3 & \\
\hline 2 & 4 & 4 & $2 / 3=0.67$ \\
\hline
\end{tabular}




\section{Appendix J}

\section{Interview Guide}

Describe your experience with Wimba

Best thing

Worst thing

What is your opinion about this assignment?

What is your opinion about the having to use a computer for this assignment?

Place of access

Opinion about access in general

What is your opinion of the Wimba software?

In your opinion, what aspects of this technology are positive and negative for language learning?

How did you feel when speaking in Wimba?

Speaking in general

Making mistakes

Not understanding what others say

How would you describe your level of anxiety when speaking in Wimba?

How did Wimba affect your willingness to take risks with what you said and how you said it, in comparison with the classroom?

How did you feel about the fact that your instructor and the other students were not present when you spoke in Wimba? 


\section{Appendix K}

\section{Evaluation of Risk-Taking in Wimba Postings and Classroom Contributions}

\section{- Quantity of linguistic output}

- Average number of words per posting/contribution

- Average number of sentences per posting/contribution

Number of times in which English was used in the discussion

\section{- Complexity of linguistic output}

- Average number of simple sentences per posting/contribution

- Average number of complex sentences per posting/contribution

- Average number of questions per posting/contribution

- Accuracy of linguistic output

- Average number of grammatical errors per posting/contribution

\section{- Negotiation of meaning}

Number of requests for clarification in the discussion

- Number of occasions in which feedback was given to other students in the discussion

○ Modified output: Number of elaborations and expansions of previous postings/contributions

\section{- Student-centred versus teacher-centred interaction}

Number of interventions by the instructor in the discussion 


\section{Appendix L}

\section{Cover Letter Read to Participants}

TO: Spanish 204 students from sections 002 and 004

FROM: María Isabel Charle

Dr. John Wells

Dear Spanish 204 students,

This research is being conducted in partial fulfillment of the requirements for my dissertation. The purpose of the study is to investigate the influence of asynchronous computer voice conferencing (the Wimba voice board) on learners' anxiety when speaking a foreign language.

Participation in this study involves the completion of four short questionnaires about demographic information, computer anxiety, foreign language anxiety, and anxiety when speaking in the voice web board. Additional data will be collected by tape-recording class interactions and transcribing online voice conversations. All questionnaires, tapes, and transcripts will be stored by the researcher and only she and the advisor will have access to the data. You may see the questionnaires before signing the consent form.

Your responses will be kept confidential throughout the study. In order to protect anonymity of the responses, all names will be removed from the questionnaires and substituted with codes by a person other than the researcher. At no time will student names be mentioned in recordings and transcripts.

Your participation is entirely voluntary and you may refrain from answering any or all questions without explanation. Your grades for this class will not be affected by refusal to participate or by withdrawal from the study.

Feel free to ask any questions about this research and your participation in the study.

Thanks for your cooperation. Your participation is greatly appreciated.

The researcher,

María Isabel Charle 


\section{Appendix M}

\section{Final List of Categories for the Coding of the Interview Data}

\begin{tabular}{|c|c|c|}
\hline In class & On Wimba & Using the technology \\
\hline 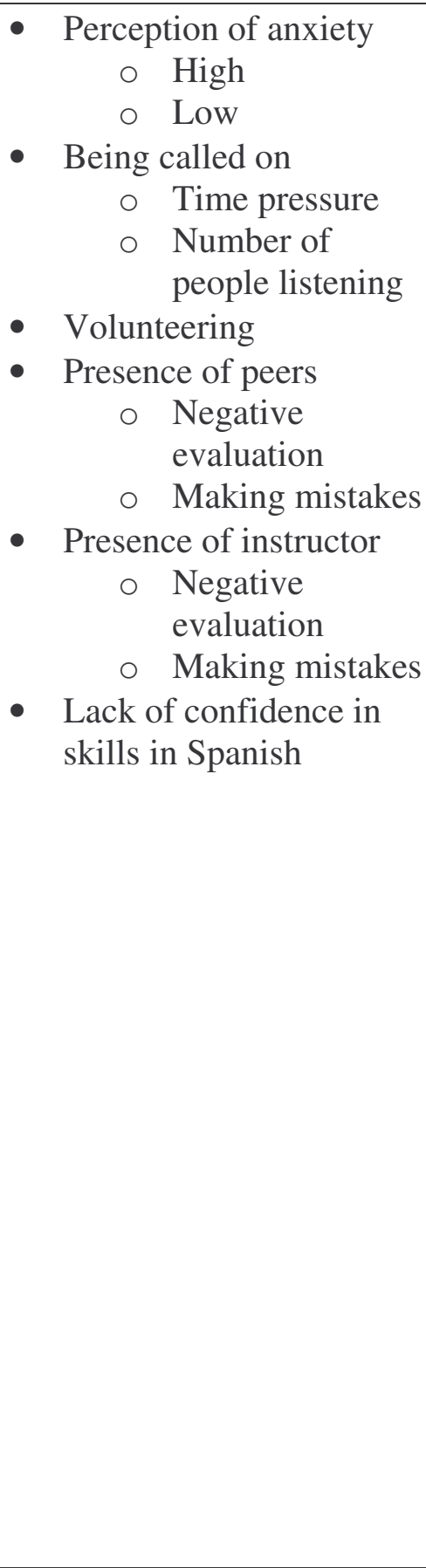 & 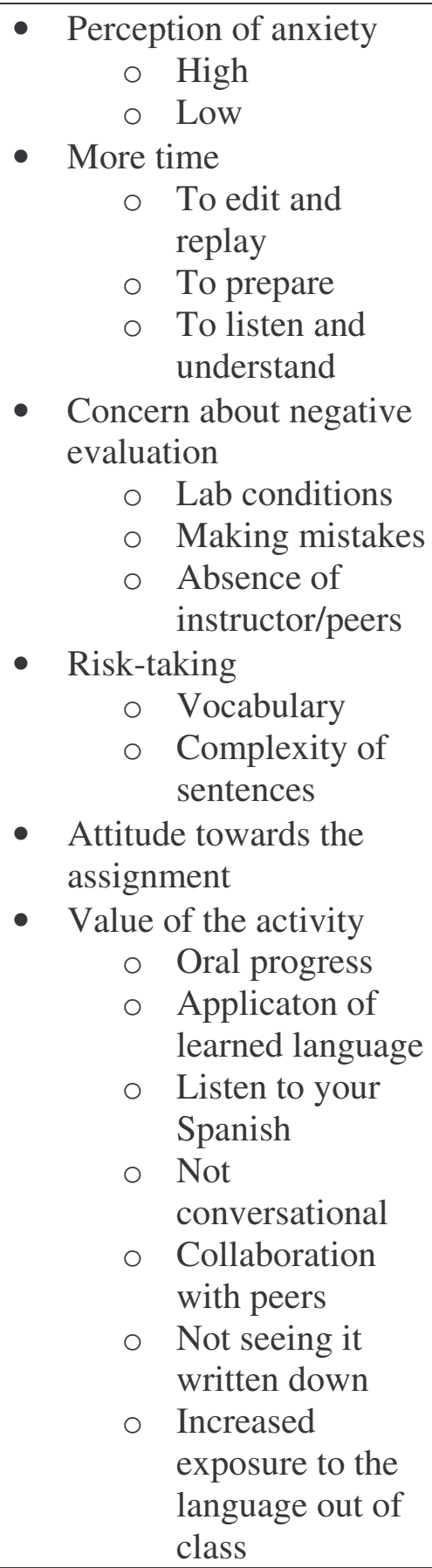 & $\begin{array}{l}\text { - Software } \\
\text { - Technical difficulties } \\
\text { - Access } \\
\text { - Attitude towards } \\
\text { - } \text { computers } \\
\text { - Attitude towards the lab }\end{array}$ \\
\hline
\end{tabular}

